\title{
Monitoring Biological Activity at Geothermal Power Plants
}

\author{
Peter A. Pryfogle
}

September 2005

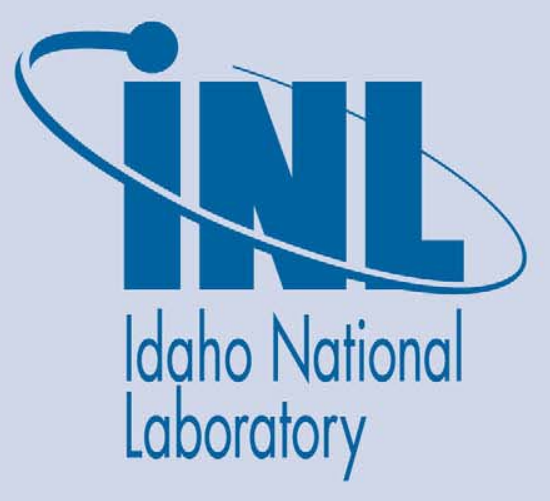

The INL is a U.S. Department of Energy National Laboratory operated by Battelle Energy Alliance 


\title{
Monitoring Biological Activity at Geothermal Power Plants
}

\author{
Peter A. Pryfogle \\ September 2005 \\ Idaho National Laboratory \\ Idaho Falls, Idaho 83415
}

Prepared for the

U.S. Department of Energy

Assistant Secretary or Office for Energy Efficiency and Renewable Energy

Under DOE Idaho Operations Office

Contract DE-AC07-99ID13727 


\begin{abstract}
The economic impact of microbial growth in geothermal power plants has been estimated to be as high as $\$ 500,000$ annually for a $100 \mathrm{MWe}$ plant. Many methods are available to monitor biological activity at these facilities; however, very few plants have any on-line monitoring program in place. Metal coupon, selective culturing (MPN), total organic carbon (TOC), adenosine triphosphate (ATP), respirometry, phospholipid fatty acid (PLFA), and denaturing gradient gel electrophoresis (DGGE) characterizations have been conducted using water samples collected from geothermal plants located in California and Utah. In addition, the on-line performance of a commercial electrochemical monitor, the BIoGEORGE ${ }^{\mathrm{TM}}$, has been evaluated during extended deployments at geothermal facilities. This report provides a review of these techniques, presents data on their application from laboratory and field studies, and discusses their value in characterizing and monitoring biological activities at geothermal power plants.
\end{abstract}




\section{ACKNOWLEDGMENTS}

The author would like to thank the operations staff at PG\&E, Calpine and NCPA for their support of the microbial sampling and characterization activities conducted in The Geysers field. In particular, the assistance of Walt Southall (PG\&E), Milt Rhine (PG\&E), Murray Grande (NCPA), Jeff Furst (NCPA), Charlotte Dority (Calpine), Diane Tullos (Calpine), and Jacob Rudisill (Calpine) was extremely helpful in accomplishing this work. The contributions of Allan Sonneville, John Avery, and Beth Kershaw of Calpine in support of the biofilm monitor deployment at the Aidlin facility and the water sample collection at the Sonoma plant for use in the respirometry measurements are also gratefully acknowledged.

The author would like to thank Todd Sperry, Plant Manager, the operations staff at the Bonnett Geothermal Plant, and Bob Allred, Chemical Consultant, at Alpine Services for their help with the installation of the biofilm monitor and with the data collection and interpretation activities. The contributions of Chad Blackburn at Bonnett to this effort were greatly appreciated.

Finally, the author would like to thank his colleagues, Joel Renner, Greg Mines, and Kit Bloomfield at the Idaho National Laboratory for their contributions to the project.

This work was supported by the U. S. Department of Energy, Assistant Secretary for Energy Efficiency and Renewable Energy, under DOE-NE Idaho Operations Contract DE-AC07-05ID14517 


\section{CONTENTS}

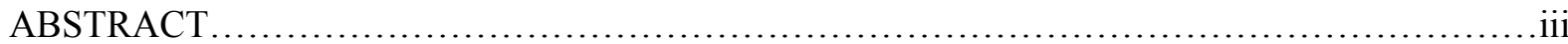

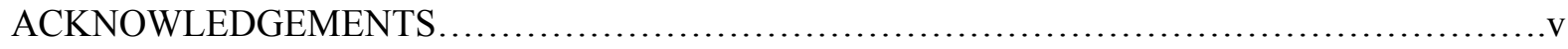

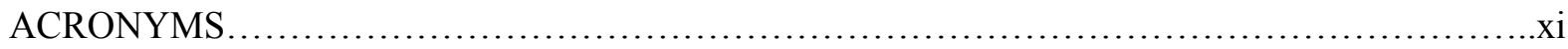

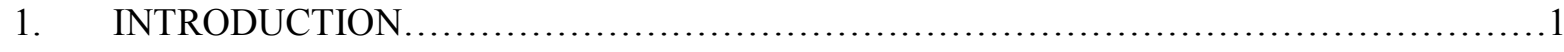

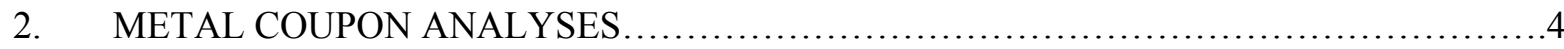

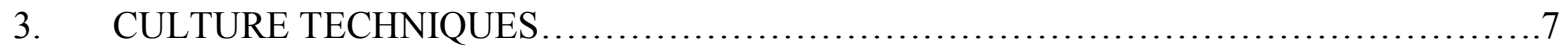

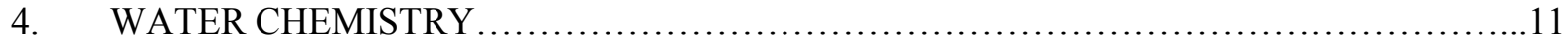

4.1 Analysis of Condenser Influent and Effluent at Geysers Plants......................12

4.2 Analysis of Cooling Basin at Bonnett Plant.....................................

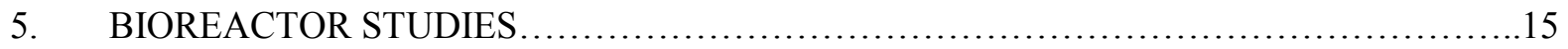

5.1 Nutrient Cycling in Geothermal Fluids...................................... 15

5.1.1 Sixfors Bioreactor Measurements......................................15

5.1.2 Gilson Differential Respirometer Measurements...........................17

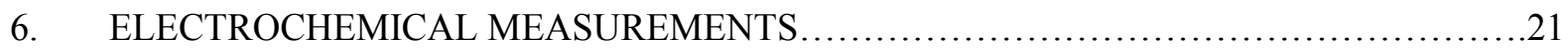

$6.1 \quad$ Electrochemical Split Cell.......................................................

6.2 BIoGEORGETM Biofilm Activity Monitor......................................23

6.2.1 Bonnett Geothermal Plant Deployment.................................25

6.2.2 Aidlin Plant Deployment.................................................28

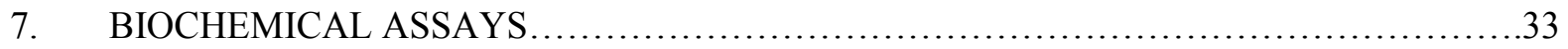

7.1 Adenosine Triphosphate (ATP) ................................................

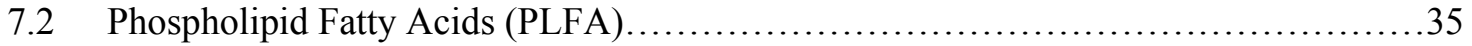

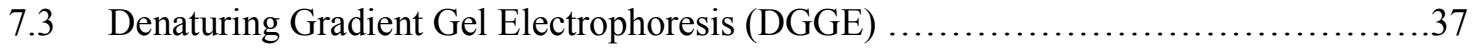

7.4 PLFA and DGGE Analyses of Geysers Plant Effluents...........................37

7.5 Molecular Probes............................................................... 42

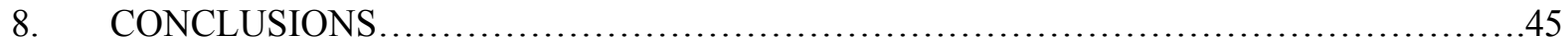




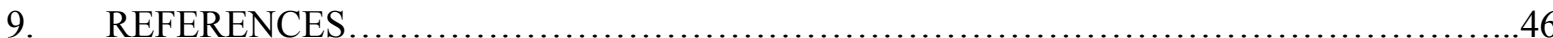

\section{FIGURES}

1. Condenser taken out of service at a geothermal plant..................................

2. Eagle Rock Geothermal Plant one of 19 facilities operated by Calpine at the Geysers..........3

3. Bonnett Geothermal Power Plant located near Cove Fort, Utah.......................... 3

4. Microscopic images of coupons collected from NCPA stained to identify bacteria............4

5. XPS plots containing sulfur peaks in exposed coupon.................................

6. SEM photograph showing biofilm on surface of coupon after one month exposure...........6

7. Examination of sample dilution vials of various cultures for MPN analyses................7

8. Number density of heterotrophic bacteria at Geysers plant, seasonal sampling..............8

9. Number density of denitrifying bacteria at Geysers plants, seasonal sampling................9

10. Number density of acid forming bacteria at Geysers plants, seasonal sampling..............9

11. Number density of sulfate reducing bacteria at Geysers plants, seasonal sampling...........10

12. Total Organic Carbon Analyzer, OI Corporation (College Station, Texas)...................11

13. TOC concentrations in the condenser influent (I) and effluent (E) streams at Geysers.........12

14. Bonnett water sample temperature, $\mathrm{pH}$, conductivity, and sulfate data.....................13

15. Bonnett water sample microbial density and TOC concentration data.....................

16. Bonnett water sample sulfate concentration and microbial cell density data....................14

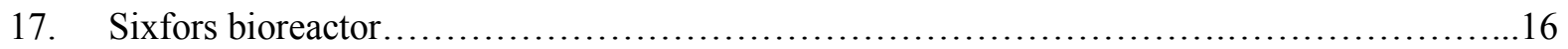

18. Gilson differential respirometer and close-up of $15 \mathrm{ml}$ reaction flask.......................18

19. Respiration rate change in Sonoma sample with $20 \mathrm{ppm}$ nitrate and phosphate additions.......19

20. Respiration rate change in Sonoma sample with $10 \%$ and $20 \%$ sulfide amendments .........20

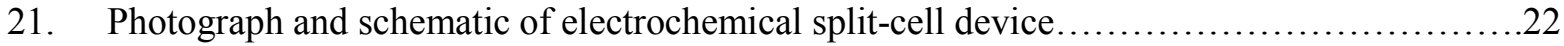

22. Response of electrochemical split cell to biological attack............................. 22

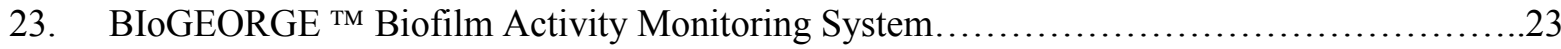

24. Increase in applied current indicative of biofilm development on probe......................24 
25. Installation of the BIoGEORGETM Monitor at Bonnett Geothermal.....................25

26. BIoGEORGE ${ }^{\mathrm{TM}}$ Biofilm Monitor Data collected at Bonnett Geothermal..................26

27. BIoGEORGE ${ }^{\mathrm{TM}}$ Biofilm monitor data and calculated condenser thermal resistance $\ldots . . . .27$

28. Summer 2002 fouling event recorded at Bonnett Geothermal...........................28

29. BIoGEORGE ${ }^{\mathrm{TM}}$ Monitor probe installed at the Aidlin Unit 1 cooling tower..............29

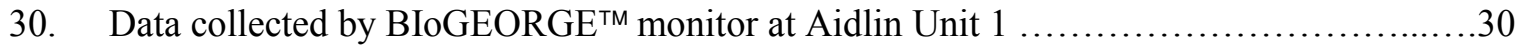

31. BIoGEORGE TM data as a function of calculated operational cleanliness...................30

32. Image of biomass on coupon pulled from Aidlin process stream, 253 day exposure........31

33. BetzDearborn Bioscan ${ }^{\mathrm{TM}}$ ATP luminometer with sampling pens........................33

34. Correlation of ATP signal with direct microscopic cell count numbers...................34

35. ATP Data collected at NCPA plant..............................................

36. ATP signal quenching with sulfate concentration................................. 35

37. DGGE sequencing and analyses using samples from the Geysers field....................37

38. PLFA types identified at various Geysers plants during September 1999 sampling.........38

39. PLFA types identified at various Geysers plants during February 2000 sampling...........38

40. PLFA types identified at various Geysers plants during June 2000 sampling...............39

41. Comparison of cell numbers derived from PLFA analyses to averaged MPN values.......40

42. Molecular probe preparation......................................................

43. Molecular probe interaction with geothermal water sample $\ldots \ldots \ldots \ldots \ldots \ldots \ldots \ldots \ldots \ldots . \ldots \ldots$

\section{Tables}

1. Description of PLFA structural groups........................................... 36

2. Dominant species distribution identified from DGGE analyses........................41

3. Cost comparison of biological measurement methods............................. 45 


\section{ACRONYMS}

\begin{tabular}{|c|c|}
\hline $\mathrm{AO}$ & acridine orange \\
\hline ATP & adenosine triphosphate \\
\hline AFM & atomic force microscope \\
\hline CFLM & confocal laser microscope \\
\hline GC/MS & gas chromatograpy/ mass spectroscopy \\
\hline DNA & deoxyribonucleic acid \\
\hline DGGE & denaturing gradient gel electrophoresis \\
\hline DIC & differential interference contrast \\
\hline EDS & energy dispersive spectroscopy \\
\hline EDTA & ethylenediaminetetraacetic acid \\
\hline FISH & fluorescently-tagged, in-situ hybridization \\
\hline INL & Idaho National Laboratory \\
\hline MIC & microbially-influenced corrosion \\
\hline MPN & most probable number \\
\hline NCPA & Northern California Power Agency \\
\hline PG\&E & Pacific Gas and Electric \\
\hline PLFA & phospholipid fatty acid \\
\hline SEM & scanning electron microscope \\
\hline SRB & sulfate reducing bacteria \\
\hline TOC & total organic carbon \\
\hline TSB & trypticase soy broth \\
\hline UMPA & Utah Municipal Power Agency \\
\hline XPS & x-ray photoelectron spectroscopy \\
\hline ZRA & zero resistance ammetry \\
\hline
\end{tabular}




\section{Monitoring Biological Activity at Geothermal Power Plants}

\section{INTRODUCTION}

Microbial activity is an operational issue in geothermal power plants using evaporative heat rejection systems. In geothermal steam plants, the condensed steam is used as cooling water makeup. This steam may contain impurities such as hydrogen sulfide, ammonia, carbon dioxide, as well as entrained liquid containing a variety of dissolved solids. While a significant portion of these gases are removed from the condenser, some partition into the liquid condensate that is used for cooling water makeup. These dissolved gases, along with the dissolved solids, provide nutrition for microbial growth within the cooling water system. Some of the gases may require abatement in order to meet regulatory requirements. For example, an iron chelate is added to some systems to treat hydrogen sulfide dissolved in the steam condensate. The chelating compound is an organic acid, which may also serve as a nutrient source for bacteria. Similarly, other chemical treatments that are applied to inhibit corrosion or scaling may provide nutrients that encourage growth. In addition, the cooling water cycles from reducing to highly oxygenated as it travels through the condenser and through the evaporative cooling system. The shift from anaerobic to aerobic conditions also influences biological activity. Changes in thermodynamic or chemical conditions may also stimulate growth.

The consortia of microorganisms attach to the surfaces of critical components in geothermal cooling systems and form complex structures called biofilms. ${ }^{1}$ The development of biofilms can impact plant performance in a number of ways. Due to their relatively low thermal conductivity, biofilms add thermal resistance to the transfer of heat across the tube wall to the cooling water. (These films also have the ability to incorporate inorganic materials, such as calcium salts in the cooling water, stimulating their deposition.) As the biofilm accumulates on the tube wall, this material can rapidly become the dominant resistance to heat transfer. To offset this added thermal resistance a larger temperature difference is required to completely condense the steam. This larger temperature difference results in an increasing condensing temperature, which in turn increases the turbine exhaust pressure and decreases turbine power output; and consequently, plant revenues. Experience at some of the plants studied indicated that the condensing pressure dropped by $\sim 0.5$ inch-Hg after routine cleaning as part of a two year maintenance cycle. Examination of "fouled" condensers (Figure 1) and coupons deployed at similar facilities indicated the fouling was dominated by the presence of biofilms. Assuming the increase in condenser pressure due to fouling is linear with time and the cost of power is $\$ 0.03$ per $\mathrm{kW}-\mathrm{hr}$, the associated lost revenues can approach $\$ 400,000$ annually for a $100 \mathrm{MWe}$ plant. Biofilms may also damage equipment by direct corrosion, or by accelerating chemical corrosion activity. When the eventual tube replacement is included with the lost power revenues associated with the periodic cleaning of both the condenser and cooling tower, the impact of microbial activity on the operation of the plant can exceed $\$ 500,000$ annually.

In addition, there have been recent concerns that biofilms may serve as hosts for pathogenic organisms that can present a health risk to facility employees and others living in close proximity to the plant. Biofilms in open circulation systems may develop to a degree that pathogens, such as Neagleria spp., Acanthamoebe spp., and Legionella pneumophila, grown and detached from the film substrate may become airborne in aerosols and come into contact with people. Outbreaks of the Legionnaires Disease have been tied to cooling tower operations; however, there have not been any reported cases of associated illnesses from operations at geothermal power plants. ${ }^{2}$ 

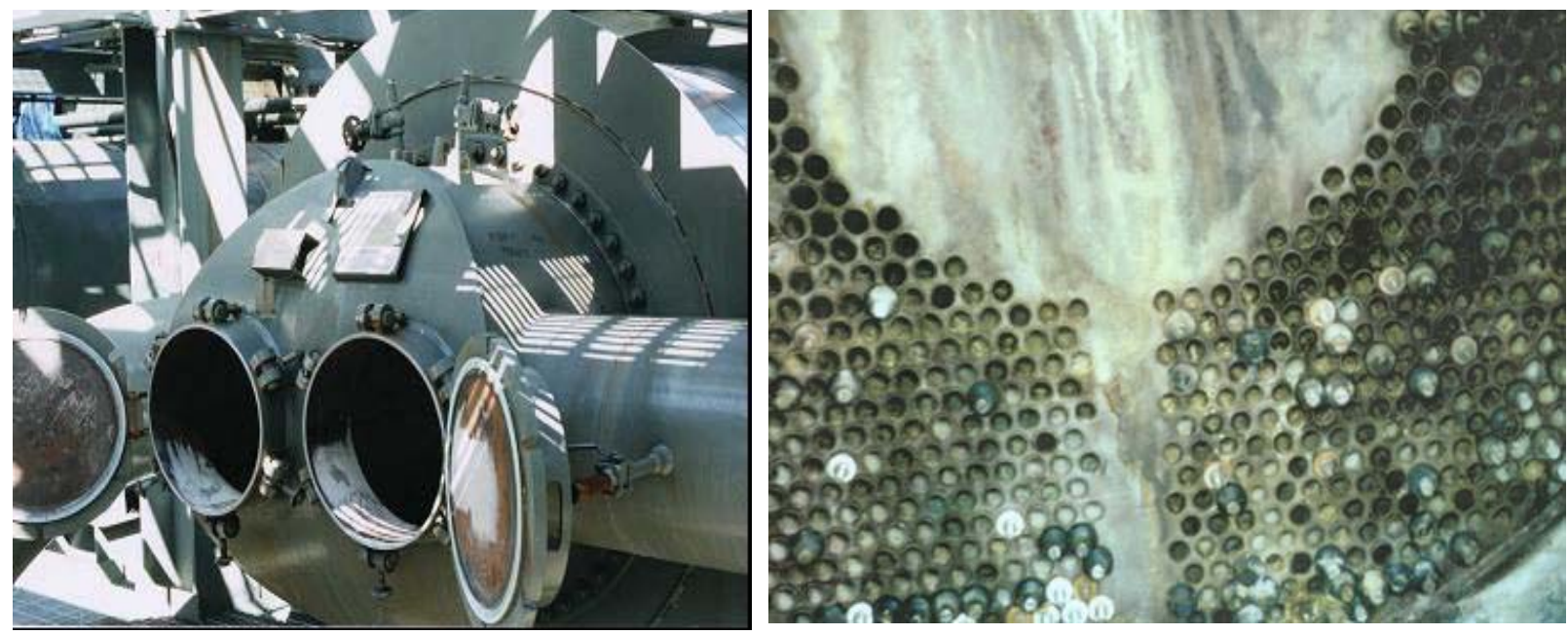

Figure 1. Condenser taken out of service at a geothermal plant (left) and evidence of corrosion and fouling on the internal tube sheet (right).

Plant operators are well aware of the impact of microbial activity, which they attempt to control and mitigate with costly chemical applications. (An operator of a small $10 \mathrm{MWe}$, flash plant has indicated that their annual expenses for water treatment approach $\$ 100,000$.) In spite of the high costs, few geothermal plants have biological monitoring programs in place to detect growth problems. ${ }^{3}$ Most apply treatments on a predefined schedule, or in response to growth as evidenced by changes in flow parameters or film formation on coupons or other structures. In either case the operating efficiency has been impacted to some extent and larger doses of biocides may be required to eliminate the film. In addition, treatments are typically designed by the vendors selling the chemicals, who have little incentive to reduce the plant's chemical usage.

Most biological control strategies are also geared toward reducing the number density (cells per unit volume) of the bacteria present. Work conducted by Idaho National Laboratory (INL) and other researchers indicate that is possible to dramatically reduce the numbers of bacteria present without having any significant impact on biofilm development. ${ }^{4}$ Furthermore, not all the bacteria found in process streams may be detrimental. For example, species of sulfur oxidizing bacteria are found in geothermal cooling tower basins that are capable of metabolizing sulfide compounds and converting them to less toxic sulfate compounds, potentially reducing the amount of chemicals required for abatement. ${ }^{5}$ The ideal monitoring program would allow operators to identify, track and control the "activities", such as biofilm development or sulfur oxidation/reduction, of the microorganisms for the most cost effective mitigation of these problems in their plants. Consequently, a multi-year investigation to characterize and evaluate microbiological activity in geothermal power plant cooling systems has been conducted. The goals of this investigation were to establish what types and levels of microbial activities occur at the facilities, how these activities change with environmental and process conditions, and which analytical techniques might be the most productive in identifying and mitigating the impact of the activities on the efficient operation of the plants.

These studies were conducted at dry and flash-steam geothermal plants located in California and Utah. The principal field evaluations were performed at the Geysers Geothermal Field in Northern California and the Bonnett Geothermal Plant near Cove Fort, Utah. The Geysers field uses dry steam to generate power at the 19 plants, previously owned by Pacific, Gas and Electric (PG\&E), and now operated by Calpine Corporation. The total output of these plants is on the order of 880 megawatts (MW). One of these facilities, the Eagle Rock (Unit 11 under PG\&E) is shown in Figure 2. The Northern California 
Power Agency (NCPA) also owns and operates two plants at The Geysers, each with an average net capacity of approximately $65 \mathrm{MW}$. The Bonnett Geothermal Plant, shown in Figure 3, was a small flashsteam, 10 MW facility previously owned and operated by Utah Muncipal Power Agency. (In 2003, this plant was acquired by Recurrent Resources.)

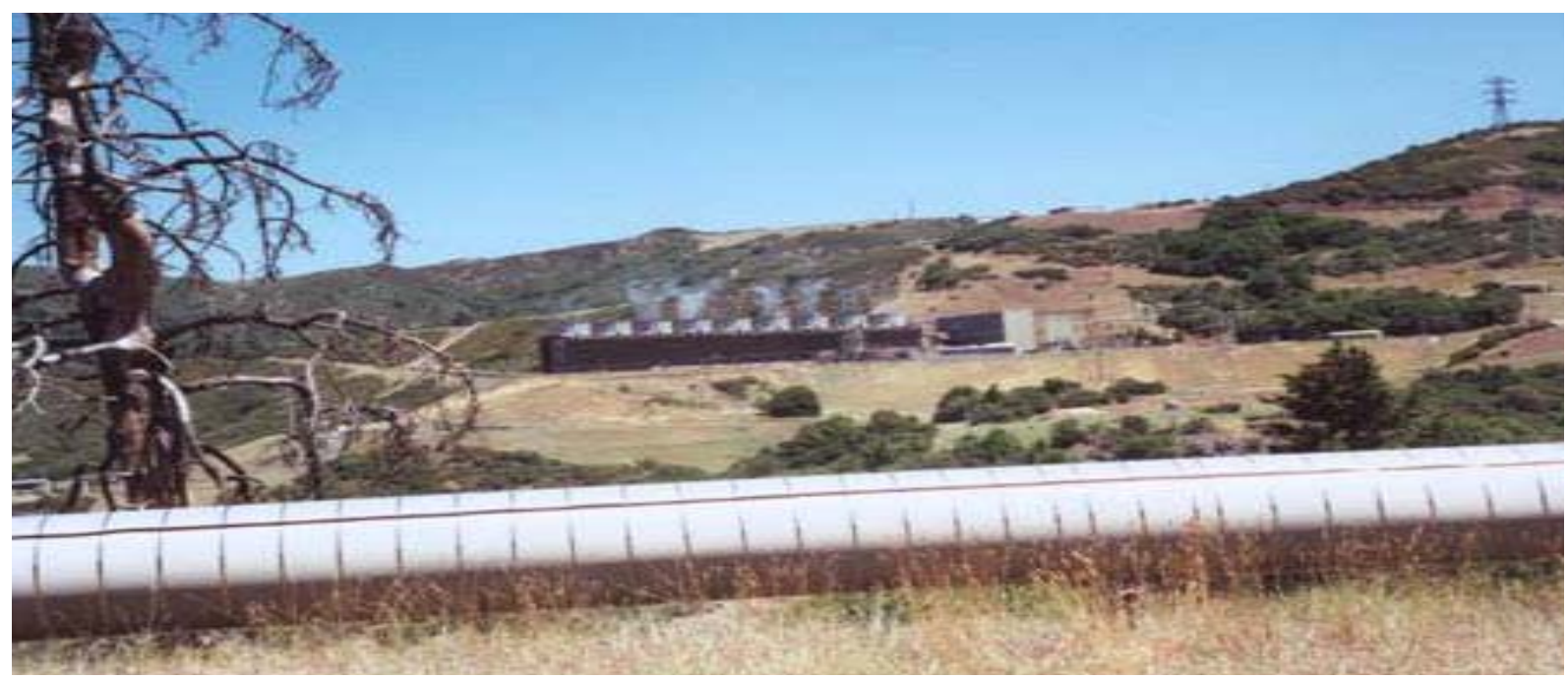

Figure 2. Eagle Rock Geothermal Plant one of 19 facilities operated by Calpine at The Geysers.

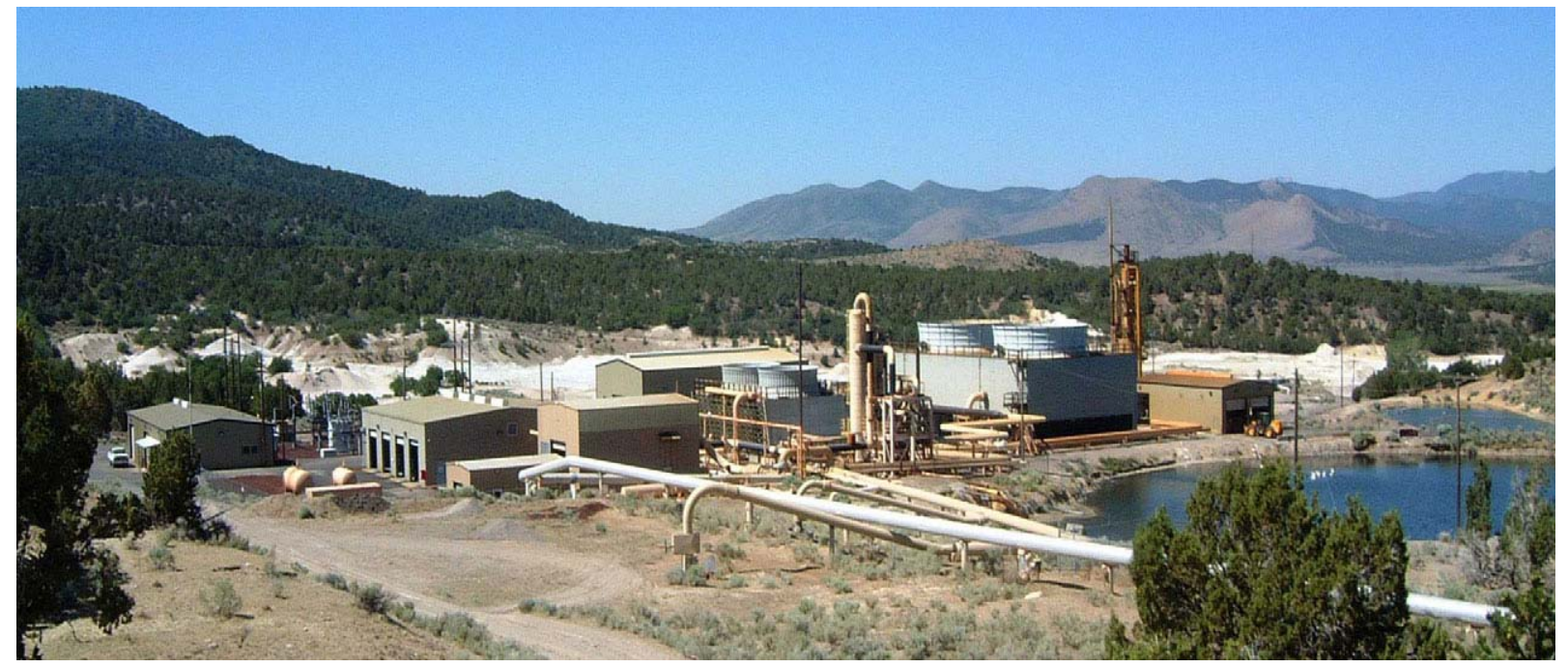

Figure 3. Bonnett Geothermal Power Plant located near Cove Fort, Utah.

The techniques investigated include: deployed coupon analyses, selective culturing to determine microbial most probable numbers (MPN), changes in water chemistry including total organic carbon (TOC) levels, bioreactor studies including respirometry, electrochemical measurements, and biochemical analyses such as adenosine triphosphate (ATP), phospholipid fatty acid (PLFA) and denaturing gradient gel electrophoresis (DGGE).

This report provides a review of these techniques, presents data on their application from laboratory and field studies, and discusses their value in characterizing and monitoring biological activities at geothermal power plants. 


\section{METAL COUPON ANALYSES}

Metal coupon analyses are frequently utilized to estimate the effects of corrosion and fouling within industrial operating systems. In these studies, a coupon of the same type metal used in the system component is weighed and deployed in the plant environment. The samples are then collected after exposure and analyzed for evidence of biofouling or corrosion. An individual sample may then be reweighed and depth profiles performed to determine the degree of physical deterioration. Other more detailed surface analyses are required to determine if microbially-influenced corrosion (MIC) has occurred. A typical scheme involves staining the coupon and performing sessile bacterial counts. Surface analyses are then conducted using scanning electron microscopy (SEM), energy dispersive X-ray spectroscopy (EDS), and Auger electron spectroscopy (AES) to confirm the presence of a biofilm and identify corrosion products. Other techniques, such as confocal scanning laser microscopy (CFLM) and atomic force microscopy (AFM) may be used for detailed visualization of the physical properties of the biofilm. $^{6}$

Surface analyses have been performed on 304L stainless steel coupons exposed to circulating water at The Geysers plants. In particular, three coupons were deployed in August 1997 at NCPA and retrieved at monthly intervals. The coupons were placed in an isolation package, filled with process water before closure, and sent to INL for analyses. The coupons were sectioned and prepared for a series of surface analyses. One section was stained with fluorescent dye, acridine orange (AO), for a determination of cell densities. Another section was analyzed by X-ray photoelectron spectroscopy (XPS). Upon completion of this analysis, the section was examined under scanning electron microscopy (SEM) and analyzed with energy dispersive spectrometry (EDS).

A Nikon PCM2000 confocal laser scanning microscope (CLSM) equipped with differential interference contrast optics was used to perform visual observations of the coupon surface and to determine cell densities. The cell numbers per square centimeter were extrapolated from the number identified by the system in a calibrated field of view. As illustrated in the image of the stained coupons depicted in Figure 4, the cell numbers increased from a count of $6.6 \times 10^{6}$ at the end of the first month to $1.5 \times 10^{7}$ at the end of the third month of exposure. Film thickness was also seen to increase, as noted by an increase in the number of optical sections observable with the scanning confocal microscope.
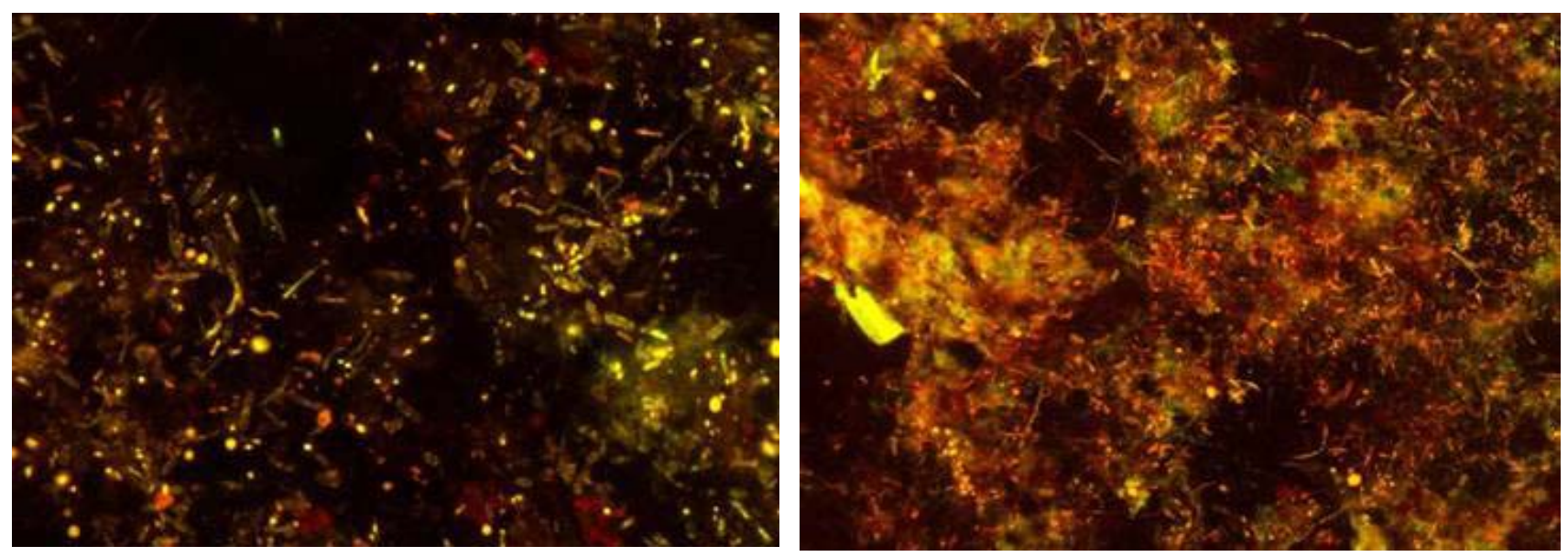

Figure 4. Microscopic images of coupons collected from NCPA and stained with an AO fluorescent stain to aid in identifying bacteria. The coupon on the left was processed after one month of exposure in the 
plant's cooling water system and the coupon on the right was collected and analyzed after a three month exposure.

The XPS analyses were performed on the outer layers of the film. In this technique the sample coupon is irradiated with soft x-rays which induce the emission of photoelectrons from the core atomic levels of material. The kinetic energies of the emitted electrons are analyzed to determine their binding energies in the species of interest. Peaks in the deconvoluted spectra are associated with specific elements and valance states, or compounds of those elements, by comparison to reference spectra. Elements of interest included oxygen, carbon, nitrogen, sulfur and various metallic species, such as iron and chromium. The XPS surveys showed a general shifting of the binding energies for carbon and sulfur as a function of exposure. These shifts indicate a general reduction of the materials with the presence of more complex organic structures emerging as the exposure time increased.

A comparison of the sulfur peaks for the three coupons is presented in Figure 5. In the plot, the peaks at 168 and $169 \mathrm{eV}$ were identified as sulfate-type materials and the peaks associated with 163, 164, and $165 \mathrm{eV}$ were related to sulfide compounds. A large peak shift was observed between the first and third month corresponding to the reduction of sulfates to sulfides in the materials. This transition may be related to the development of the biofilm, and could be attributed to either direct enzymatic activity of the bacteria within the film, or an accumulation of the reduced material from the process water by the microorganisms in the film.

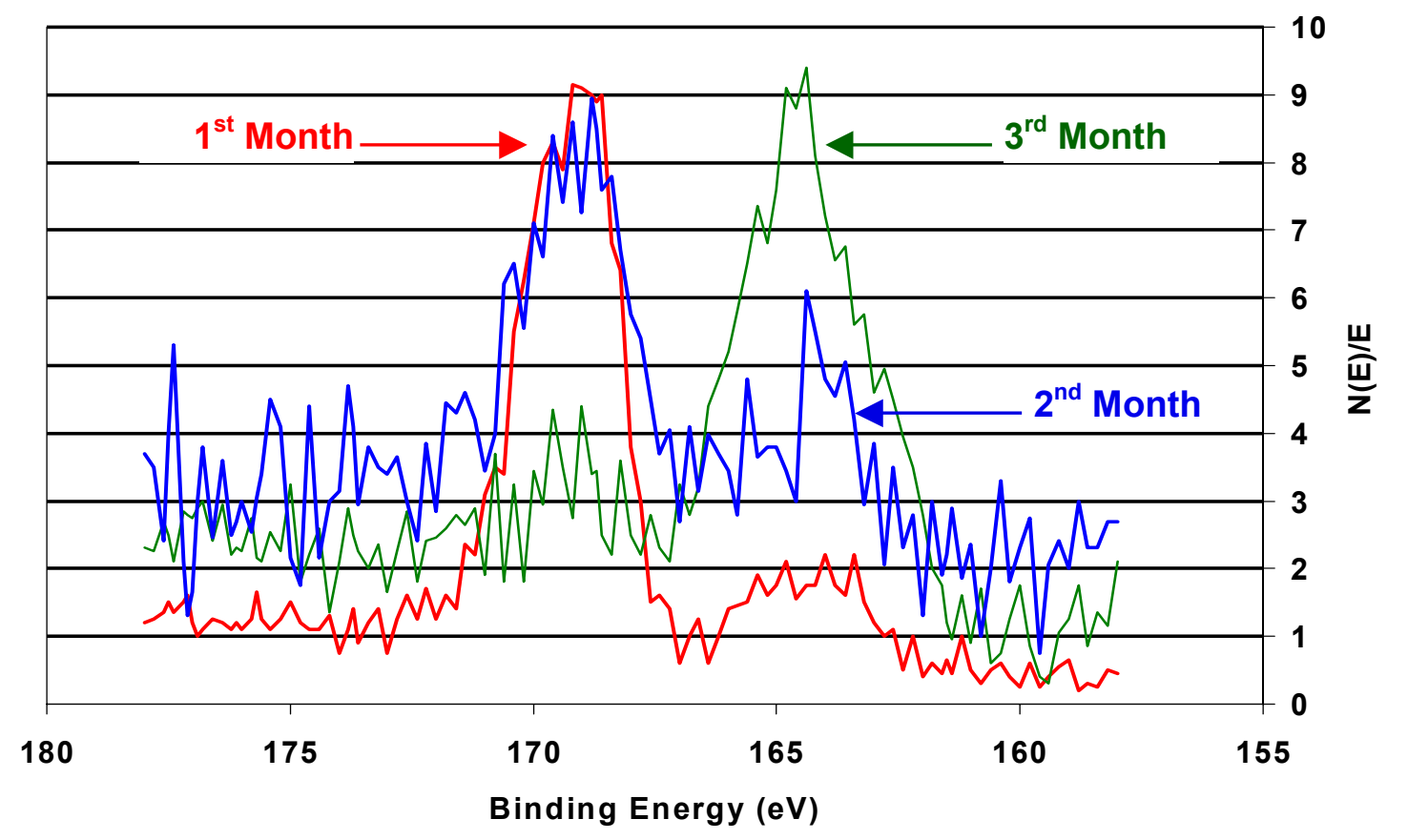

Figure 5. XPS plots containing sulfur peaks in exposed coupons.

SEM observations and EDS were also performed on the sample coupons. The SEM data (Figure 6) indicated that a film had begun to form within one month of deployment of the coupon. As indicated in the CLSM data, there was an apparent difference in the thickness of this film, with the longest exposure containing a greater amount of material on the surface. The EDS analyses showed a change in the elemental composition of the material on the surface of the coupons. In particular, the oxygen content 
decreased as a function of exposure, and the sulfur content increased. The ratio of chromium to iron and nickel to iron remained constant over the three-month exposure.

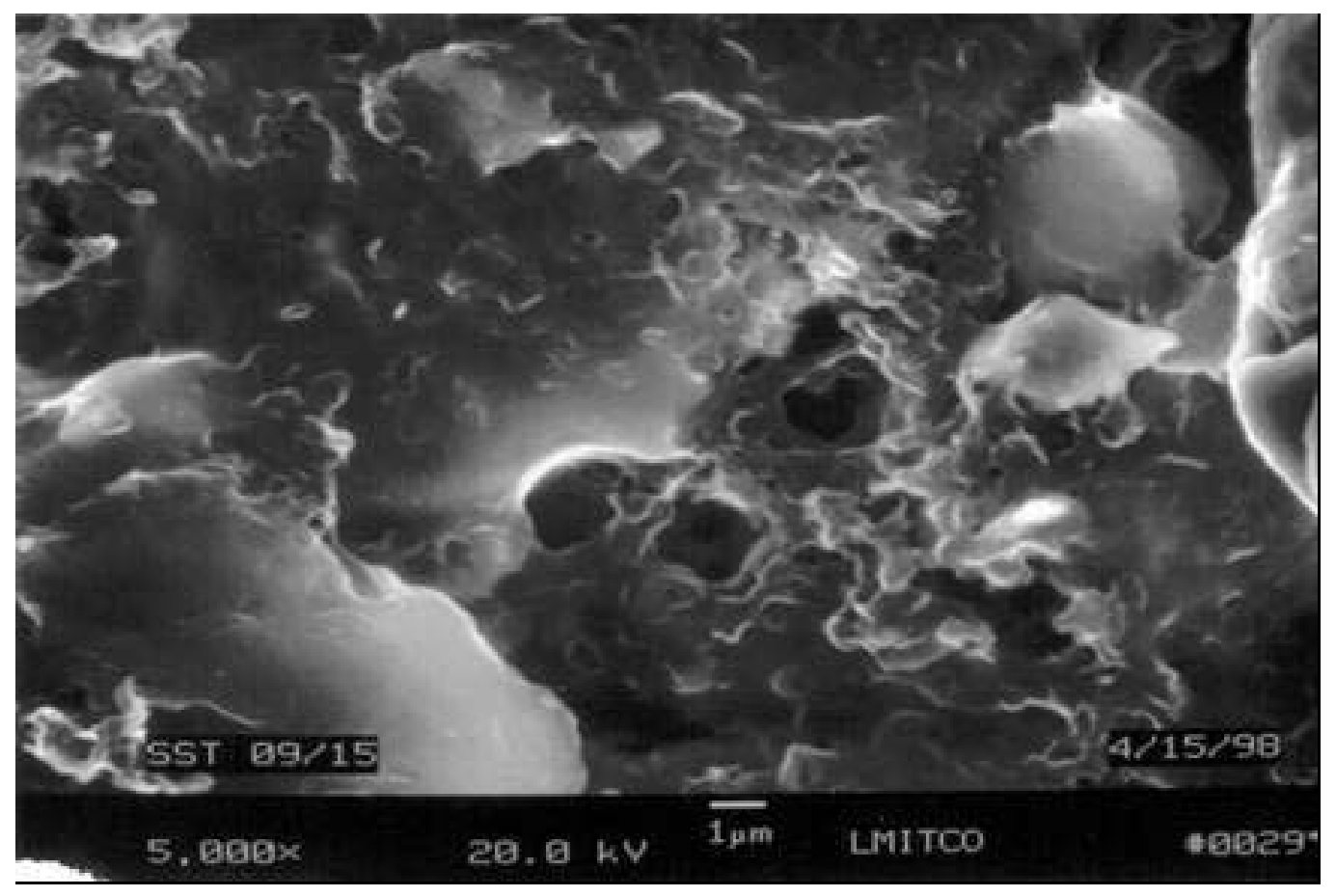

Figure 6. SEM photograph showing biofilm on surface of coupon after one month exposure.

The data collected in this investigation indicated that microbial species exist in sufficient numbers at the Northern California Geysers plants to produce biofouling and microbiologically-assisted corrosion at the plants. In particular, this study indicated that films containing microbial species may develop on metallic substrates in the facilities within relatively short periods of time. Furthermore, within a few months, if untreated, may break down the passivation layer on the stainless steel substrate and either directly, or indirectly, induce a potentially corrosive environment at the surfaces of metallic structures.

The advantage of using metal coupons for characterizing microbiological growth in geothermal cooling water systems is that they provide a means of collecting data under realistic conditions. The metal coupon compositions are chosen to match those of the system components and the exposure is typically performed in a side stream of the plant so that the operating environmental parameters are closely matched. A simple vision inspection can reveal the presence of a biofilm. As described, a large amount of data can be derived from a detailed analysis of the coupon, and in particular, the relative extent and rate of scaling and corrosion can be estimated. Unfortunately, considerable handling and processing of the coupon is required to obtain this type of data. Many of the analyses are quite time-consuming and require the use of expensive analytical instrumentation. But, perhaps the biggest disadvantage is that the biofilm has to form on the surface before it can be detected and analyzed, and the ultimate goal of biological mitigation programs is to prevent this attachment from occurring. 


\section{CULTURE TECHNIQUES}

One of the most commonly-used methods for evaluating biological activity in industrial plant systems is to determine the relative abundance, or most probable number $(M P N)$, of their growth under controlled conditions. This method consists of making a series of dilutions of an environmental sample into selective media. The specific media are designed to test for the presence of heterotrophic bacteria, sulfate-reducing bacteria (SRBs), acid-formers; and others, such as denitrifying bacteria, which may be of importance in particular environments. The inoculated media are incubated for a period of time and statistical analyses are performed to determine cell populations from growth patterns in the sample vials.

The technique is widely used for a variety of reasons. First, a number of vendors supply relatively inexpensive and easy-to-use kits for making these measurements. ${ }^{7}$ The analyses are also straightforward, requiring simple visual observations (Figure 7) of a color or turbidity change in the media. For example, when SRBs are introduced into a sodium lactate solution containing an iron substrate, the sulfate is reduced to sulfide. The sulfide then reacts with the iron, producing black ferrous oxides, which are easily visible.

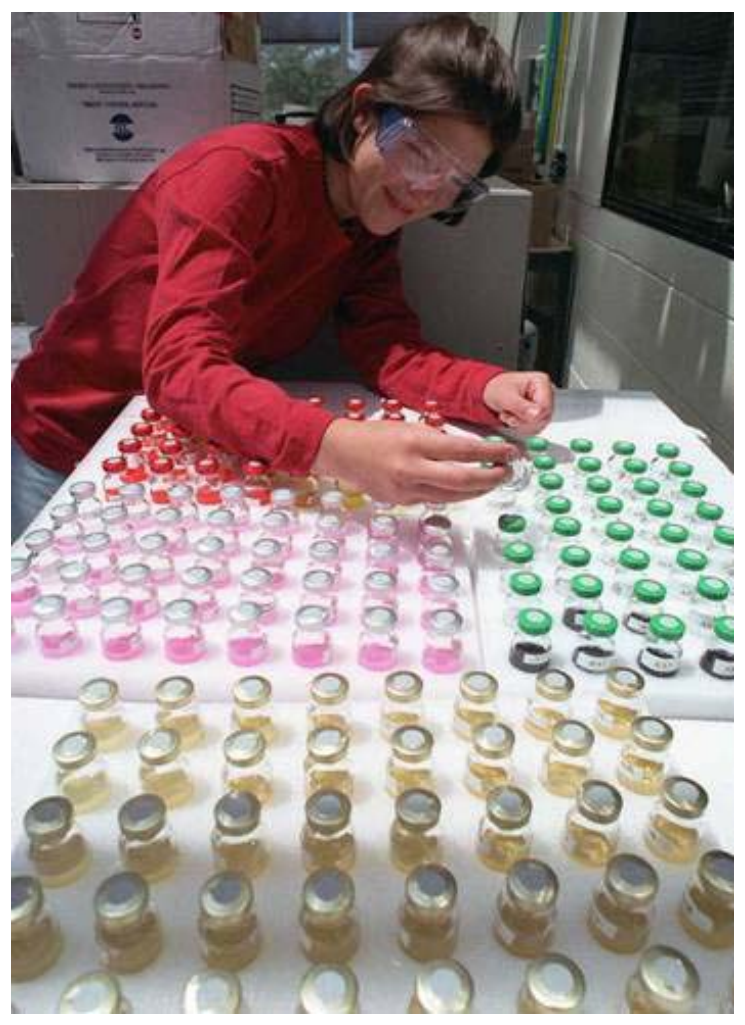

Figure 7. Examination of sample dilution vials of various cultures for MPN analyses.

Between June 1997 and February 2000, a study was conducted to track changes in microbial activity at six plants located across The Geysers field. In particular, water samples were collected and analyzed from the influent and effluent condenser lines at the Aidlin (PG\&E Unit 1), Big Geysers (PG\&E Unit 13), Sulfur Springs (PG\&E Unit 14), Quicksilver (PG\& E Unit 16), NCPA Unit 2, and West 
Ford Flat (PG\&E Unit 4) located in The Geysers field. Changes in microbial activity were measured using the MPN technique. The analyses were performed using sampling kits obtained from Sherry Laboratories (Tulsa, OK) which could detect the presence of heterotrophic, de-nitrifying, sulfate-reducing and acid-producing bacteria. The method involved the collection of a one-millimeter aliquot from each of the condenser water samples which was then injected into a vial that contained 9 milliliters of a particular growth media. The media was mixed well, and then a one-milliliter sample was withdrawn from that bottle and added to the next sterile bottle containing the same media. This procedure resulted in a 1 to 10 dilution factor, which was carried out into eight vials and replicated five times. Bacterial growth or activity, observed as a color or turbidity change, was noted for periods up to 28 days and used for the MPN calculations derived from statistical growth tables.

The data for the condenser in-let line is summarized in Figures 8-11. The data indicate that relatively high densities of bacteria $\left(>10^{4}\right)$ were almost always detected at all of the facilities. In particular, the heterotrophic culture which supports a very broad range of microbial species was generally saturated at a number density of $10^{9}$ or greater. Both seasonal and process change variations have been recorded in this data. For example, the sulfate reducing bacteria and to a lesser extent the acid-forming bacteria, exhibit seasonal variances with the highest number densities recorded during the warmer weather.

These types of analyses can be very sensitive and can be used to successfully track growth trends in facilities when used properly. In particular, the data must be collected from the same location in the plant and incubated for the same time under the same environmental conditions to obtain consistent results. (Studies have indicated that variations in time, temperature and location can produce order of magnitude changes in readings.) Even when care is taken in the measurement methodology there are some inherent disadvantages in relying on this type of data to identify biofouling problems. First, the selective media are, by definition, preferential to some bacterial species and may not support all the types present in the process stream. This may cause some important microbial components to be missed. Also, the susceptibility of planktonic, or free floating, organisms to biocides differs markedly from those protected by a biofilm; and therefore, treatment assessments may not be accurate. The long incubation period also presents a significant disadvantage, since conditions in the plant may change between time of sample collection, the identification of a problem, and application of a treatment. 


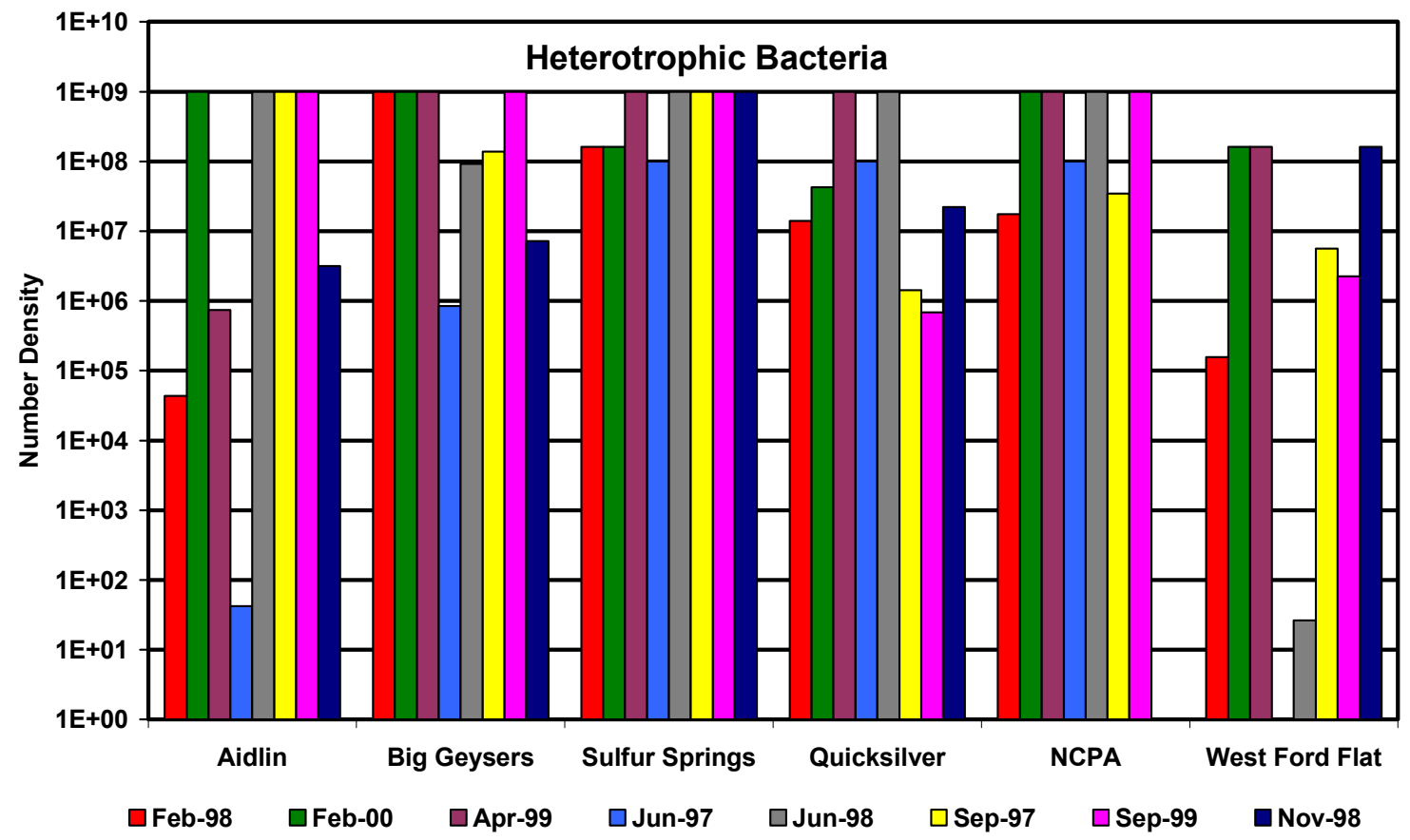

Figure 8. Number density of heterotrophic bacteria at Geysers plants as a function of seasonal sampling.

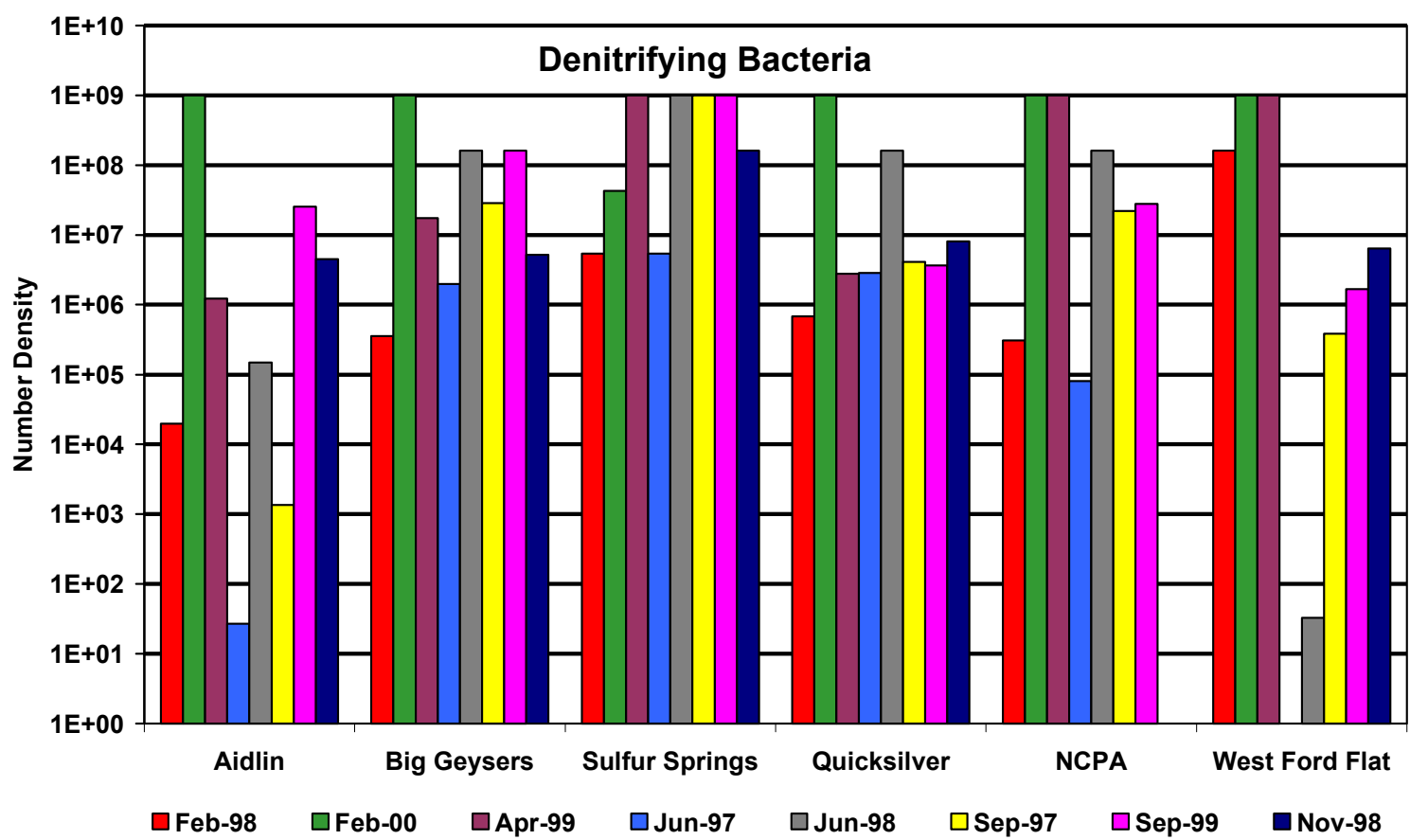

Figure 9. Number density of denitrifying bacteria at Geysers plants as a function of seasonal sampling. 


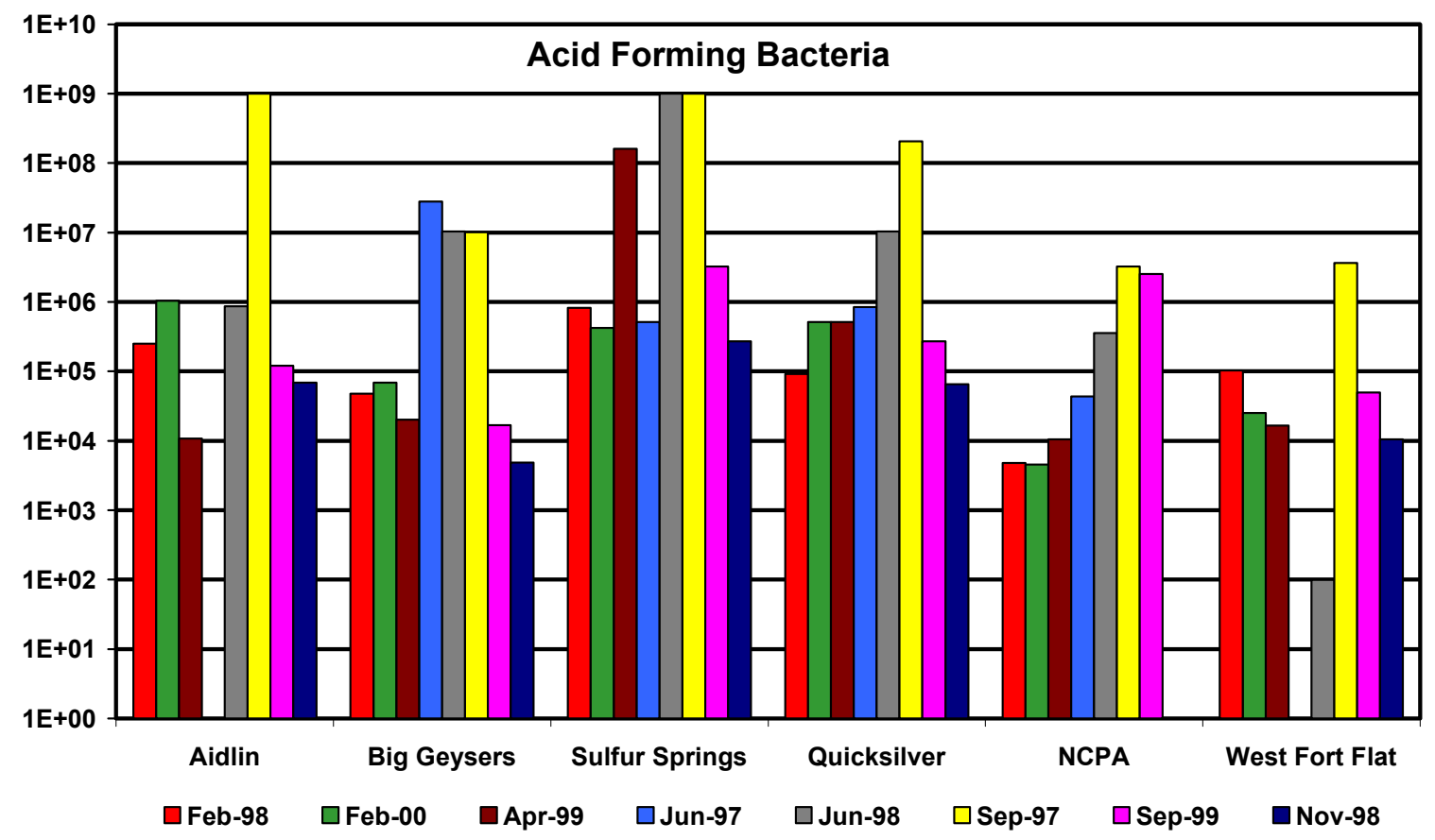

Figure 10. Number density of acid forming bacteria at Geysers plants as a function of seasonal sampling.

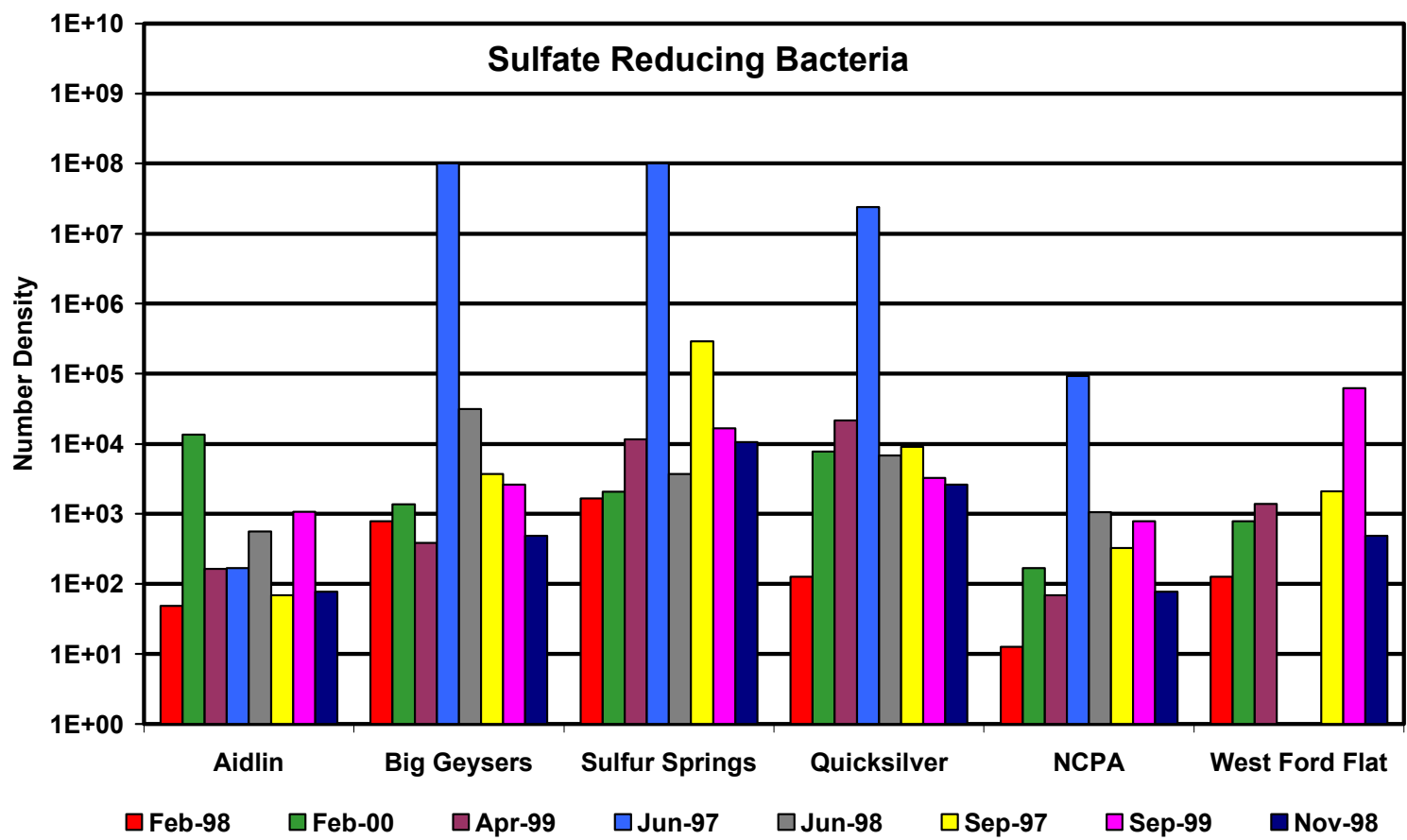

Figure 11. Number density of sulfate reducing bacteria at Geysers plants as a function of seasonal sampling. 


\section{WATER CHEMISTRY DATA}

Microbial growth may also impacted by the properties, such as the temperature, conductivity, or $\mathrm{pH}$, of the water in which it occurs. ${ }^{8}$ A small increase in the temperature $\left(\sim 5^{\circ} \mathrm{C}\right)$ of the process stream can double the metabolic rate of an organism, provided that the temperature is within the normal range of tolerance for the bacteria. Temperature can also indirectly impact growth by changing the solubility of various gases that may serve as nutrient sources. Changes in conductivity, or the concentration and types of ions, in geothermal fluids may alter the ability of microbes to transfer nutrients across their cell membranes. Solution $\mathrm{pH}$ also affects the solubility of many minerals and other materials that support biological growth and activity. Oxygen is critical to the growth of aerobic bacteria; and conversely, the absence of oxygen is critical to the growth of anaerobic bacteria.

Another chemical indicator, total organic carbon (TOC) analyses, can be used to determine the levels of biological activity in a system component, particularly if the component can be isolated as a subsystem of a linear flow process, such as a condenser. Dissolved carbon in aquatic systems can be divided into inorganic and organic components. These carbon compounds can serve as substrates for biological metabolism and may provide an indication of the degree of eutrophication. ${ }^{9}$ The technique requires that a sample be collected and injected into an analyzer (shown in Figure 12) where it is acidified to release the dissolved inorganic carbon $\left(\mathrm{CO}_{2}\right)$. The gas is then purged from a reaction vessel into an analytical chamber where an infrared absorption measurement is used to determine the $\mathrm{CO}_{2}$ concentration. The sample is then activated with a chemical oxidant and heated to $100{ }^{\circ} \mathrm{C}$ to oxidize the organic carbon fraction in the sample. This fraction is purged and analyzed, resulting in a calculation of the dissolved organic component. These two fractions, the organic and inorganic carbon, are added to obtain the total carbon for the sample. 


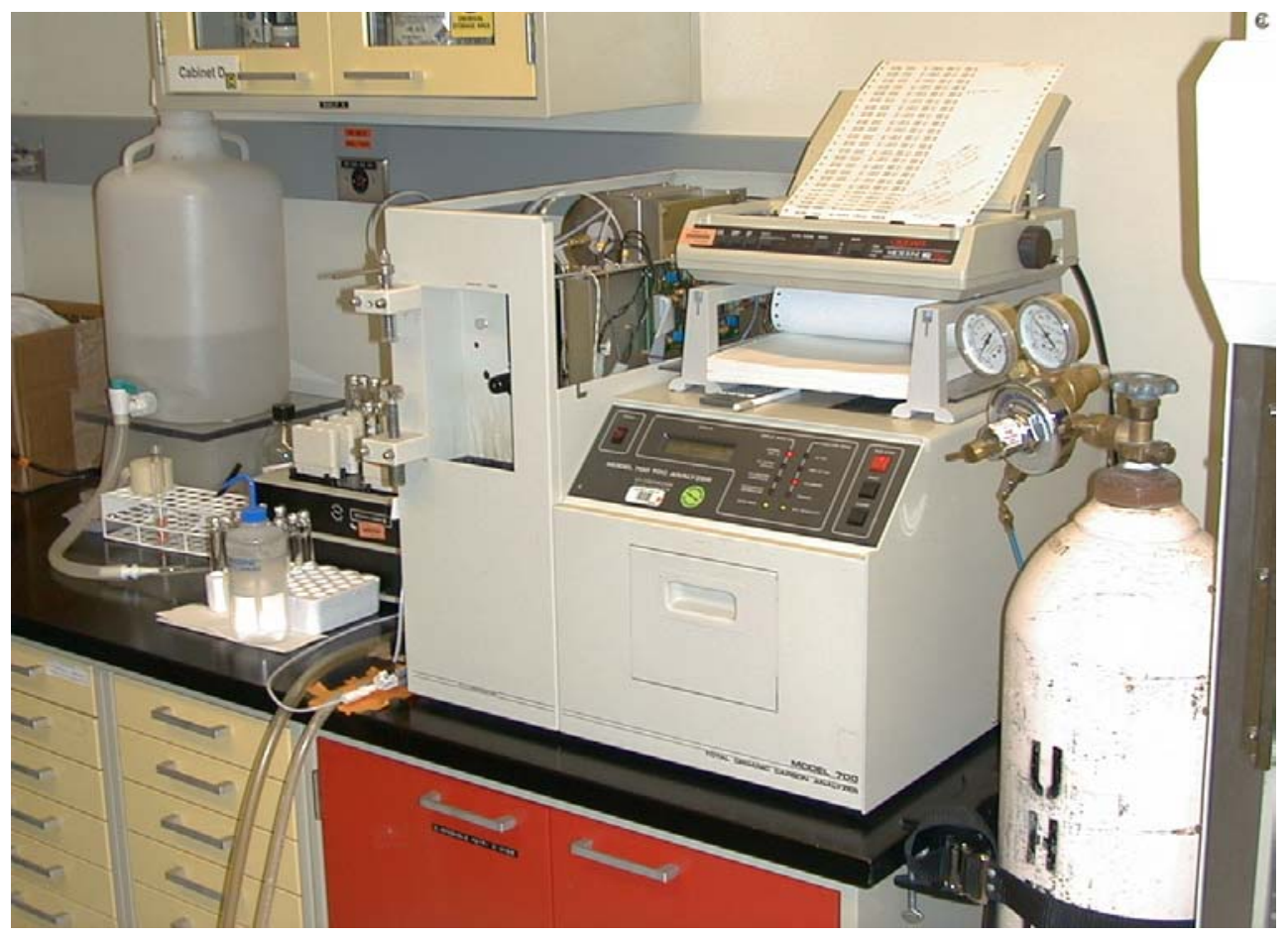

Figure 12. Total Organic Carbon Analyzer, OI Corporation (College Station, Texas).

\subsection{Analysis of Condenser Influent and Effluent at Geysers Plants}

Water samples were collected and analyzed for TOC concentration from the influent and effluent condenser lines at the Aidlin, Big Geysers, Sulfur Springs, Quicksilver, NCPA, and West Ford Flat located in The Geysers field. The data for three sample collection periods conducted in the fall, winter, and summer are presented in Figure 13. Significant changes in TOC between the in-let and out-let streams signal a potential growth problem since the microbes may be using either using carbon from the process stream as a substrate for growth; or alternatively, producing excess carbon as a metabolite during growth. 


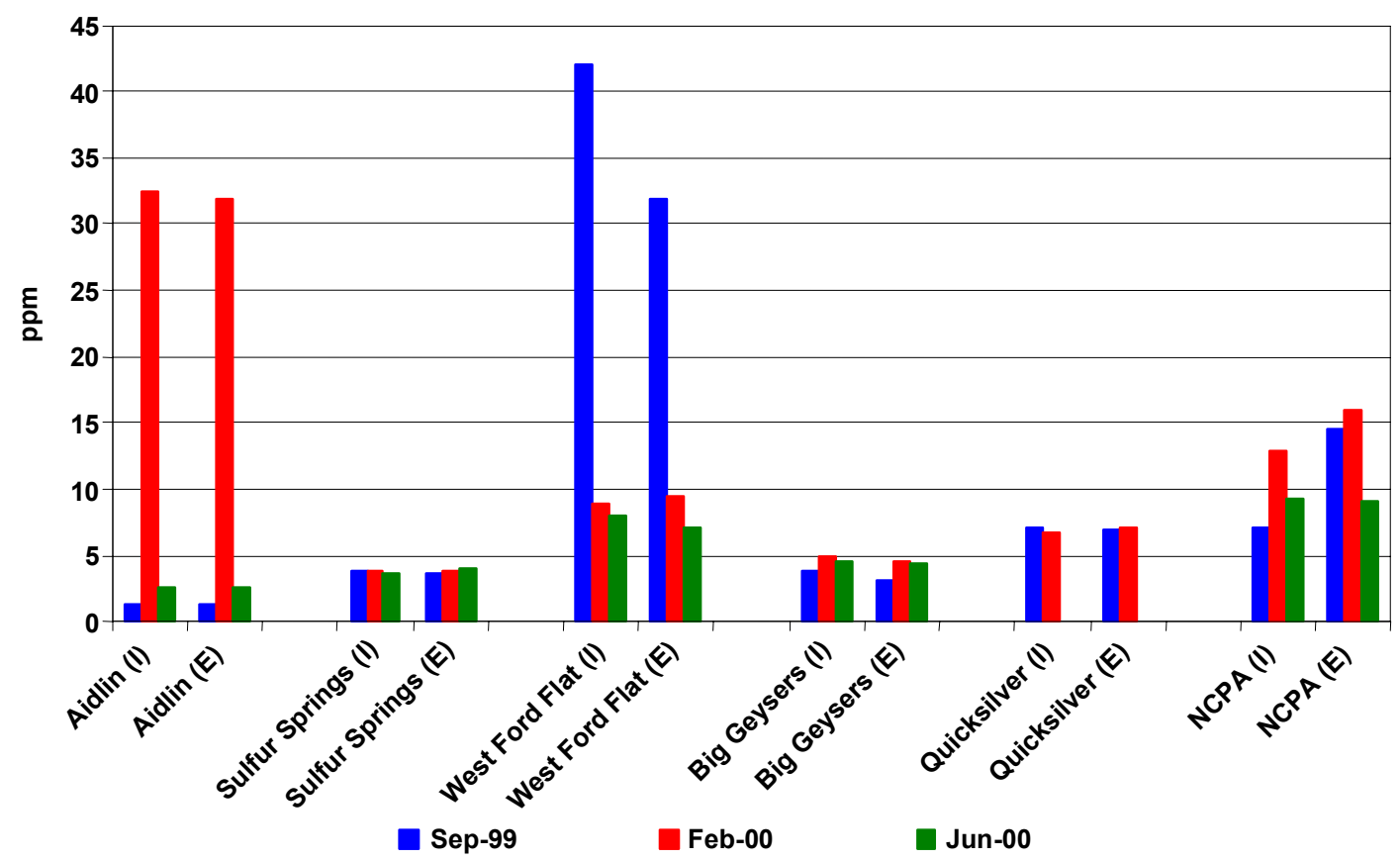

Figure 13. TOC concentrations in the condenser influent (I) and effluent (E) streams at Geysers plants.

\subsection{Analysis of Cooling Basin at Bonnett Plant}

From December 2001 through January 2002 water samples were collected from the cooling basin at the Bonnett Geothermal Plant near Cove Fort, Utah and shipped to the INL for analyses. The water chemistry data was compared with changes in microbial numbers determined from direct microscopic cells counts also performed on the samples. Samples were typically collected weekly; however, during some time periods samples were missed due to other operational priorities.

Data collected and analyzed from the water samples is presented in Figures 14-16. In Figure 14, water temperature, conductivity, $\mathrm{pH}$ and sulfate levels are plotted as a function of date. Sample temperatures are seen to increase in the summer months and then decline in the fall, as would be expected. Conductivity follows the same trend. The higher conductivity is most likely due to the higher evaporative loss experienced in the warmer months, resulting in a build-up of ions in the condenser cooling water. Changes in the sulfate concentration, which is a component of the conductivity measurement, track with changes in conductivity. The solution $\mathrm{pH}$ showed little variation over the measurement period, as might be expected since $\mathrm{pH}$ is a parameter that is monitored and controlled at the plant. The plots of microbial cell numbers and total organic carbon (TOC) concentrations analyzed from the water samples are presented in Figure 15. The relative changes in these values track reasonably well, particularly during the summer and fall months. The cell counts are also seen to increase in number just prior to growth problems that were observed in the tower during this time.

The period from April 30 through September 1 exhibited the highest values and the largest variances. This variability in the data is most likely in response to plant chemical treatments, which were administered on a weekly basis. The differences between the TOC readings and the cell counts during the colder months could be attributed to the growth mode supplying the carbon. That is, if the carbon was being released primarily from a biofilm rather than planktonic organisms, then the TOC reading could be higher than indicated by total cell numbers. In reviewing the chemical and biological data, the relationship between sulfate concentration and biological growth (shown in Figure 16) was found to be 
particularly interesting. The data generally showed an inverse relationship between sulfate concentration and biological growth, indicating that sulfate reduction by organisms may be occurring in this system.

Water chemistry analyses can be operated in an on-line sampling mode and used to provide information that can be indicative of microbiological growth problems in geothermal cooling systems. In particular, the TOC technique uses a small sample volume, and the analysis can be completed within minutes of sample injection. The drawback of this technique is that it does not provide a specific analysis of the origin of carbon and, as all indirect measurement methods, must be correlated with other process parameters to be meaningful.

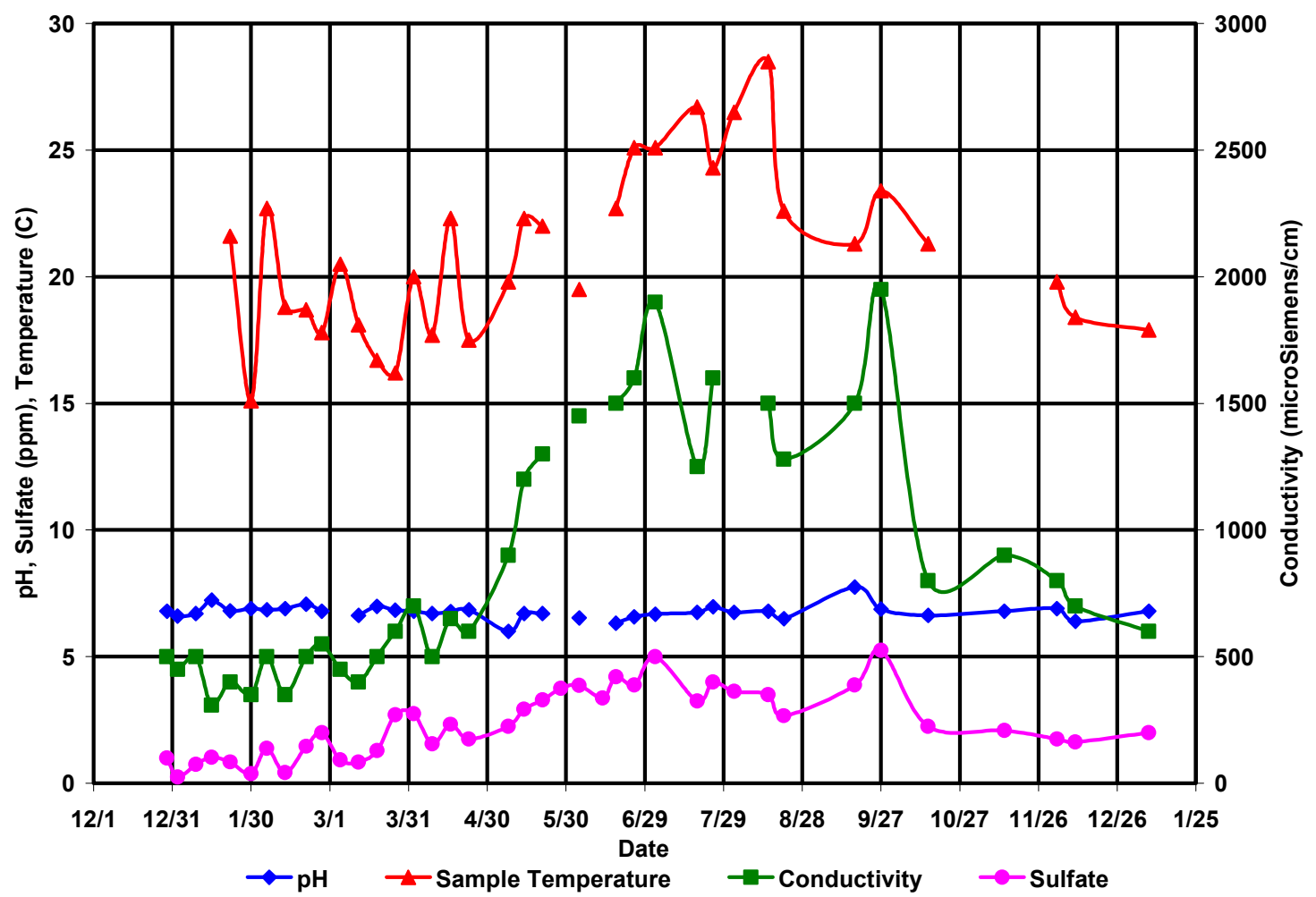

Figure 14. Bonnett water sample temperature, $\mathrm{pH}$, conductivity, and sulfate data. 


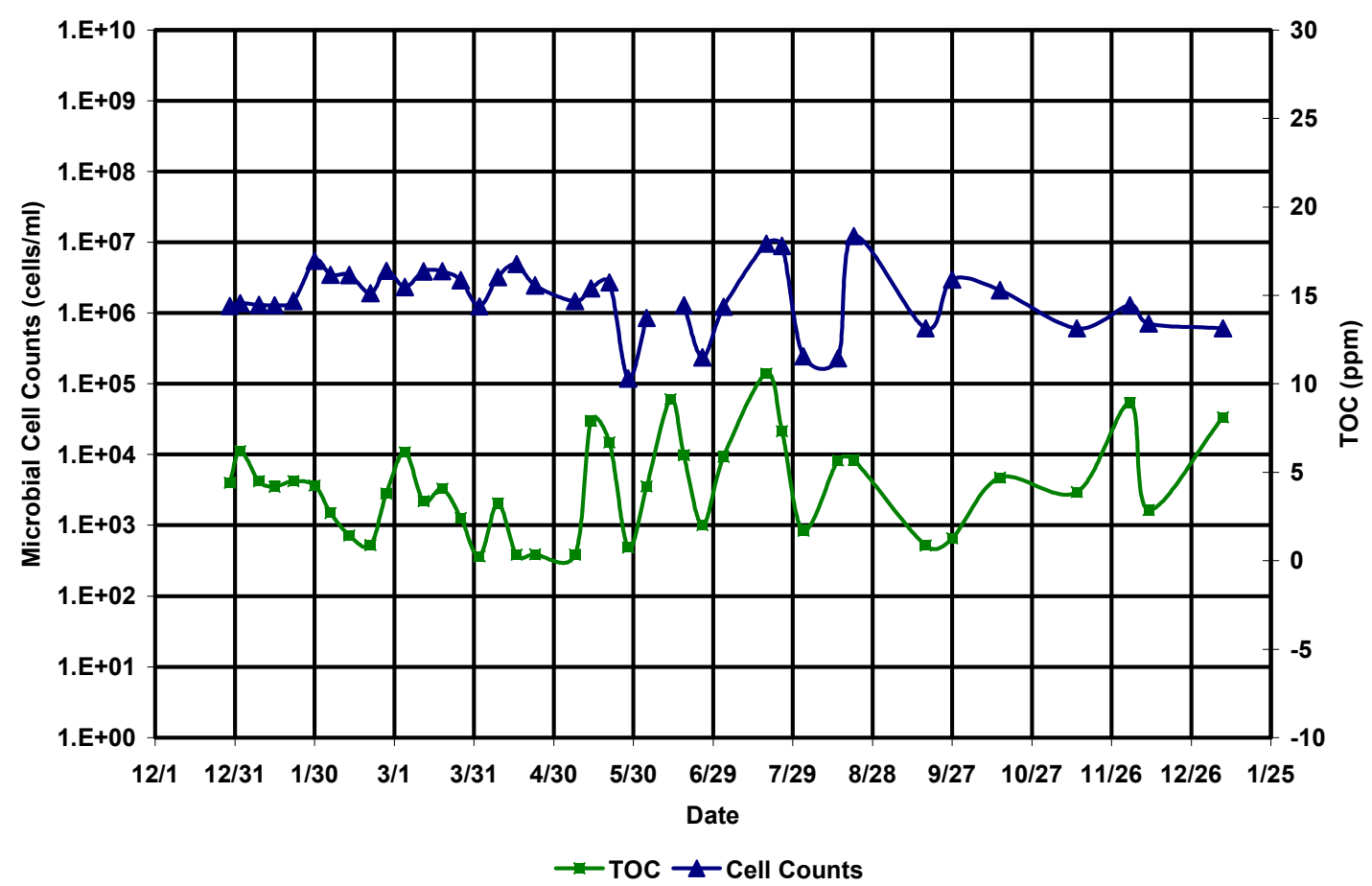

Figure 15. Bonnett water sample microbial density and TOC concentration data.

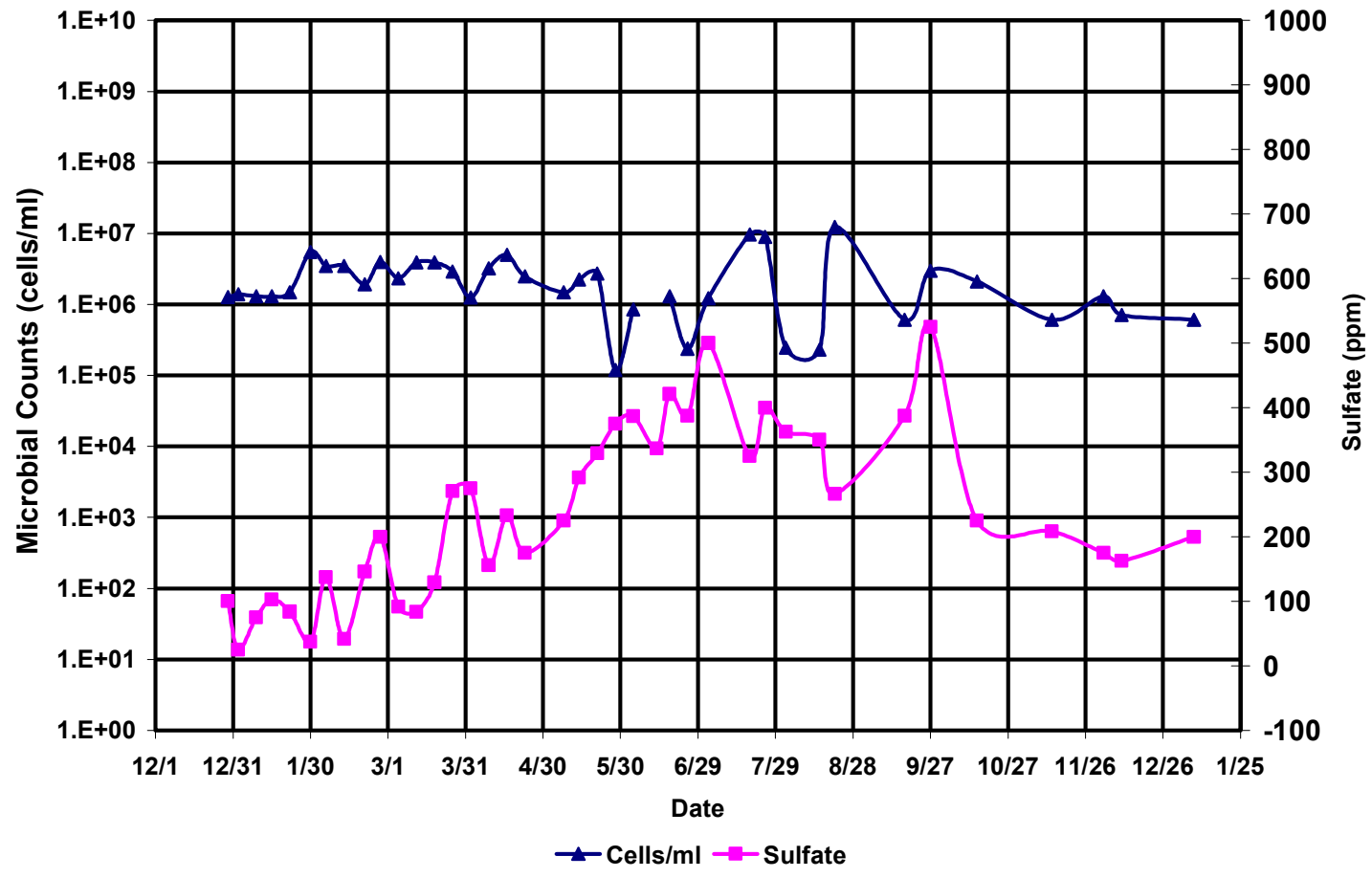

Figure 16. Bonnett water sample sulfate concentration and microbial cell density data. 


\section{BIOREACTOR STUDIES}

Understanding how microorganisms utilize and cycle nutrients from steam impurities, chemical additives, and component substrates is valuable in predicting and minimizing their impact on geothermal cooling water systems. In general, microorganisms obtain nutrients and energy for cellular processes and growth through oxidation/reduction reactions, which are catalyzed by specific enzymes. ${ }^{10}$ Oxidation and reduction, or redox, reactions involve the transfer of electrons from one reactant to another. This transfer occurs through the donation of one or more electrons from a material substrate, called the electron donor, and accepted by the electron acceptor, leading to changes in the chemical state of both the donor and acceptor. In a redox reaction, the electron donor is oxidized and the electron acceptor is reduced. And, because electrons cannot exist independently, an oxidation cannot occur without a subsequent reduction. In systems with abundant carbon and nutrients for supporting microbial growth, there is a well-defined sequence of redox reactions that occur. Initially, nearly all the $\mathrm{O}_{2}$ is consumed. When the $\mathrm{O}_{2}$ is nearly depleted, nitrate $\left(\mathrm{NO}_{3}\right)$ is reduced to $\mathrm{NO}_{2}^{-}, \mathrm{NH}_{4}, \mathrm{~N}_{2} \mathrm{O}$, or $\mathrm{N}_{2}$ through various reactions. After the nitrate is used, the dissolution of $\mathrm{Fe}^{3+}$ to $\mathrm{Fe}^{2+}$ occurs. Finally, when the potential drops even lower, sulfate reduction becomes the dominant redox reaction leading to the formation of $\mathrm{HS}^{-}, \mathrm{H}_{2} \mathrm{~S}$, and $\mathrm{S}_{2} \mathrm{O}_{3}{ }^{-11-12}$

A number of studies have been published on various aspects of microbially-mediated oxidation and reduction. These reactions are of considerable interest since they form the basis for a wide range of industrial mineral leaching, wastewater treatment, and environmental remediation applications. ${ }^{13-14}$ In addition, sulfide production by bacteria is considered to be a key factor in the corrosion of steel and concrete infrastructure. Many of these studies are directed at identifying and measuring the impact of specific organisms known to participate in a particular redox pathway. In actual field environments these interactions are far more complex. For example, in the case of steel corrosion, sulfate-reducing organisms may indirectly influence corrosion through the production of aggressive species, such as bisulfides or hydrogen sulfide. Intermediate metabolic products, such as thiosulfate, may also be produced that are equally corrosive. The interaction with iron may produce an iron sulfide coating, enhancing corrosion through changes in cathodic depolarization. ${ }^{15}$ In addition, the physiochemical characteristics of the liquid environment, including $\mathrm{pH}$, ionic composition, and/or oxygen levels can modify reaction pathways, eventually changing them from passivating to corrosive. ${ }^{16-17}$

\subsection{Nutrient Cycling in Geothermal Fluids}

\subsubsection{Sixfors Bioreactor Meaurements}

One means of probing these types of complicated interactions involves the use of bioreactor systems such as the Sixfors Model Fermentation Unit (INFORS Biotech Inc., Allentown, PA) pictured in Figure 17. Bioreactors allow one or more experimental conditions to be varied as function of time so that a complex environment can be broken down into a series of known perturbations. The Sixfors is a multiple bioreactor system, allowing up to six separate experiments to be performed at the same time. Each vessel has a working volume of $500 \mathrm{ml}$ with independent measurement and control of temperature, $\mathrm{pH}$, stirrer speed, and dissolved oxygen. A feed pump can be set up to deliver medium to each vessel on a user-defined duty/delay cycle. Initial operating parameters can be downloaded from a liquid crystal display screen. A memory card system is used to store set-up data and set-point values to permit multiple users on the system. Up to three pumps per vessel allow for reagent and nutrient feeds and a number of other options and accessories are provided to allow the Sixfors to perform a wide range of tasks. The system is interfaced to a PC for data logging and control with software that has been designed to complement manual operation. 


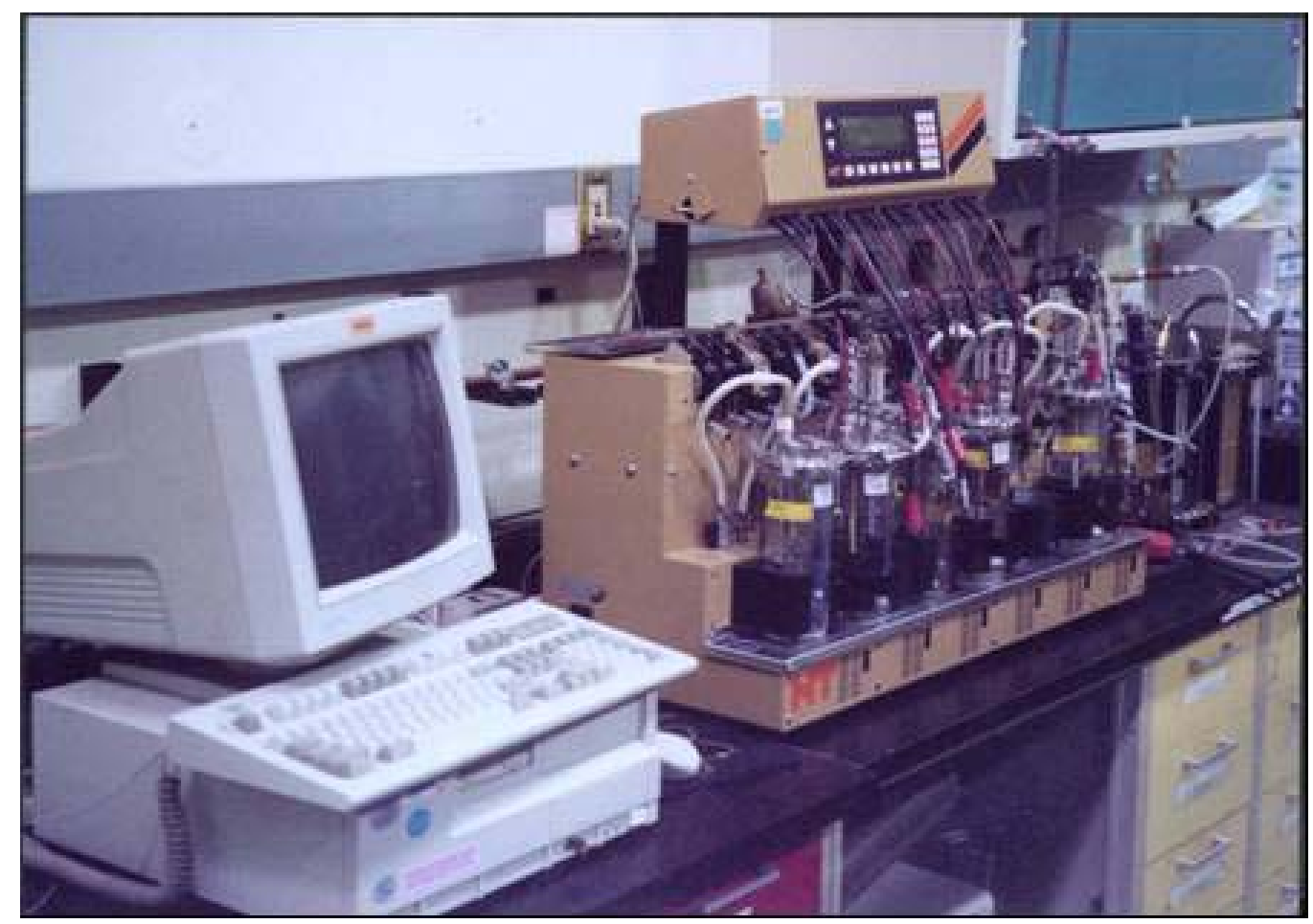

Figure 17. Sixfors bioreactor.

A series of experiments were conducted in the Sixfors bioreactor to measure iron and sulfur reduction by consortia of organisms found at geothermal facilities. The goal of this study was to investigate measurement techniques for understanding how consortia of organisms from the geothermal facilities utilize sulfur and iron for metabolic activity; and in turn, what role that activity plays in initiating or promoting the development of a biofilm on plant substrates. Sulfur utilization by bacteria is of interest because sulfur is produced as impurity in the resource. Iron is found in some of the steel formulations used in plant components and is also added as chemical treatment for reducing sulfide emissions from the plants.

Each experiment utilized two chambers of water obtained from geothermal facilities, including composite water samples from The Geysers and Bonnett Geothermal plants. The iron and sulfur content of the samples from both plants were tested and found to be similar in composition. One chamber, containing fluid that had been filtered sterilized by passing it through a 0.2 -micron pore size membrane, served as the experimental control. (Filter sterilization was used in place of autoclaving since the application of high temperature could change the chemical properties of the sample fluids.) The sample in the other chamber was inoculated with organisms that had been cultured from the filtrate and/or obtained from selective media cultures used in most probable number (MPN) analyses of species performed on samples taken from the respective plants. Comparisons of the MPN data also indicated comparable numbers for the two areas with the exception that Bonnett plant typically exhibited a higher number of acid-forming bacteria.

Various additives were also introduced into the chambers. In particular, iron chelate, trypticase soy broth (TSB), sulfate, and organic acids were added to both the control and inoculated samples. The iron chelate was introduced in order to increase the concentration of iron available for reduction. It also contains an organic acid that may serve as a nutrient to certain microorganisms. Similarly, the sulfate was added to determine if changes in chemical concentration would have an impact on the measured 
parameters of microbial activity. The soy broth (TSB) and organic acids were introduced to stimulate growth and increase biomass in the system. The purpose of increasing growth was to stimulate potential changes without having to operate over a long time period. Some vessels were also purged with nitrogen during testing to create an anaerobic environment, while other chambers were oxygenated. In addition, these conditions were suddenly switched by purging a previously oxygenated reactor with nitrogen and a previously anaerobic reactor with oxygen, in order to simulate changes that occur as the condensate cycles through the condenser and into the cooling tower.

During the experiments, samples were pulled from the air-sparging line of each bioreactor. The iron and sulfate analyses were performed using standard chemical reactions, measured as color changes with a spectrophotometer and compared to standards to obtain quantitative data. Carbon analyses were performed using Model 700 TOC Analyzer. The oxygen and $\mathrm{pH}$ were monitored using ingold electrode sensors integrated with the Sixfors instrument for feedback and control of levels.

Indications of both iron and sulfuring cycling were recorded. In particular, tests using ferric nitrate and ferric EDTA (iron chelate Dow RT2) as nutrient additives exhibited changes in $\mathrm{pH}$ and corresponding changes in nutrient levels, that could be attributed to sulfate reduction activity. Experiments with some geothermal fluids also indicated that they are predisposed to the growth of certain types of organisms. In one case, geothermal fluid from the Bonnett plant was inoculated with a laboratory culture of sulfate reducing bacteria. After no sulfate reduction was observed the system was sampled and found to contain primarily acid-forming bacteria. In this case the native population of organisms had out-competed the organisms introduced into the system.

This scoping work indicated that the use of bioreactor experiments can be utilized to track how routine operating changes, such as varying chelate concentrations, impacts or triggers the growth of bacteria in plants. This knowledge could lead improved controls by slightly varying the nutrient (chelate) level or through improved timing for biocide applications based upon the nutrient levels found in the process stream.

\subsubsection{Gilson Differential Respirometer Measurments}

Geothermal plant operators are also interested in investigating the ability of microorganisms found in the cooling tower basin to metabolize and cycle sulfide to less toxic sulfur compounds. If the growth or activity of the organisms participating in sulfur-oxidation could be selectively enhanced, then hydrogen sulfide could be naturally abated in the cooling basin, substantially reducing the costs associated with the chemicals used for abatement. The use of a bioreactor system to measure respiration rates was proposed as a technique for monitoring the response of the microbial populations found in geothermal cooling towers to various conditions, including the addition of nutrients such as nitrogen and phosphorus, which could be added to stimulate bacterial growth for sulfur oxidation.

Respirometry is based upon a manometric measurement of dissolved gases that are in equilibrium in a confined sample volume. Since microbes expire varying amounts of carbon dioxide or oxygen as they metabolize nutrients, this technique can be used to evaluate their activities in process streams. Respirometry is a well-established tool for process control in the biological treatment of wastewater and has also been used to assess the biodegradation of specific chemicals. And, while it is most commonly performed on samples in a laboratory environment, it is also possible to implement as an on-line instrument. ${ }^{18-19}$

A series of measurements to determine if differential respirometry could track changes in microbial activity induced by changing the nutrient concentration were conducted using water from the Sonoma Geothermal Plant at The Geysers field. The Sonoma facility was selected for study since it is using wastewater from nearby Santa Rosa, California as tower make-up during the summer months. The 
addition of the Santa Rosa wastewater may alter the water chemistry of the cooling tower basin by introducing phosphates and nitrates, which are, in turn, expected to increase some types of microbial activity. (These nutrients may also impact the addition of chemicals used for sulfide abatement.) Tests were conducted to investigate the impact of adding phosphate and nitrate additions to existing microbial populations in the sample water and to populations of sulfate-reducing (Desulfovibrio vulgaris) and sulfur-oxidizing (Thiobacillus neopolitanus) bacteria introduced into water from laboratory cultures.

A Gilson Differential Respirometer Model IGRP-14 shown in Figure 18, was used in the experiments. The instrument consists of a series of tubes and two chambers separated by a manometer U-tube. One of these chambers is the reaction flask and the other serves as reference flask, or thermo-barometer, acting as a control for slight temperature or pressure changes in the water bath. The two flasks are initially open and in equilibrium with the surrounding environment. During testing, the system is sealed so that one side maintains the head-space volume at the time of closure and the other contains the test solution and materials. If gas is either used up (e.g. oxygen consumed) or produced (carbon dioxide expired) in the reaction flask, a differential change in gas pressure is detected. (In this instrument, the carbon dioxide is scrubbed out of the system by an alkali resulting in a negative gas pressure.) The change in pressure causes fluid to move in the U-tube. Turning one of the knurled knobs, shown at the top left in the picture, causes a metal plunger to change the volume on the reaction vessel side of the tube and when the fluid is moved back to its original starting point, the volume change is indicated on the dial in microliters. The respirometer also contains a circulating water bath to control the temperature of the reaction flasks and shaker feature that can be used to stir the test solutions. Prior to testing, the water bath was filled with deionized water, the stirring motor and heaters were activated, and the system was allowed to stabilize for approximately one hour.

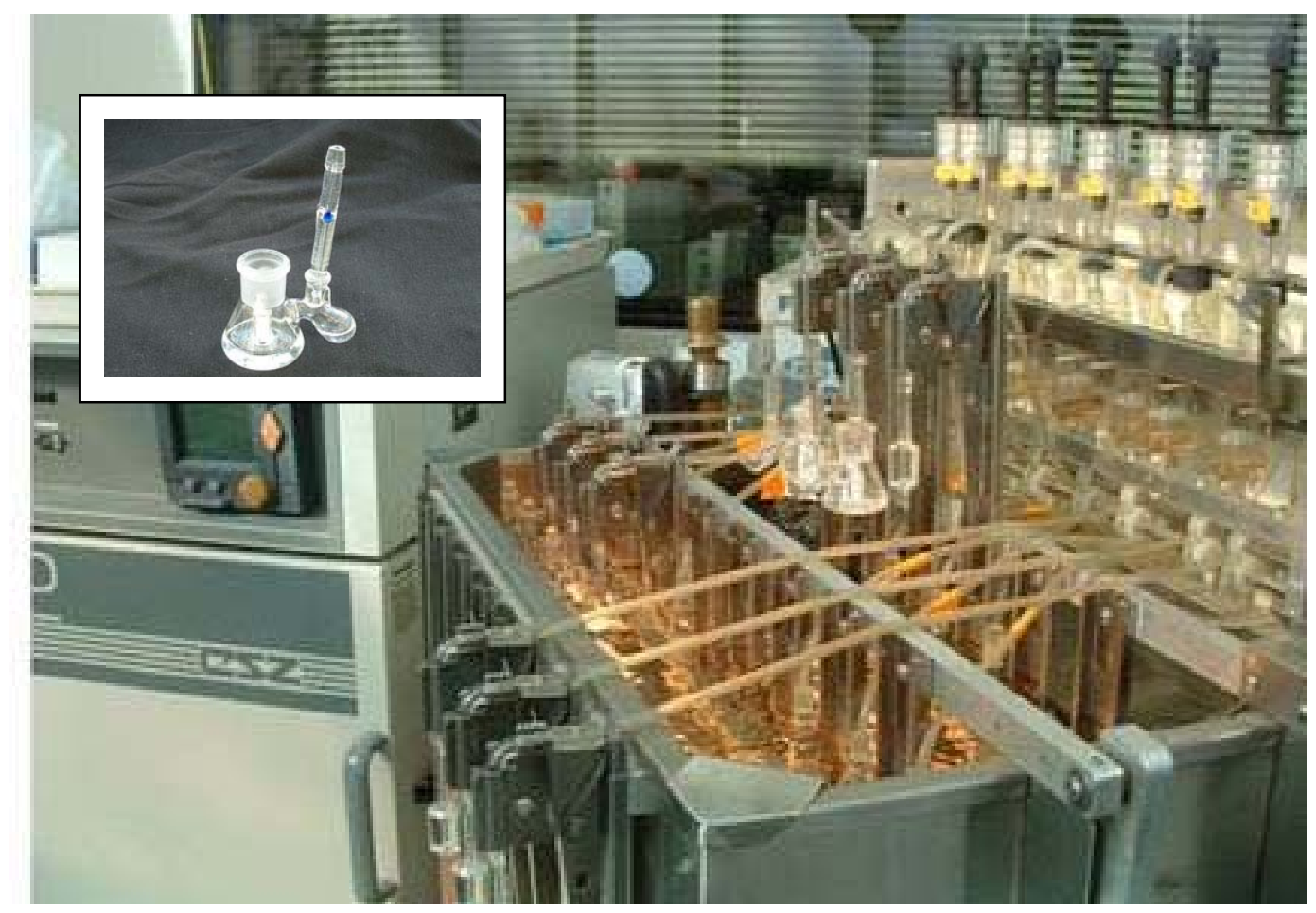

Figure 18. Gilson differential respirometer and close-up of $15 \mathrm{ml}$ reaction flask.

Data from one of these experiments is shown in Figure 19, where 20 ppm additions of sodium nitrate $(\mathrm{N})$ and phosphate $(\mathrm{P})$ solutions were added to a water sample containing a natural population of bacteria. The plot shows increased microbial activity, as evidenced from increased gas consumption, 
when small concentrations of phosphorus and nitrogen were added. Figure 20 illustrates the impact of adding sulfides to the Sonoma water sample. In this experiment, $10 \%$ and $20 \%$ sodium solutions were added to water samples. While there were dramatic differences observed in the results of this test, there are uncertainties associated with the interpretation of the data, since sulfides can be trapped in an alkaline solution. There were, however, other indications that the addition of sulfide was affecting the natural population of microbes. The sulfate analyses indicated a slightly higher concentration of sulfate at the end of the experiment in the flasks that received sulfide additions, which is consistent with an increase sulfur oxidation due to microbial action.

The results of these experiments indicate that respirometry may be a useful method for observing the impact of nutrient additions associated with the Sonoma tertiary treated water in the cooling tower basin water. Both nitrate and phosphate additions produced detectable changes in the rate of microbial activity in the indigenous population of bacteria. There was also evidence that microbial sulfate oxidation was occurring and that the rates of this activity could be enhanced by increasing the population of sulfur oxidizing bacteria in the samples. Results from experiments taken with water samples collected at differing times also showed similar trends. Also, since the experiments were conducted on water samples collected from the basin, shipped to the laboratory, stored at $4^{\circ} \mathrm{C}$ and then tested, it is very likely that under these conditions the natural population of bacteria were stressed. Consequently, they may not be as active as the microbes would be if sampled and processed immediately. Based upon these results, the respirometric technique for tracking microbial activity in the geothermal basin is not only feasible but would be even more effective if it could be used on site and implemented as an on-line technique.

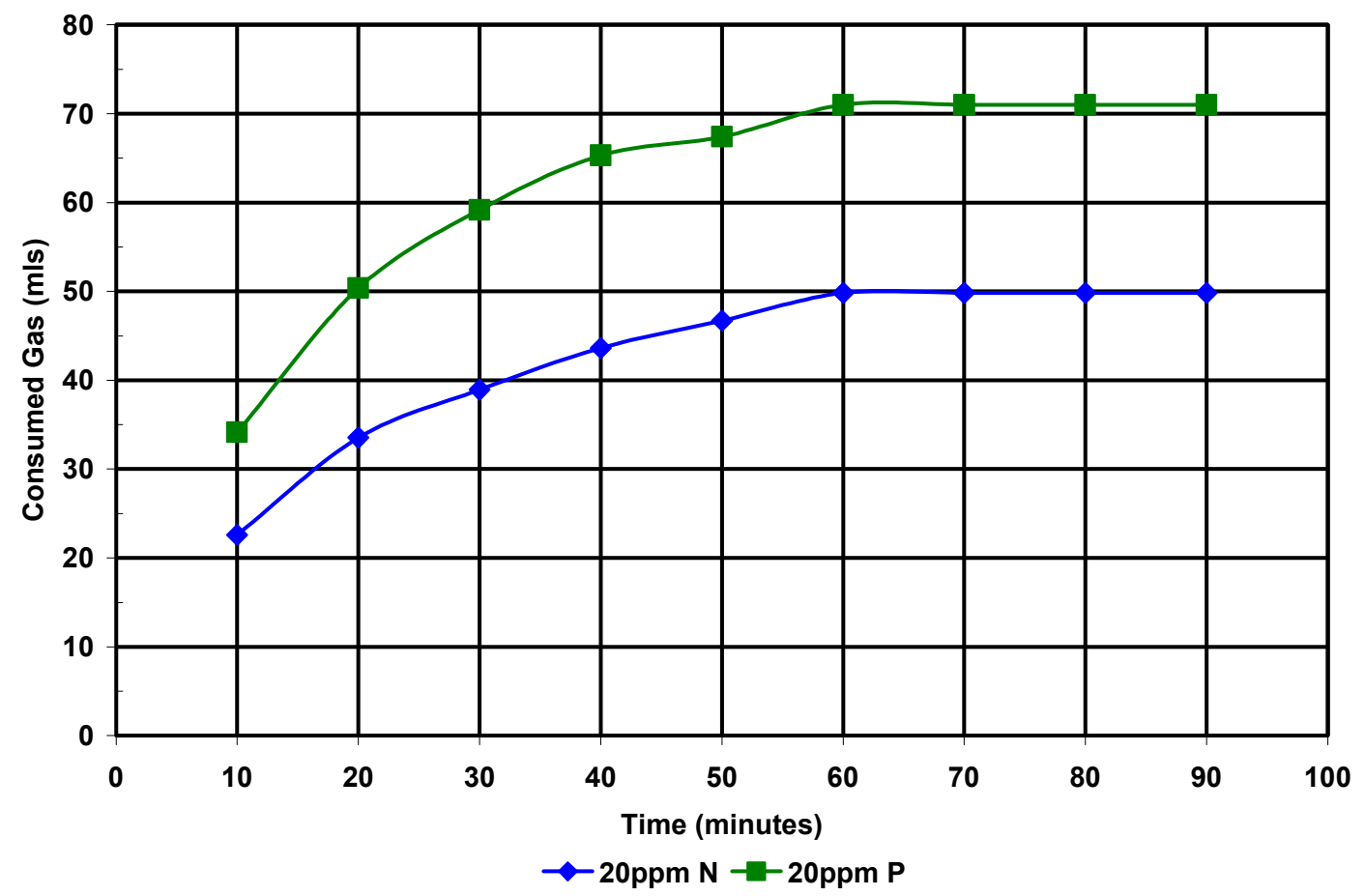

Figure 19. Respiration rate change detected in Sonoma water sample with the addition of $20 \mathrm{ppm}$ nitrate $(\mathrm{N})$ and phosphate $(\mathrm{P})$ nutrients. 


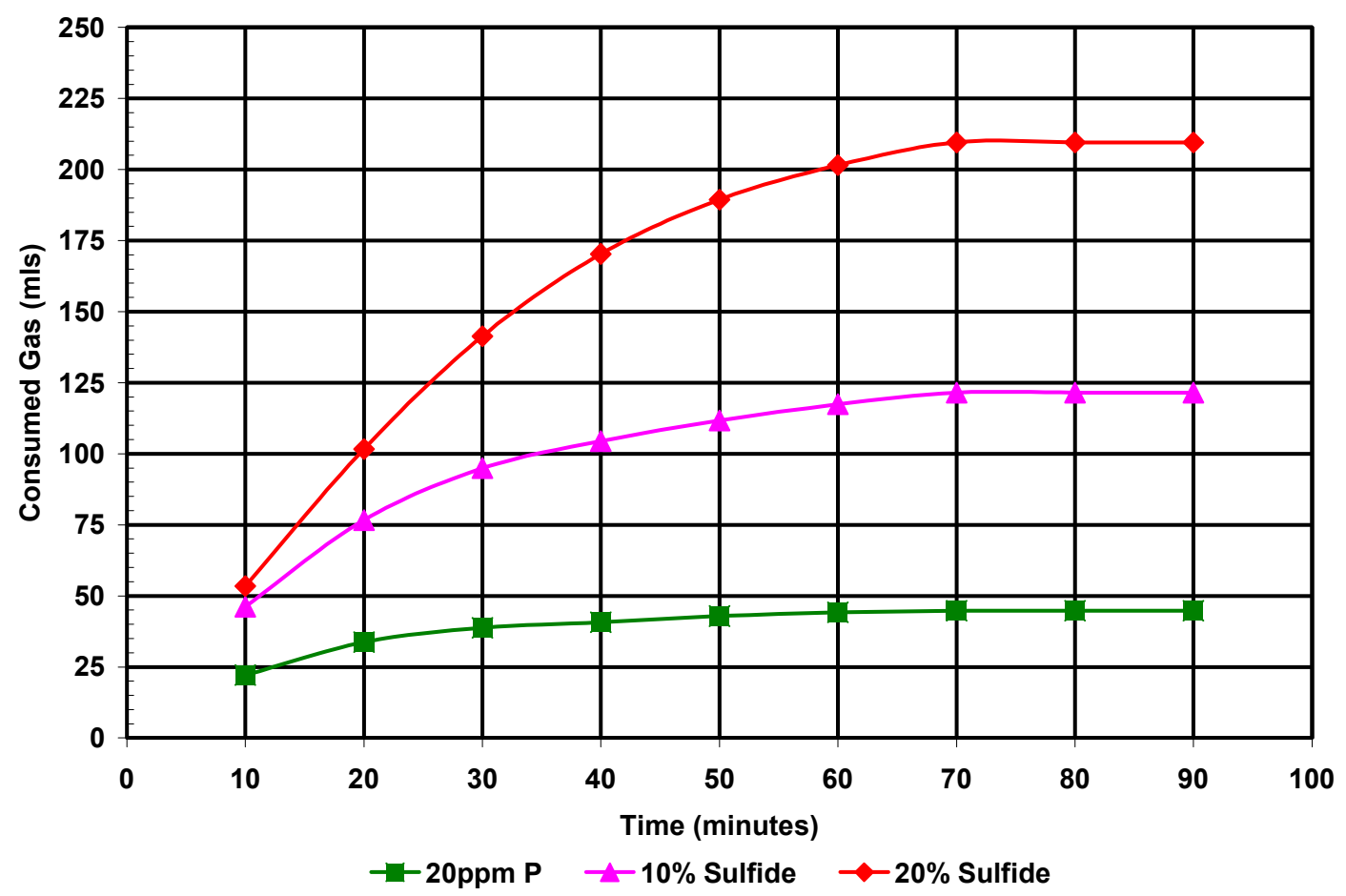

Figure 20. Respiration rate change detected in Sonoma water sample with the addition of $10 \%$ and $20 \%$ sulfide amendments compared with an (20 ppm) addition of a phosphate nutrient. 


\section{ELECTROCHEMICAL MEASUREMENTS}

Electrochemical measurements have been widely used to detect and characterize corrosion. Metal corrosion is an electrochemical oxidation/reduction reaction that can be influenced by the physical, chemical and biological properties of the surrounding environment. In particular, bacteria within biofilms are capable of changing the type and concentration of ions, $\mathrm{pH}$, dissolved oxygen level, flow velocity and the buffering capacity at the metal/solution interface, thereby influencing the corrosion resistance of components. ${ }^{20}$

The most widely used field technique of this type is based upon the measurement of electrical resistance, sometimes referred to as zero resistance ammetry (ZRA). In this technique, a metallic strip is inserted into the process medium and its electrical resistance is monitored with time. The electrical resistance of the probe is inversely proportional to the cross-sectional area and directly proportional to temperature. Therefore, at constant temperature, the corrosion will cause the metallic strip to suffer a decrease in cross-sectional area, and as a result, an increase in resistance. The strip is sampled over a period of time and the average corrosion rate is extrapolated from the difference in resistance between two readings. Electrochemical measurements have been used in on-line monitoring devices for various process plant environments. Disadvantages of these techniques include that the data are often difficult to interpret and localized corrosion can be masked by changes in the stream environment. In addition, standard configurations of these devices do not readily allow the partitioning between the chemical and biological contributions, and finally the measurable signal changes occur typically after a film has been formed and chemical alteration of the surface has taken place.

\subsection{Electrochemical Split Cell}

In order to address some of these drawbacks for microbial fouling applications, two special configuration cells have been investigated. One is a split-cell arrangement, illustrated in Figure 21, in which one of the cells contains process fluid and bacteria. The other cell is sterilized and the process fluid is filtered to prevent microbial contamination. The cells share a common internal pathway connected to a semi-permeable membrane that permits the exchange of ions but will not allow the passage of bacteria into the sterile side. An electrode of the material of interest is placed into each cell and connected to via an external pathway to potentiostat to complete the circuit. As the electrode in the cell containing the bacteria is perturbed by microbial activity, anodic or cathodic currents are detected. ${ }^{21}$

Experimentation in the laboratory demonstrated that the introduction of a bacterial cell pellet, cultured from geothermal process fluids, initiated a significant imbalance between the cells as shown in Figure 22. This response is consistent with microbially-induced oxidation of the coupon. Within a month, the current has returned to near its initial value, indicating that a biofilm had developed, forming a passivation layer on the surface.

While the electrochemical split-cell proved to be a good laboratory tool, several problems were identified with its application as a field instrument. For example, it requires that the measurement stability be maintained over a relatively long period of time which may be difficult to accomplish in a plant environment. In particular, the sterility of the abiotic compartment is difficult to maintain since the filter may plug or become contaminated. 

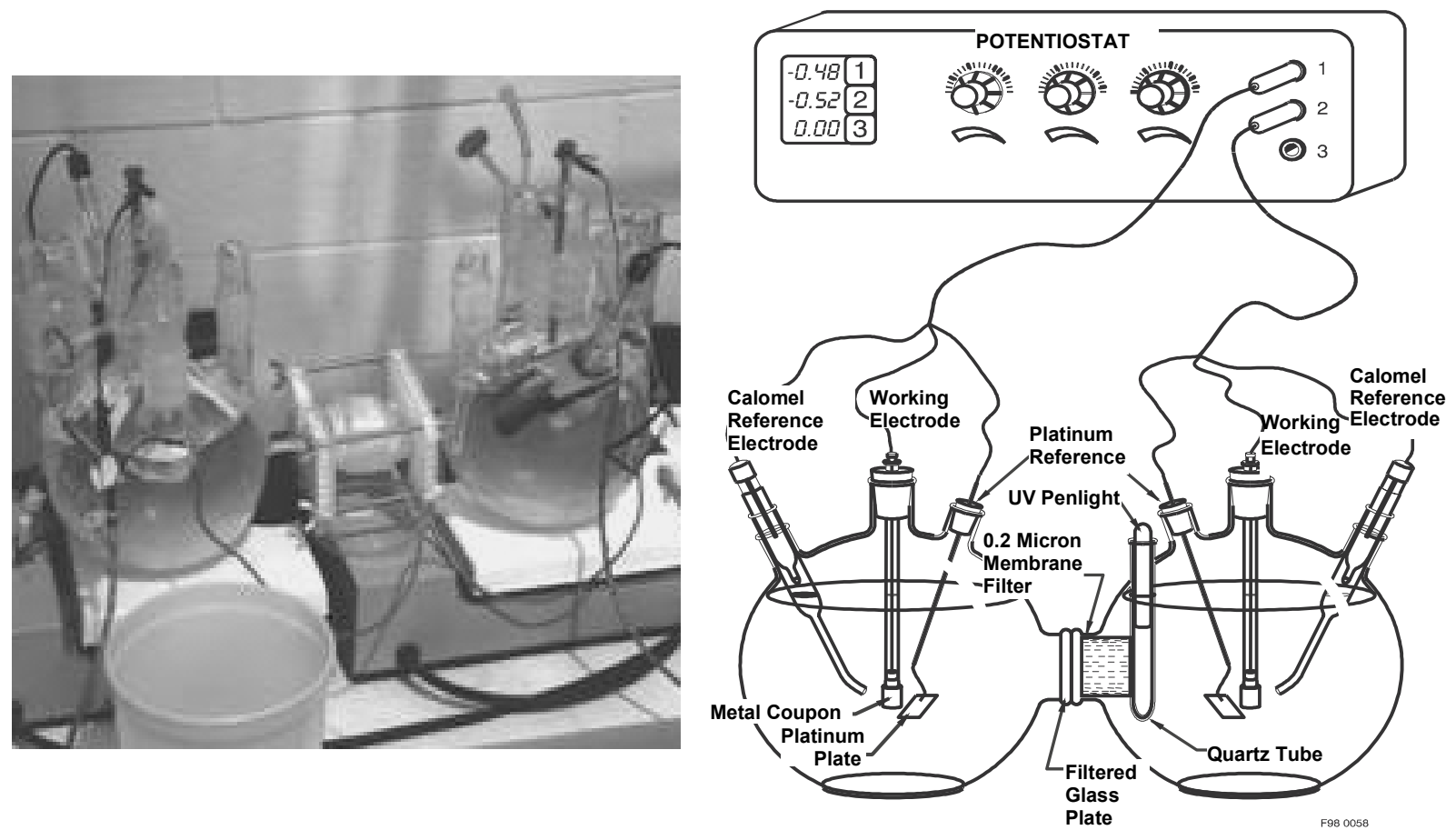

Figure 21. Photograph and schematic of electrochemical split cell device for distinguishing between chemically and microbiologically-induced corrosion.

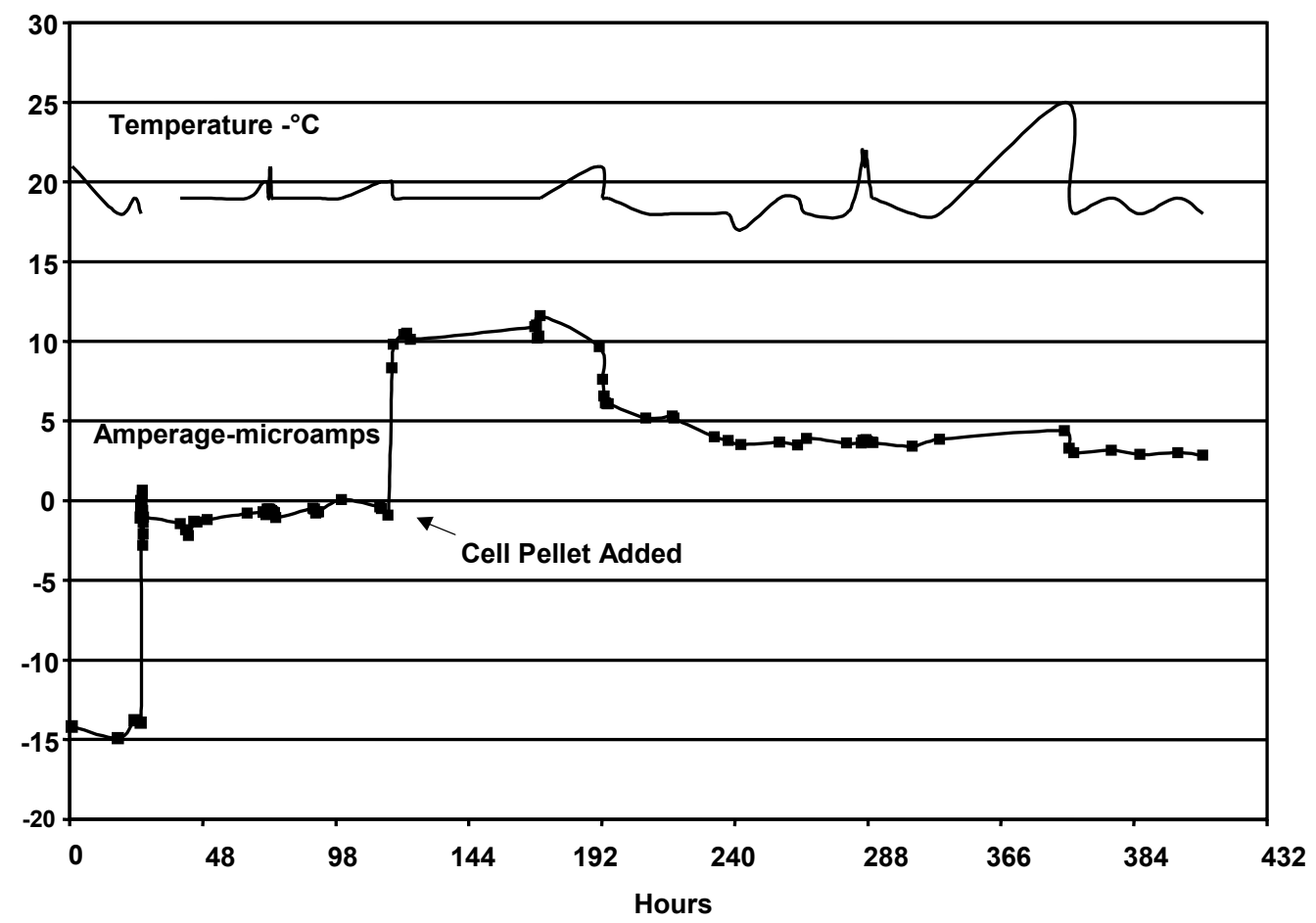

Figure 22. Response of electrochemical split cell to biological attack. 


\subsection{BloGEORGE TM Biofilm Activity Monitoring System}

The second device, the BIoGEORGE TM Biofilm Activity Monitoring System is pictured in Figure 23. The system, procured from Structural Integrity Associates (San Jose, CA), consists of a stack of stainless steel discs comprising two identical electrodes. ${ }^{22-23}$ The electrodes are electrically isolated from each other and from the stainless steel plug that serves as the body of the probe. (An epoxy resin fill between the electrodes incorporates a circular cylinder of metal discs and insulating resin.) One electrode (set of discs) is polarized relative to the other for a short period of time (typically one hour) each day to a preset DC potential. Experimental data indicates that the polarization cycle creates an environment that encourages biological growth on the discs; and therefore, growth occurs on the instrument as a precursor to fouling on plant components. ${ }^{24}$

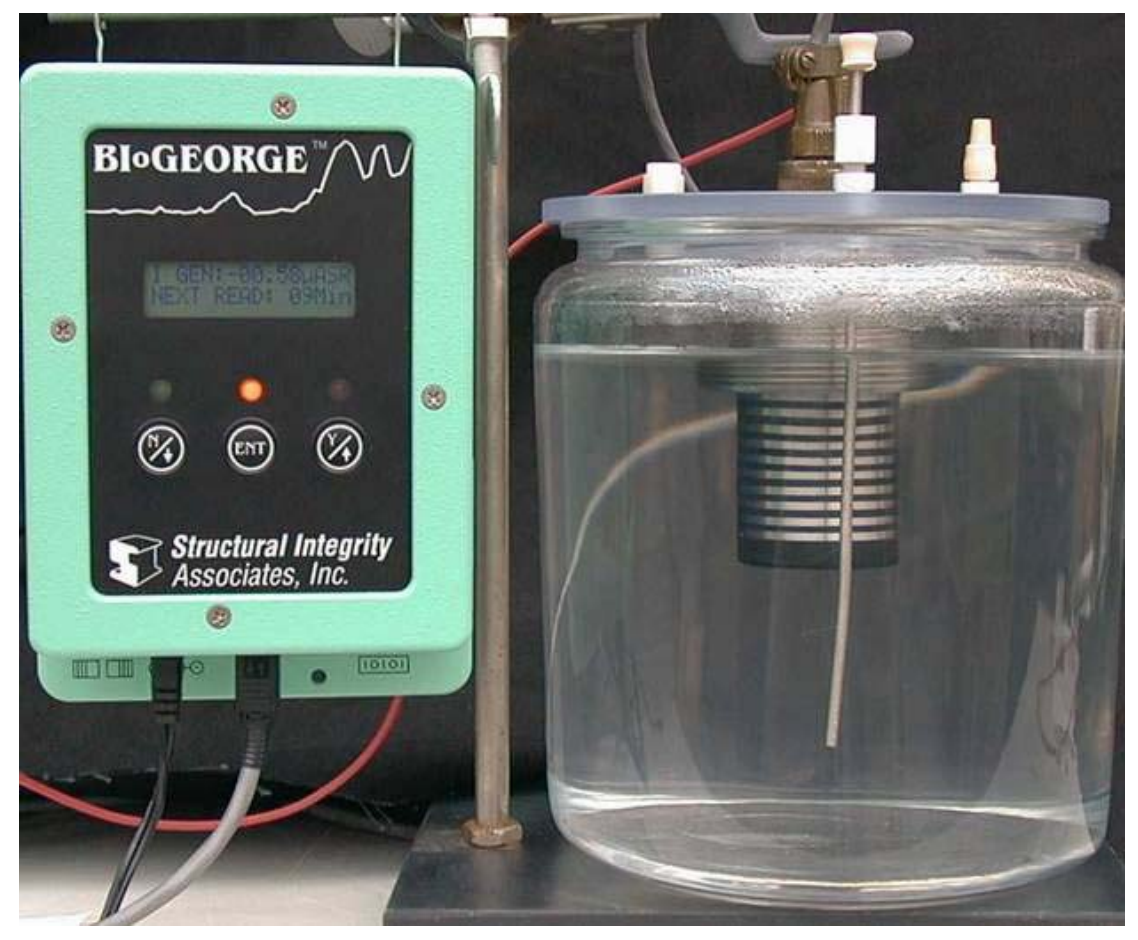

Figure 23. BIoGEORGE TM Biofilm Activity Monitoring System.

Biofilm formation is typically detected as an increase in the applied current required for achieving the preset potential. When a biofilm forms on the probe it provides a more conductive path for the applied current than the flowing cooling water, causing the current to increase over the baseline value. Metabolic processes in the film, many of which involve oxidative and reduction reactions may also act to enhance the current. In contrast, inorganic materials have only minimal impact on the applied current; and in fact, tend to impede cathodic reactions. The instrument also monitors the current generated between the two electrodes when no external potential is applied. This current can also provide an indication of biofilm formation. Depending upon the type of bacteria in the biofilm, the relationship between the biofilm and the cooling water and other variables, the generated current can be positive or negative. In either case, a variance in the reading from the baseline is indicative of film formation. This variance is illustrated in Figure 24, which shows data collected from the probe installed in a condenser system of a geothermal plant operated by the NCPA in October 2000. The applied current began to increase significantly around the 25th of November. The probe was removed from the system in early December and a build-up of biofilm was confirmed. 


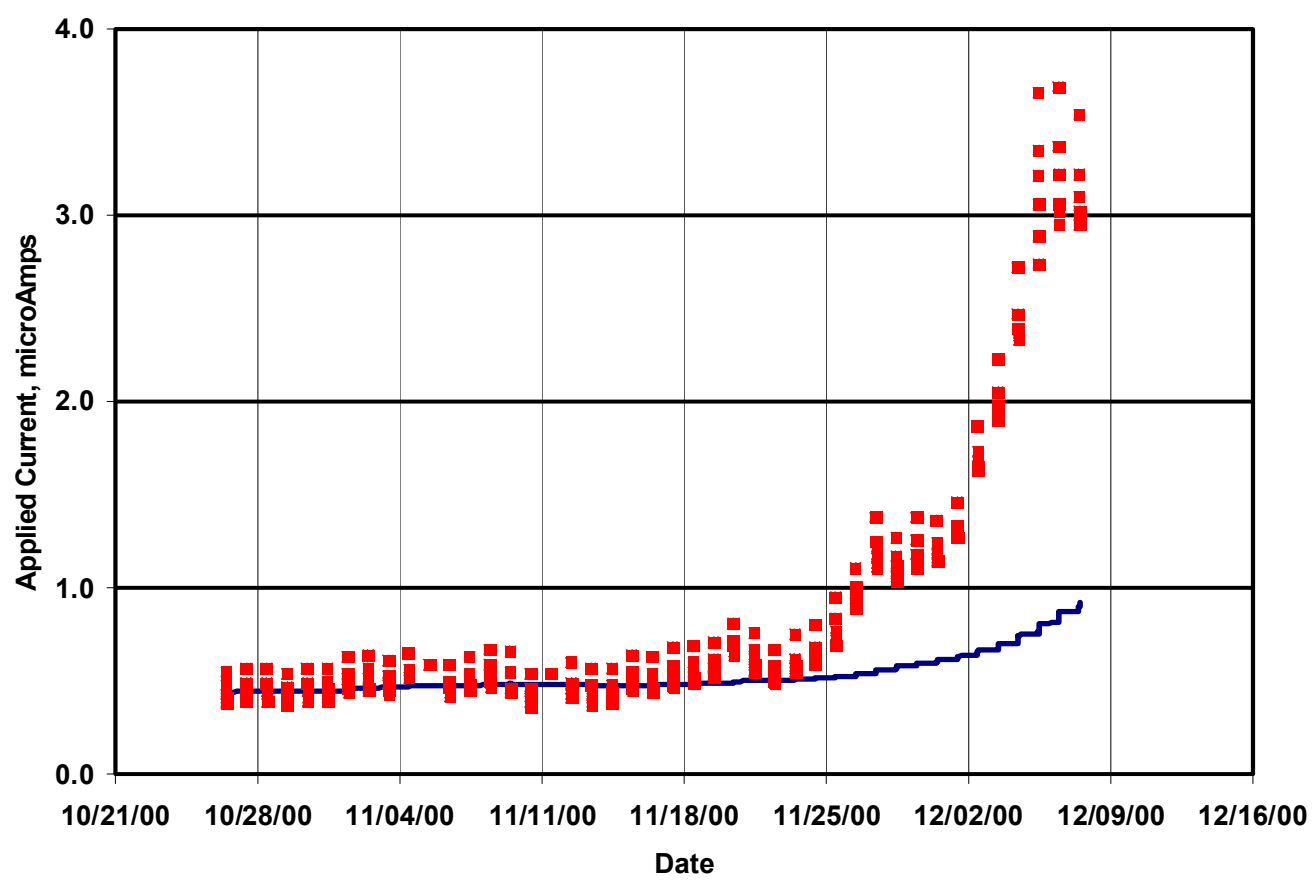

Figure 24. Increase in applied current indicative of biofilm development on probe.

The electronics for the control, data acquisition and data analyses are housed in the box pictured at the left of the probe (Figure 23). The system collects and stores potential and current readings and updates the display every few seconds. Every ten minutes, these data points are written into an on-board database. The system software then calculates the baseline values for the applied and generated currents. Individual measurements are compared with these baseline values to determine the extent of biofilm development on the probe. The controller also contains three light emitting diodes that provide an easy-to-interpret, visual status of the probe's condition. A green light indicates that no film has been detected, a yellow light indicates that the probe is evaluating or establishing the baseline, and a red light indicates that a biofilm has been detected. The calibration or sensitivity for these alarm setpoints is determined by the conditions in the process stream where the instrument is deployed. The unit is compact, operates on $110 \mathrm{VAC}$, and contains built-in battery backup. Data can also be downloaded to a personal computer through an RS-232 port and imported into a spreadsheet for trend analyses, or for comparison with other plant parameters. A recent upgrade to the instrument provides for the real-time transfer of data between the controller and a personal computer. Consequently, the trend plot can be automatically displayed; and in addition, accessed and remotely viewed via a modem connection.

The metal probe is installed into the piping system using a two-inch national pipe thread (NPT) connection. (Hot tap fittings are also available from the manufacturer.) The installation should allow the probe to be exposed to flowing fluid whenever the cooling water system is operational. If piping connections are not readily available in the cooling water piping, the probe can be deployed in a sampling line that provides a continuous cooling water flow. The sampling line should be properly sized to both physically accommodate the probe and to provide a fluid velocity past the probe that is representative of velocities in the cooling water system. The probe should placed at an off vertical angle in order to minimize the collection of debris and should be located at least 10 pipe diameters from any bends in the system to reduce flow disturbances. The data acquisition system can be located at a distance of several hundred feet from the probe. 
The collection and correlation of the data recorded by the BIoGEORGETM Biofilm Monitor with other plant parameters provides a means for establishing that device is correctly sited in the plant and is providing meaningful data for use in optimizing biocide applications. The deployment of metallic coupons near the probe location, which can be removed and examined for biofilm in response to current variations detected by the BioGEORGE ${ }^{\mathrm{TM}}$, may also be used to validate the instrument's performance and to determine the minimal signal that can be reliably used to as an indicator of film formation. The data should also be compared with plant operational log, indicating any off-normal conditions in the facility, since these factors may also alter the instrument's performance. The comparison of the monitor readings with heat transfer performance of the condenser can also be used as an indicator that the biofilm monitor is correctly tracking in-plant film development.

\subsubsection{Bonnett Geothermal Plant Deployment}

The application of the BIoGEORGE TM Biofilm Activity Monitor in geothermal cooling water systems has been investigated through extended deployments at the Bonnett Geothermal Plant, Cove Fort, Utah operated at the time by the Utah Municipal Power Agency and at the Aidlin Plant operated by Calpine Corporation near Middletown, California. ${ }^{25}$

The Bonnett plant, where the first extended deployment was conducted, is representative of a typical facility in that growth problems were occurring at the plant, treatments were applied on a predefined schedule, and traditional methods (pressure drop and biological cell counts) were used to identify and assess problems. Consequently, it provided an ideal facility for the testing and evaluation of the online biofilm monitor.

The stainless steel probe was installed into a two-inch pipe that by-passes a valve in the cooling water line upstream of the condenser. The installation in the side-stream flow loop, shown in Figure 25, allowed the probe to have direct contact with the flowing process stream and also provided the ability to adjust the flow to fluid velocities approaching those found in the condenser tubes.
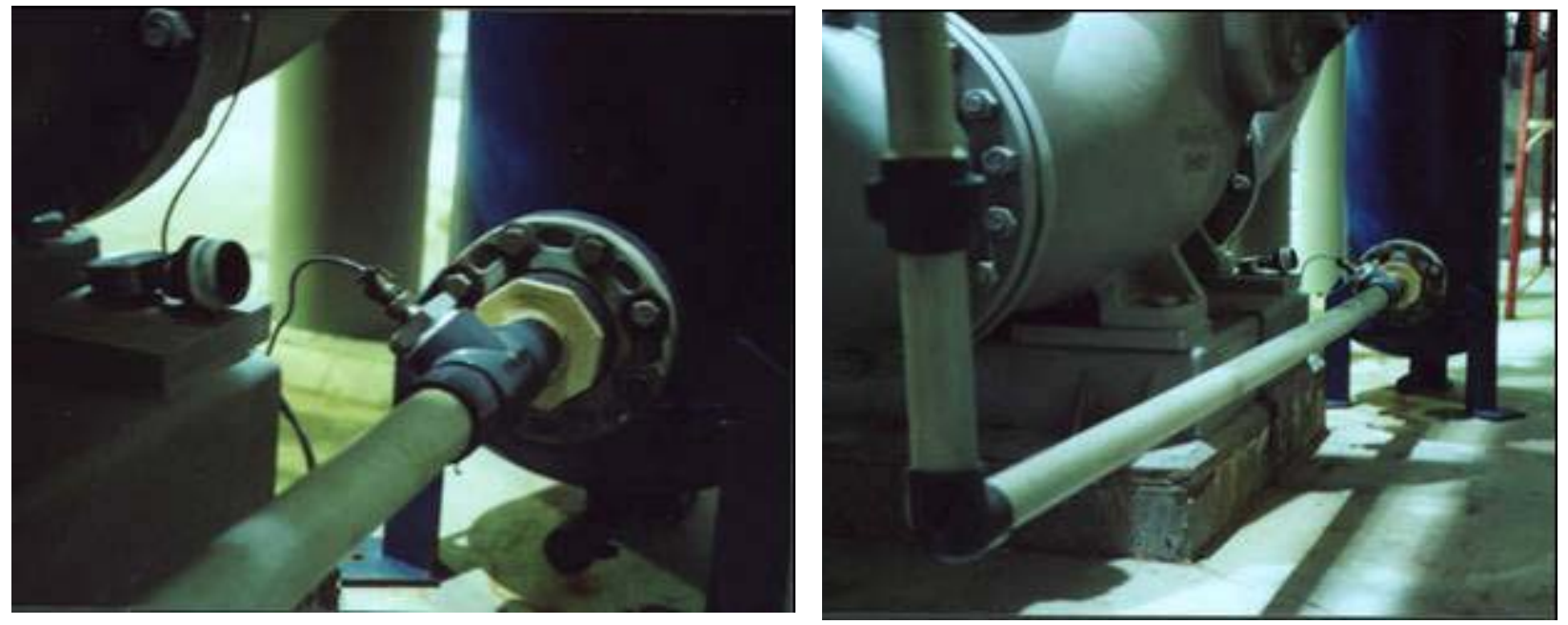

Figure 25. Installation of the BIoGEORGETM Monitor at Bonnett Geothermal.

The monitor was installed at Bonnett Geothermal in December 2000 and operated continuously until March 2002, just before the plant was shut down for routine maintenance. The probe was cleaned and re-installed in July 2002 and operated until January 2003. Instrument data, as well as plant 
operational data, were collected at regular intervals and evaluated to assess the capability of the instrument to detect the onset of microbial activity excursions.

Data recorded by the BIoGEORGETM from December 2001 to January 2002 is presented in Figure 26. For the data collection, the probe was polarized to a preset potential of 100 millivolts for approximately one hour each morning. The instrument then recorded the applied current required to achieve that potential. Increases in that value are related to the fouling condition of the probe. Referring to the figure, the monitor appeared to track with (and in some cases be predictive of) changes that occurred in the plant operation during this period. For example, around February 27, operations personnel noted an increase in back-pressure possibly indicating fouling. The BIoGEORGE ${ }^{\mathrm{TM}}$ applied current was increasing during the period of time immediately preceding this change. On March $8^{\text {th }}$ algal growth was seen in the cooling tower and by March 22 was producing a viscous dirty slime in the system. The monitor showed a very sharp increase in current around this same time. Treatments were applied and the system recovers during the first week of April. Excursions noted in early May were related to problems with the brominedispensing system in the tower. A new bromerator was installed on May 2.

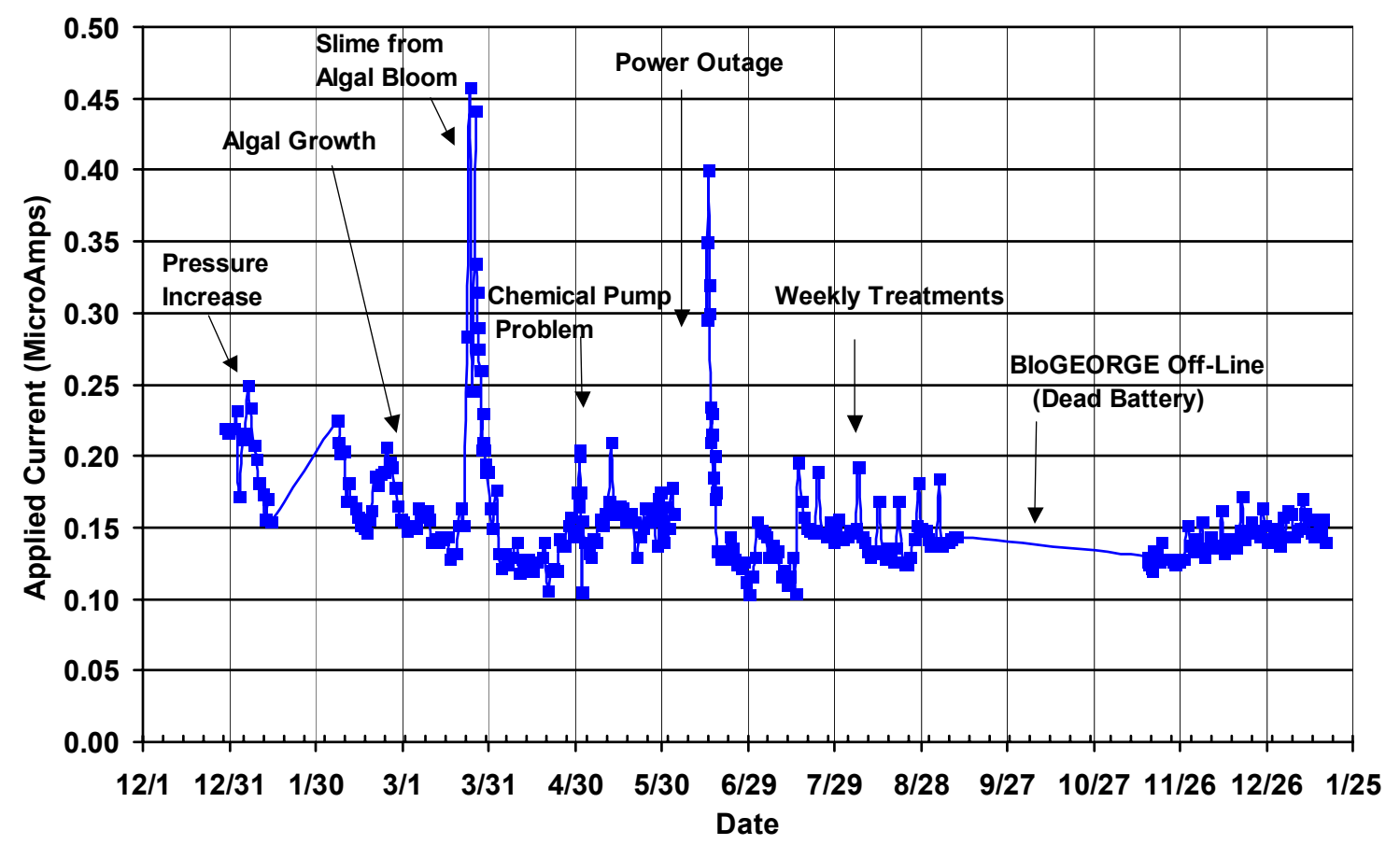

Figure 26. Data collected by BIoGEORGE ${ }^{\mathrm{TM}}$ Biofilm Monitor at the Bonnett Geothermal Plant (December 2001- January 2002).

The gap in data in June was caused by a forced power outage experienced by the plant caused by storm damage to the power transmission system. The monitor follows the plant recovery following this event. Another outage, experienced by the plant on July 15, also produced a significant increase in the current measured by the instrument. The periodic spikes in the applied current, which begin to show up in the data around the July 16, seemed to correlate with weekly biocide treatments. It is speculated that these treatments change the conductivity of the water causing these sharp current increases.

In Figure 27, the BIoGEORGE ${ }^{\mathrm{TM}}$ monitor data is again shown as a function of time along with an overall condenser thermal resistance that can be calculated from the process data. Two thermal resistances are shown in this figure; one calculated basing the total heat load on the cooling water measure- 
ments, and the second based upon the process steam measurements. (The thermal resistance is the inverse of the overall heat transfer coefficient, which is calculated from the heat load, condenser area, and process temperature measurements.) The BIoGEORGE ${ }^{\mathrm{TM}}$ data in this figure differs from that in Figure 26, in that the data related to the different operational excursions has been removed. This was done to determine whether the BIoGEORGE ${ }^{\mathrm{TM}}$ data would track those trends in fouling that would be indicated by the process data.

Because of uncertainties in process measurements and operating conditions (status of auxiliary systems such as the non-condensable removal system), it is difficult to compare a calculated condenser performance from individual data points to readings from the monitor. However, if the data is examined over time, it is apparent from the results in Figure 27 that the BIoGEORGE ${ }^{\mathrm{TM}}$ readings follow a trend similar to that of the total thermal resistance for the condenser. (The trend lines are shown in the figure for each set of data.) All three sets of data indicate that the fouling is at its lowest during the summer months and tends to increase during the cooler periods of the year. The reduction in fouling at this time may be attributed to more aggressive treatments of the growth problems typically encountered in the summer months.

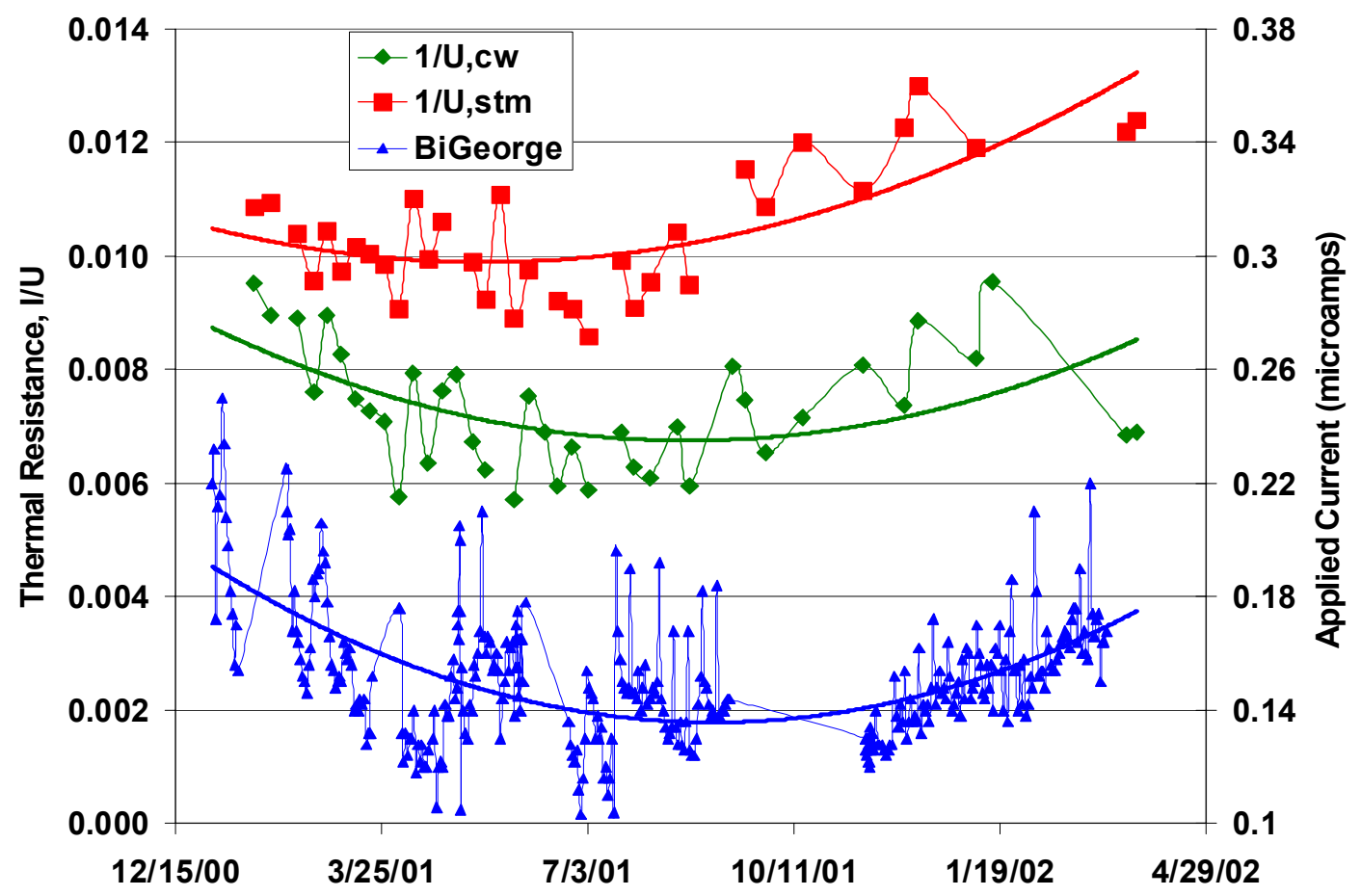

Figure 27. BIoGEORGE TM Biofilm monitor data and condenser thermal resistance calculated from process parameters.

The BIoGEORGETM probe was then cleaned and re-installed following the maintenance shutdown in June 2002. The monitor began to indicate possible fouling within one month, as shown in Figure 28, with evidence of significant fouling by early August that required additional doses of biocide to reestablish control. When the probe was pulled from the process stream, extensive film development was observed on the surface. It should be noted that this fouling occurred even though the plant was applying biocides on a weekly basis. 


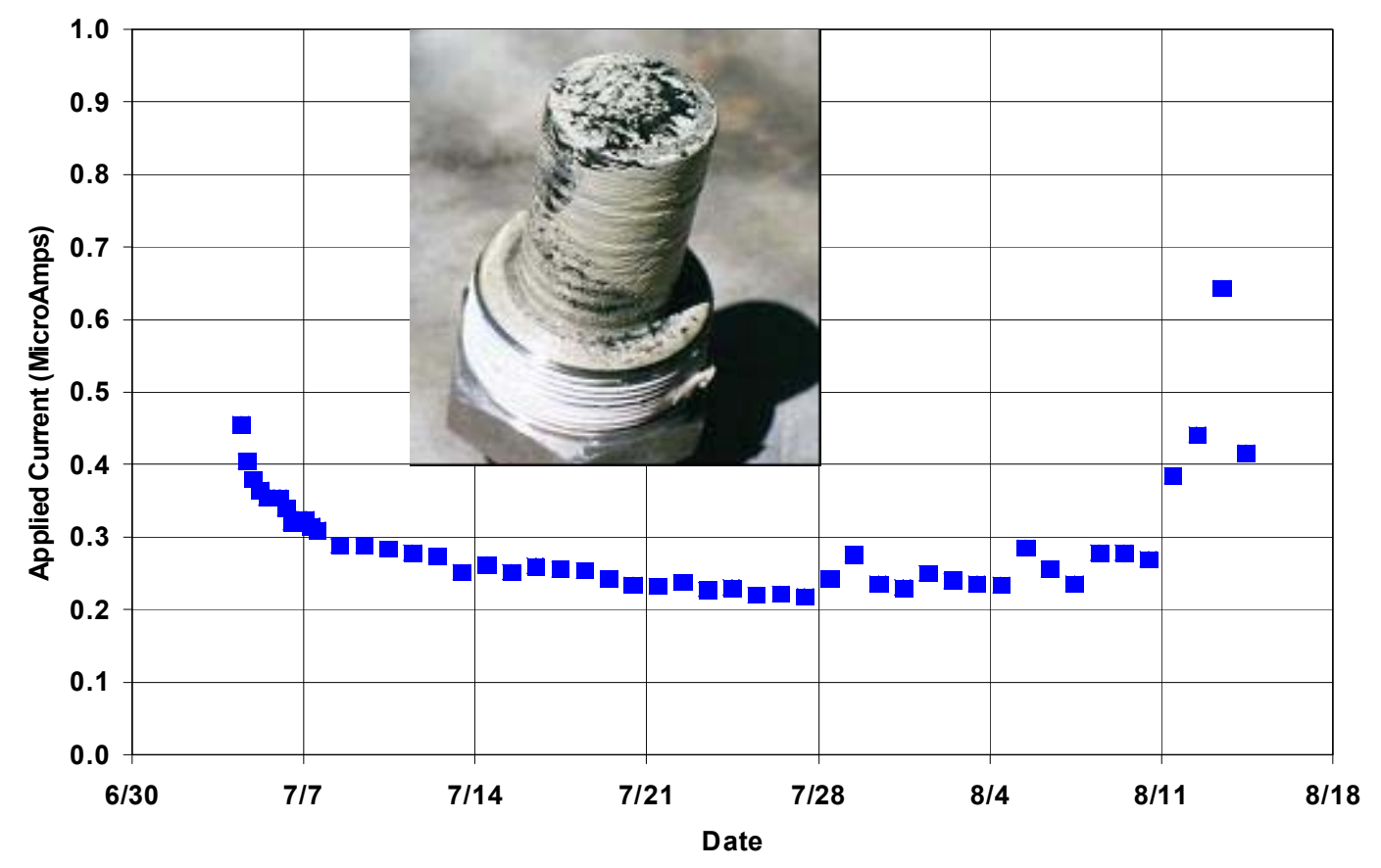

Figure 28. Summer 2002 fouling event recorded at Bonnett Geothermal.

The results of the extended field evaluation at the Bonnet plant concluded that the instrument did show promise as a real-time indicator of biofilm in geothermal plant cooling water systems. (As illustrated by the data presented in Figure 28, it was also evident that the pre-defined treatment strategy used at the plant was not sufficient to prevent the build-up of biofilm in the cooling water systems.) However, the operators at the Bonnett plant had some issues with the instrument's mode of operation. In particular, they felt that instrument would be more valuable if data automatically updated and daily trend information could be displayed in a more convenient location, i.e. the control room. (Data had to be downloaded and manipulated in a spreadsheet to provide this trending information.) They also wanted to be able to determine the minimum reliable signal change, or trend, that indicated growth in their system, since that would provide the optimal control. They felt if these changes could be incorporated then operators would be more confident about using the instrument for controlling chemical applications.

\subsubsection{Aidlin Plant Deployment}

Using input from the Bonnett plant investigation the BIoGEORGE ${ }^{\mathrm{TM}}$ Biofilm Activity Monitor vendor, Structural Integrity (San Jose, CA), modified the data acquisition software allowing the data to be automatically updated and displayed for real-time trending. In addition, the system was configured so that data could also be accessed via a modem for remote monitoring and analyses of plant stream conditions. The testing and validation of the upgraded system was originally planned at the Bonnett plant. However with the sale and closure of this plant in early 2003, it was necessary to find another location for this testing. Calpine Corporation, subsequently agreed to host this testing at its Aidlin plant located near Middletown, CA. (Aidlin Unit 1 is a dry steam plant that produces approximately $10 \mathrm{MWe}$.)

The monitor probe was installed in a sampling line at the Aidlin cooling tower July 15, 2003. The installation, shown in Figure 29, provided access to the condenser circulation, was designed to simulate flow velocity through the condenser tubes, and contained coupon holder for the placement of metal substrates to be used for biofilm calibration and verification purposes. In this deployment, the probe was 
exposed to cooling water down stream of the condenser. The real-time display was placed just outside the control room at the facility in a location that can be easily viewed by operations personnel.

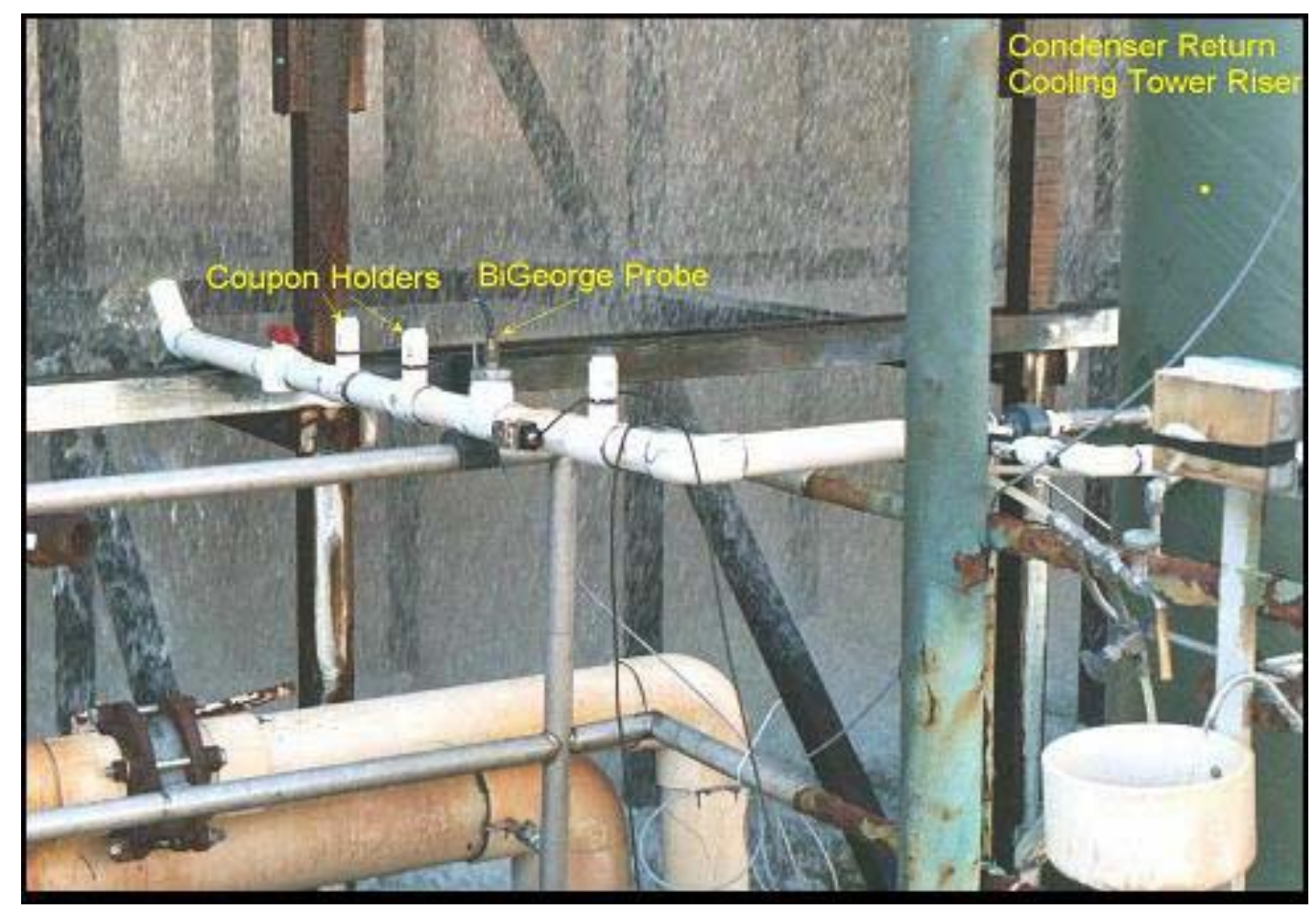

Figure 29. BIoGEORGE TM Biofilm Activity Monitor probe installed at the Aidlin Unit 1 cooling tower.

A particular goal of this deployment was to use the BIoGEORGE ${ }^{\mathrm{TM}}$ Biofilm Activity Monitor to determine if a significant biofilm problem existed at the plant and if so, establish its severity and the requirement for treatment. The applied current data recorded by the probe over a six-month period is presented in Figure 30. The data exhibits significantly more noise than from the previous deployment at the Bonnett Plant, although some trending is still evident. For example, it is clear that there is a change in the operation in mid-November resulting in a decrease the applied current. This is consistent with the expectation that less biofouling would occur during the winter months. (The lower evaporation rates due to cooler ambient conditions tend to flush or clean the total dissolved and suspended solids that accumulate in the cooling water systems.)

In Figure 31 the data from the BIoGEORGE ${ }^{\mathrm{TM}}$ monitor is compared with a cleanliness factor, analogous to thermal resistance measurement presented in Figure 27, to see how the monitor data trends with the calculated condenser performance over the same time period. Again, due to uncertainties in the process measurements and operating conditions, point comparisons are probably not meaningful. Referring to the plot, the applied current indicating the presence of a biofilm is seen to decrease as the inferred cleanliness of the condenser increases. 


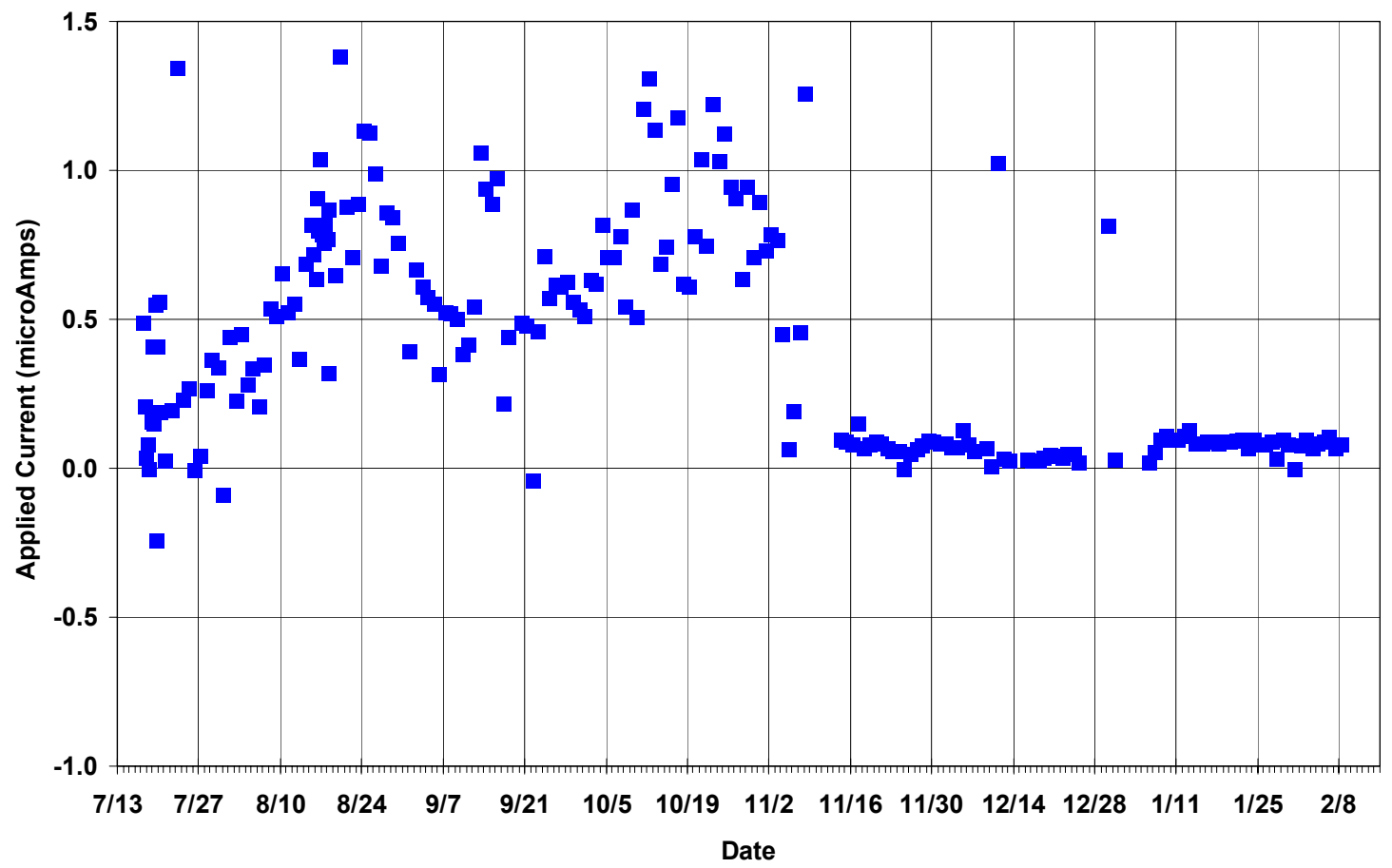

Figure 30. Data collected by BIoGEORGETM monitor at Aidlin Unit 1 (July 2003-February 2004).

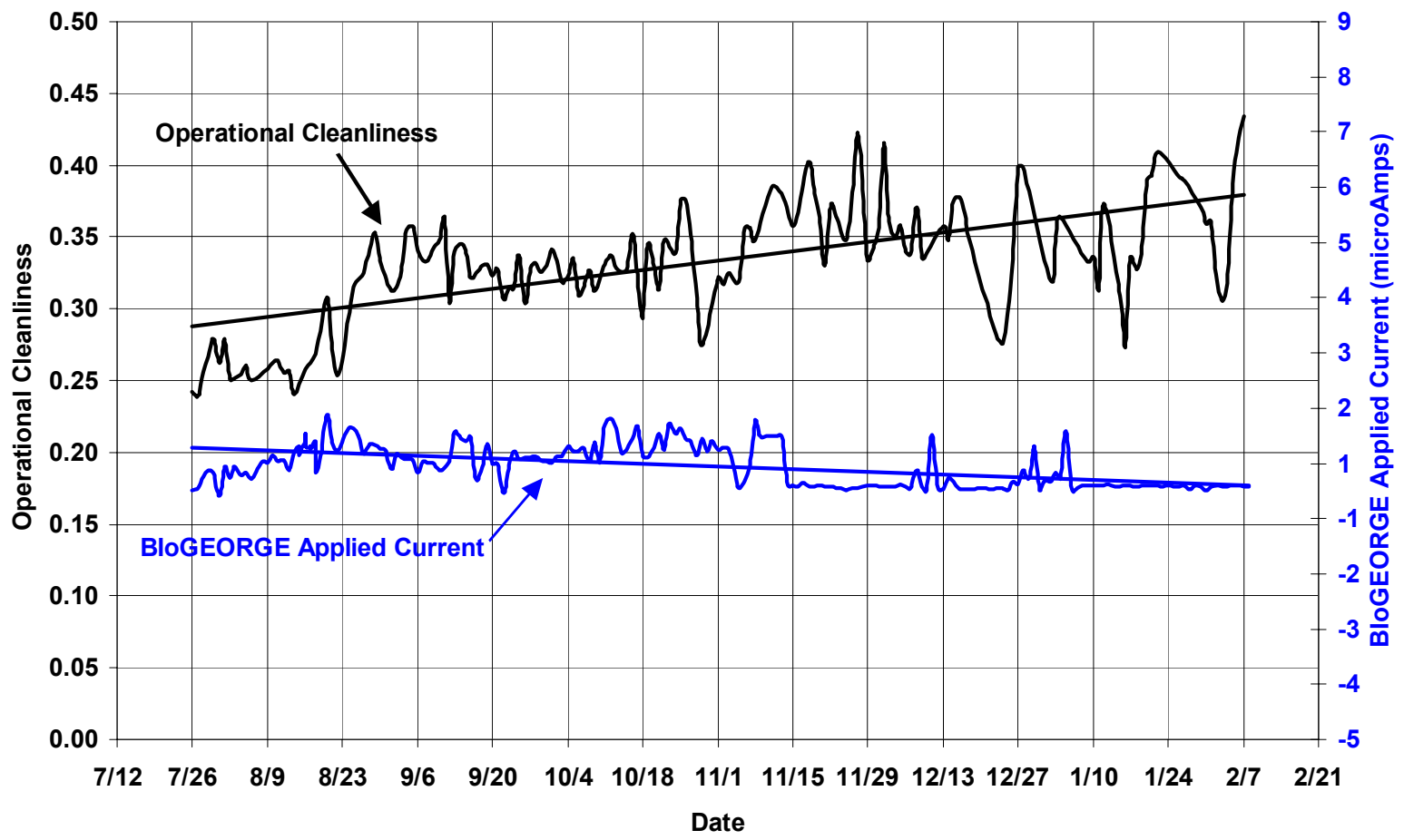

Figure 31. BIoGEORGE ${ }^{\mathrm{TM}}$ Biofilm monitor data as a function of operational cleanliness calculated from process parameters. 
The data collected from the monitor indicated that minimal biofouling was occurring in the system. In order to confirm this indication, the coupons installed on July 12, 2003 were pulled from the test train on March 24, 2004, placed into sterile $15 \mathrm{ml}$ centrifuge tubes, and sent to the INL for analyses. The coupons were stained with either Acridine Orange (AO) or 4,6-diamidino-2-phenylindole dihydrochloride hydrate (DAPI) fluorescence stains. Previous experience with metal coupons deployed at geothermal power plants indicated that under certain conditions the stains may react with chemicals in the film producing cloudy or opaque substrates; consequently, the two different stains are used to minimize this possible interference.

Observations of the stained films were initially made at a low magnification (15-20X) with a stereo-zoom microscope. Subsequent observations were made at a higher magnification (400X) using epifluorescent microscopy procedures. The DAPI and AO stains, which are preferentially taken up by biological materials, are sensitive to certain wavelengths of light and fluoresce when illuminated by this light. The latter makes it possible to see the film matrix and measure its depth on the metal coupon. A Nikon Eclipse 800 microscope with a Prior Z-scan stage controller allowing a 0.1 micron increment stage adjustment was used to conduct the film thickness measurements. The depth profile was measured by focusing on the surface of the film, marking the surface at zero in the z-axis, and then focusing through the layers to the surface of the metal coupon. The distance traveled to the coupon surface is recorded as the biofilm thickness. Depth measurements were taken at several locations across the metal coupon surface. The depth profile image stacks (Figure 32) were collected and combined as a montage. (The biofilm appears to have a hazy coloration due to the partial uptake of the stain by the film and bacteria cells and filaments that are present.)

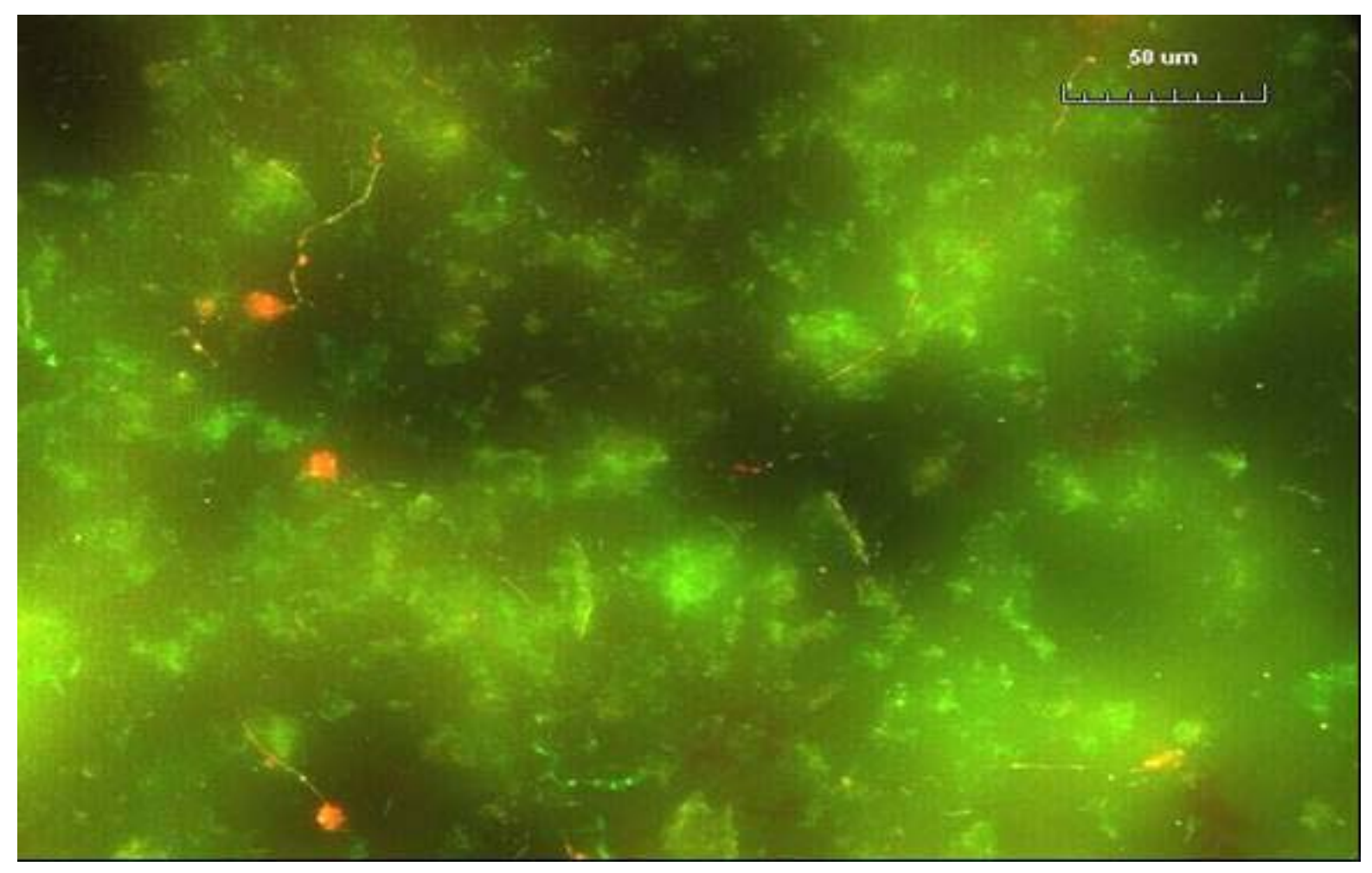

Figure 32. Image of stained biomass on coupon pulled from Aidlin process stream after a 253 day exposure. 
The measurements indicated that the Aidlin coupons had approximately 30 microns of biofilm present. By comparison, similar measurements made on metal coupons deployed for one month in the cooling tower basin at Bonnett Geothermal were found to have approximately 50 microns of biofilm on their surfaces. Since the Aidlin coupons had been exposed for a factor of eight times longer, this data is another indication that the Aidlin plant was not be experiencing problems with excessive biofilm formation during the deployment period.

The application of the BIoGEORGE ${ }^{\mathrm{TM}}$ Biofilm Activity Monitor for predicting the on-set of biofilm development in geothermal power plant cooling water systems was evaluated in long-term deployments at two different facilities. In both cases, the instrument demonstrated that if it is properly deployed in the process stream, it can provide data that is valuable for assessing and monitoring biofilm problems in these facilities. Key factors in the proper use of the instrument include:

(1) The selection of the site for probe installation in the plant is critical to the monitor's ability to provide useful data, including the following criteria,

a. Deployment at a location with the highest susceptibility to biofouling;

b. In-line installation in a continuously flowing process stream at this location or if this is not possible, then the installation should be performed in a slip-stream line that continuously provides fluid from the desired location at representative fluid velocities;

c. Placement of the probe at an orientation in the flow stream that discourages the buildup of debris and with the appropriate up and downstream piping runs that minimize flow disturbances.

(2) The placement of the data display in an area that is easily viewed by plant operators.

(3) The collection and use of other data, including various process parameters, deployed coupons, or other indicators to verify the instrument is installed properly to provide meaningful data. 


\section{BIOCHEMICAL ASSAYS}

\subsection{Adenosine Triphosphate (ATP) Measurements}

Biological productivity in process streams can also be performed by an analysis of the adenosine triphosphate (ATP) content. ATP is a high-energy molecule generated by living cells to perform metabolic functions. It is considered to be a conservative compound, which is reduced upon cell lysis and death. Therefore, it can be used as a measure of the active, or living, cells in an aquatic system and can also serve as a means of estimating the concentration of living biomass in a sample. ${ }^{26-27}$

For the analysis, a sample aliquot is collected and placed in a dark chamber containing a photomultiplier detector. A cell-lysing compound is added to the sample, along with a buffer compound to prevent the rapid decay of the released ATP. A second compound (luciferin-luciferase reagent) is added which reacts with the free ATP, emitting photons, which are detected by the photomultiplier. The intensity of the emitted light can be correlated to the amount of living biomass in the sample. Several vendors offer relatively inexpensive, user-friendly instruments for measuring the ATP compound. For example, the Bioscan ${ }^{\mathrm{TM}}$ instrument, shown in Figure 33, utilizes a sampling pen that is coated with the lysing agent and contains pre-measured chemicals for the lighting-emitting reaction that is initiated by pressing the cap of the pen after it has been dipped in the sample stream of interest. The pen is then inserted into the instrument and the ATP emission read and recorded. The measurement is straightforward and could be performed in minutes as a regular sampling procedure in a plant. However, ATP analyses can not specify the types of microorganisms present, and can be sensitive to sulfide and some types of biocides. A plot of ATP as a function of cells counts is shown in Figure 34.

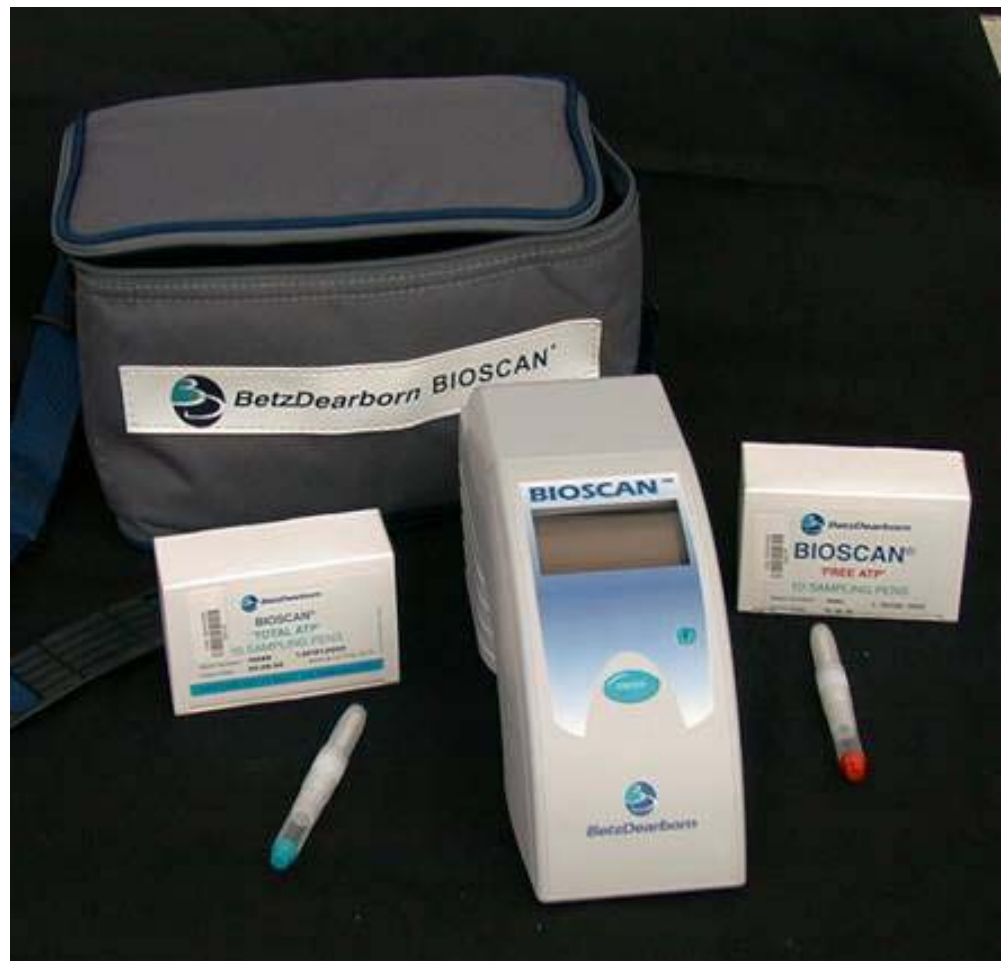

Figure 33. BetzDearborn Bioscan ${ }^{\mathrm{TM}}$ ATP luminometer with sampling pens. 


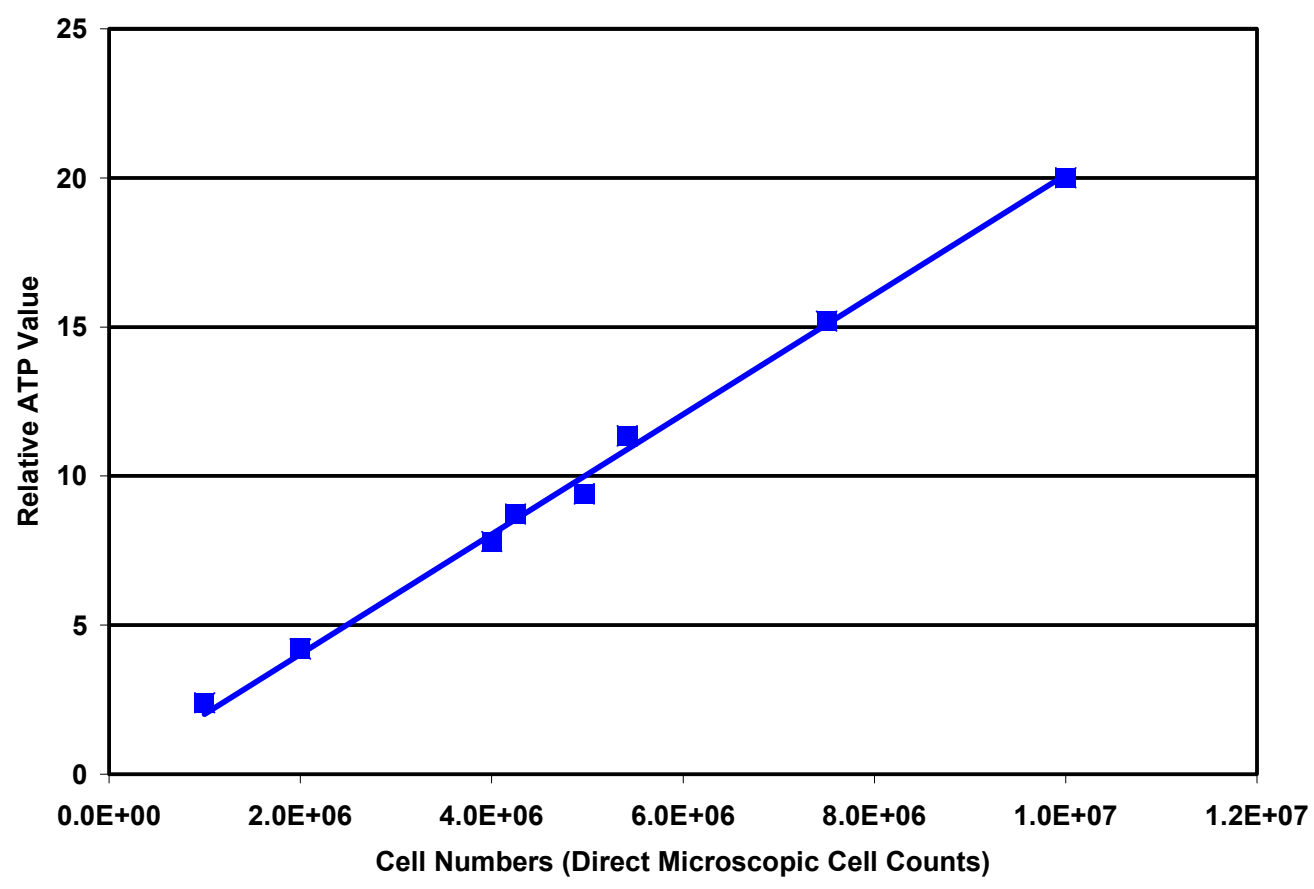

Figure 34. Correlation of ATP signal with direct microscopic cell count numbers.

The detection of microbial activity based upon ATP was also investigated at selected field sites, including the Aidlin, Quicksilver, and NCPA plants. For these measurements, an ATP luminometer was set-up at the facilities and operated over a two-day period using samples collected from the water circulation system. The ATP levels detected were correlated with microbial densities determined via visual observations using a phase contrast microscope. (Data for the NCPA plant is presented in Figure 35.)

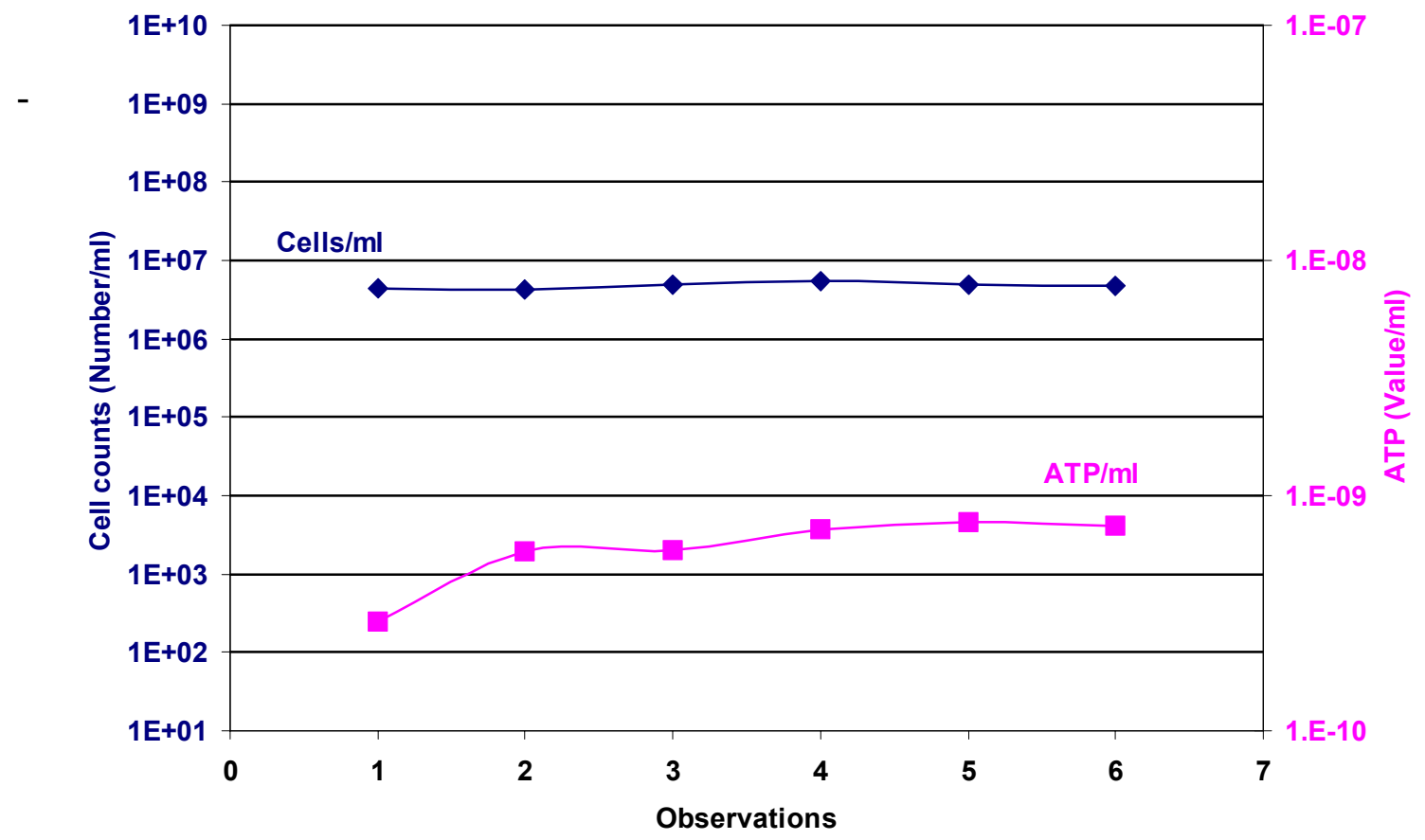

Figure 35. ATP Data collected at NCPA plant. 
While the Quicksilver and NCPA facilities recorded measurable levels of ATP (on the order of 1E16 to $1 \mathrm{E}-18$ cells) that remained fairly constant over the two-day period. No ATP signals were detected at the Aidlin plant. This was attributed to a combination of the low microbial densities present and the need to dilute the sample in order to reduce the sulfate interference. As illustrated in Figure 36, high levels of sulfate causes quenching of the ATP fluorescence signal. The sulfate levels at the Aidlin plant, which uses incineration for sulfide abatement, are 5-10 times higher than those found at Quicksilver or NCPA, which use Stretford processes for abatement.

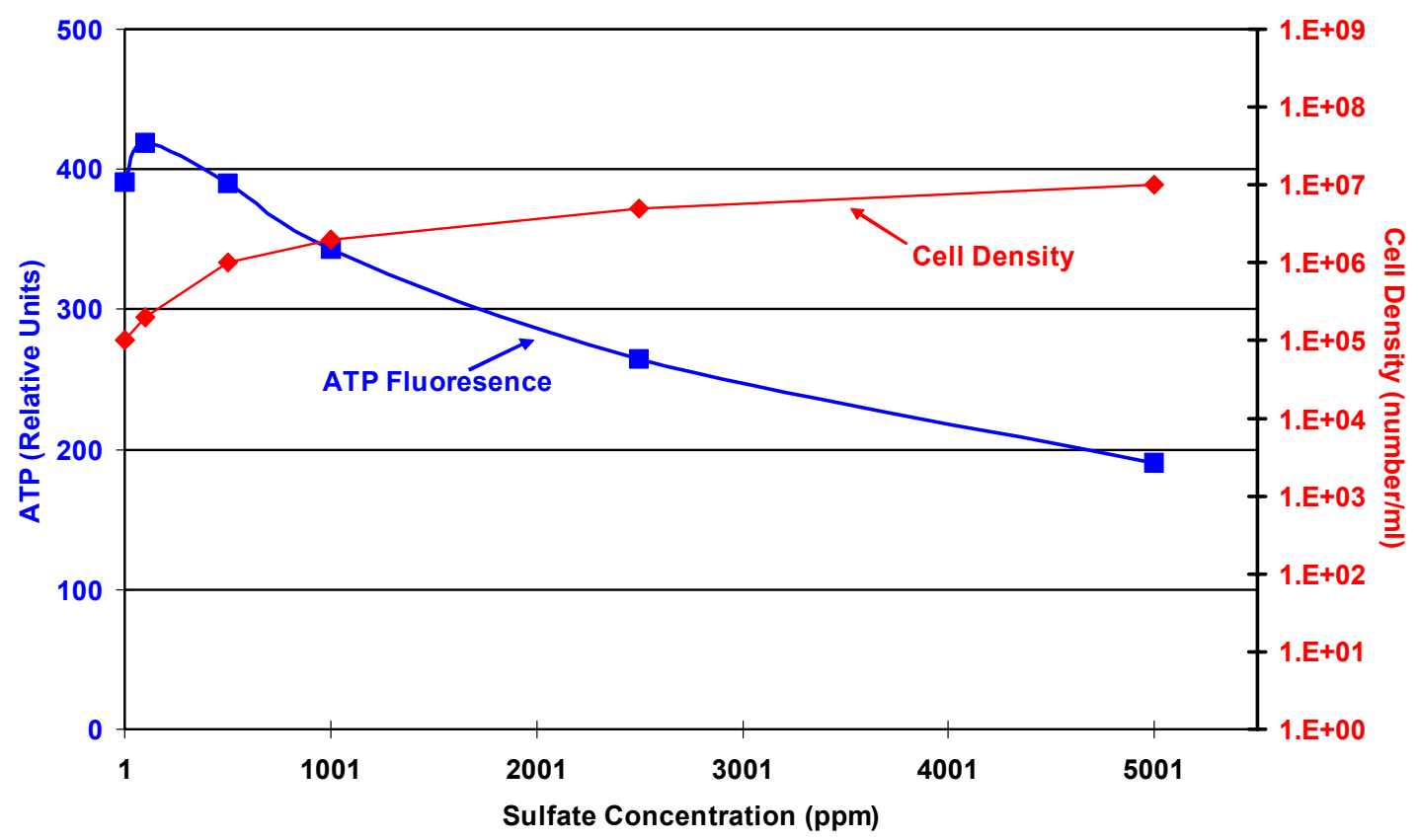

Figure 36. ATP signal quenching with sulfate concentration.

\subsection{Phospholipid Fatty Acids (PLFA) Analyses}

Phospholipid fatty acid (PLFA) analyses are based on the extraction and separation of lipid biomarkers from cell membranes and walls of microorganisms. Upon extraction with organic solvents, the lipids are concentrated and then analyzed using gas chromatography/mass spectrometry (GC/MS). PLFA are integral components of cellular membranes. They are involved in maintaining cell fluidity and enabling the transport of nutrients into the cell and elimination of metabolic by-products. Consequently, PLFA analysis provides a quantitative means to measure viable microbial biomass, community composition, and nutritional status. ${ }^{28-29}$ Since fatty acids tend to decompose quickly following cell death, the amount of PLFA found in a sample is indicative of the amount of viable biomass present. And, because different groups of microorganisms synthesize a variety of PLFA through various biochemical pathways, PLFA are also useful as taxonomic markers. Knowledge of specific lipid biosynthetic pathways can also provide insight into the nutritional status of the microbial community, as certain fatty acids provide indications of turnover and membrane permeability.

Bacteria produce a diverse range of PLFA, containing branched chained, cyclic and odd chain length fatty acids, as opposed to animals and plants that produce a very limited range. PLFA are typically reported with the fatty acids designated by the total number of carbon atoms followed by the number of double bonds, with the position of the double bond indicated from the methyl end $(\omega)$ of the molecule. The configuration of the double bonds can be either cis (c) or trans (t). For example, the lipid biomarker 


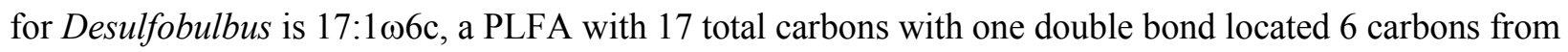
the $\omega$ end in the cis configuration. Branched fatty acids are designated as either iso (i) or anteiso (a) if the methyl branch is one or two carbons from the $\omega$ end, or by the position of the methyl group from the carboxylic end of the molecule. Methyl branching at undetermined positions in the molecule is indicated by the prefix "br". Cyclopropyl fatty acids are designated by the prefix "cy" followed by the total number of carbons, eg. cy 17:0.

The community associations are determined from the distinctive patterns released by microbes, identified via culturing and analyses of the isolates of various organisms. For complex samples, the profiles are subjected to various statistical analyses. In one technique, dendrograms from a hierarchical cluster analysis are constructed from arcsine-transformed PLFA mole percent values, with similarities based upon Euclidean distances. Two-dimensional plots based upon principal-component analysis are also used to determine similarities in profiles. These matches are taken in context with the environment from which the sample was retrieved for interpreting association. Table 1 describes the six major structural groups employed.

Table 1. Description of PLFA structural groups.

\begin{tabular}{|l|l|}
\hline $\begin{array}{l}\text { PLFA STRUCTURAL } \\
\text { GROUP }\end{array}$ & \multicolumn{1}{|c|}{ GENERAL CLASSIFICATION } \\
\hline Monoenoics (Monos) & $\begin{array}{l}\text { Found in gram negative bacteria, which are fast growing, utilize many carbon } \\
\text { sources, and adapt quickly to a variety of environments }\end{array}$ \\
\hline $\begin{array}{l}\text { Terminally Branched } \\
\text { Saturated (TerBrSats) }\end{array}$ & $\begin{array}{l}\text { Representative of gram positive bacteria, but may also be found in the cell } \\
\text { membranes of some gram negative bacteria }\end{array}$ \\
\hline $\begin{array}{l}\text { Branched Monoenoic } \\
\text { BrMonos) }\end{array}$ & $\begin{array}{l}\text { Commonly found in the cell membranes of obligate anaerobes such as sulfate } \\
\text { or iron reducing bacteria }\end{array}$ \\
\hline $\begin{array}{l}\text { Mid-Chain Branched } \\
\text { Saturated (MidBrSats) }\end{array}$ & $\begin{array}{l}\text { Common in Actinomycete, sulfate reducing bacteria and certain gram } \\
\text { positive bacteria }\end{array}$ \\
\hline Normal Saturated (NSats) & Found in both the prokaryotic and eukaryotic kingdoms \\
\hline Eukaryotes (Polyenoics) & Found in organisms such as fungi, protozoa, algae, higher plants and animals \\
\hline
\end{tabular}

The viable biomass is determined by quantifying the organic phosphate from the polar lipid fraction of the lipid extract. The viable microbes have intact cell membranes, which contain phospholipids (and PLFA). Cellular enzymes hydrolyze and release the phosphate group within a short time after death of the cell. Therefore, by targeting these phospholipids only the cells with intact membranes, or the "viable" cells, are analyzed. In addition, certain stresses, such as starvation, can induce changes in PLFA components such as the ratio of saturated to unsaturated fatty acids, the ratio of trans to cismonoenoic unsaturated fatty acids, and the proportion of cyclopropyl fatty acids. An increase in cyclopropyl formation has also been associated with anaerobic metabolism. 


\subsection{Denaturing Gradient Gel Electrophoresis (DGGE) Analyses}

Unfortunately, PLFA analyses cannot determine the composition down to the species level. To overcome this, a complementary DNA (deoxyribonucleic acid) analysis, denaturing gradient gel electrophoresis (DGGE) can be used. The DGGE approach directly determines the species composition of complex microbial pop-ulations based on the amplification of 16s rDNA fragments. DNA fragments of the same length but with different base-pair sequences are separated based on their melting behavior in a polyacrylamide gel containing a linearly increasing gradient of denaturant as illustrated in Figure 37 . The banding patterns and relative intensities of the recovered bands provide a measure of change in the community. Dominant species, which constitute at least $1 \%$ of the total bacterial community, can be excised and sequenced. Sequence analysis of individual bands is used to infer the identity of the source organism based upon phylogenetic affiliations and database searches. ${ }^{30-31}$

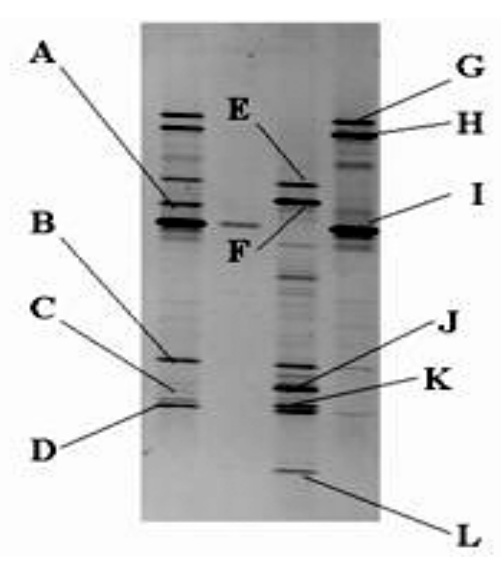

\begin{tabular}{|c|c|c|}
\hline Band & Best Match & $\begin{array}{c}\text { Similarity } \\
\text { Index } \\
(0-1.0)\end{array}$ \\
\hline A & Wolbachia persica & .718 \\
\hline B & Thiobacillus neapolitanus & .917 \\
\hline C & Piscirickettsia salmonis & .700 \\
\hline D & Thiobacillus neapolitanus & .840 \\
\hline E & Thiobacillus neapolitanus & .826 \\
\hline F & Thiobacillus neapolitanus & .982 \\
\hline G & Flexibacter filiformis & .535 \\
\hline H & Flexibacter filiformis & .585 \\
\hline I & Moraxella osloensis & .720 \\
\hline J & Thiobacillus sp & .864 \\
\hline K & Thiobacillus sp. & .804 \\
\hline L & Thiobacillus caldus & .866 \\
\hline
\end{tabular}

Figure 37. DGGE sequencing and analyses using samples from the Geysers field.

\subsection{PLFA and DGGE Analyses of Geysers Plant Effluent}

PLFA and DGGE analyses were performed on samples collected from the cooling effluent of four different facilities, including the Aidlin, Sulfur Springs, Quicksilver, and NCPA plants. Collections were made at the plants in September 1999, February 2000, and June 2000. During the June sampling, effluent from the Eagle Rock plant was substituted for the Quicksilver sample when a maintenance shut-down at the Quicksilver facility precluded sampling of the plant. The water samples collected were immediately placed into a cooler where they were maintained at a temperature of approximately $4{ }^{\circ} \mathrm{C}$ in order to minimize potential changes in the sample after it is taken out of the collection environment. The chilled packages were then mailed overnight to Microbial Insights, Inc. in Rockford, TN where the PLFA and DGGE analyses were performed.

The community structures detected using the PLFA technique (defined in Table 1) are shown in Figures 38,39 and 40 . 


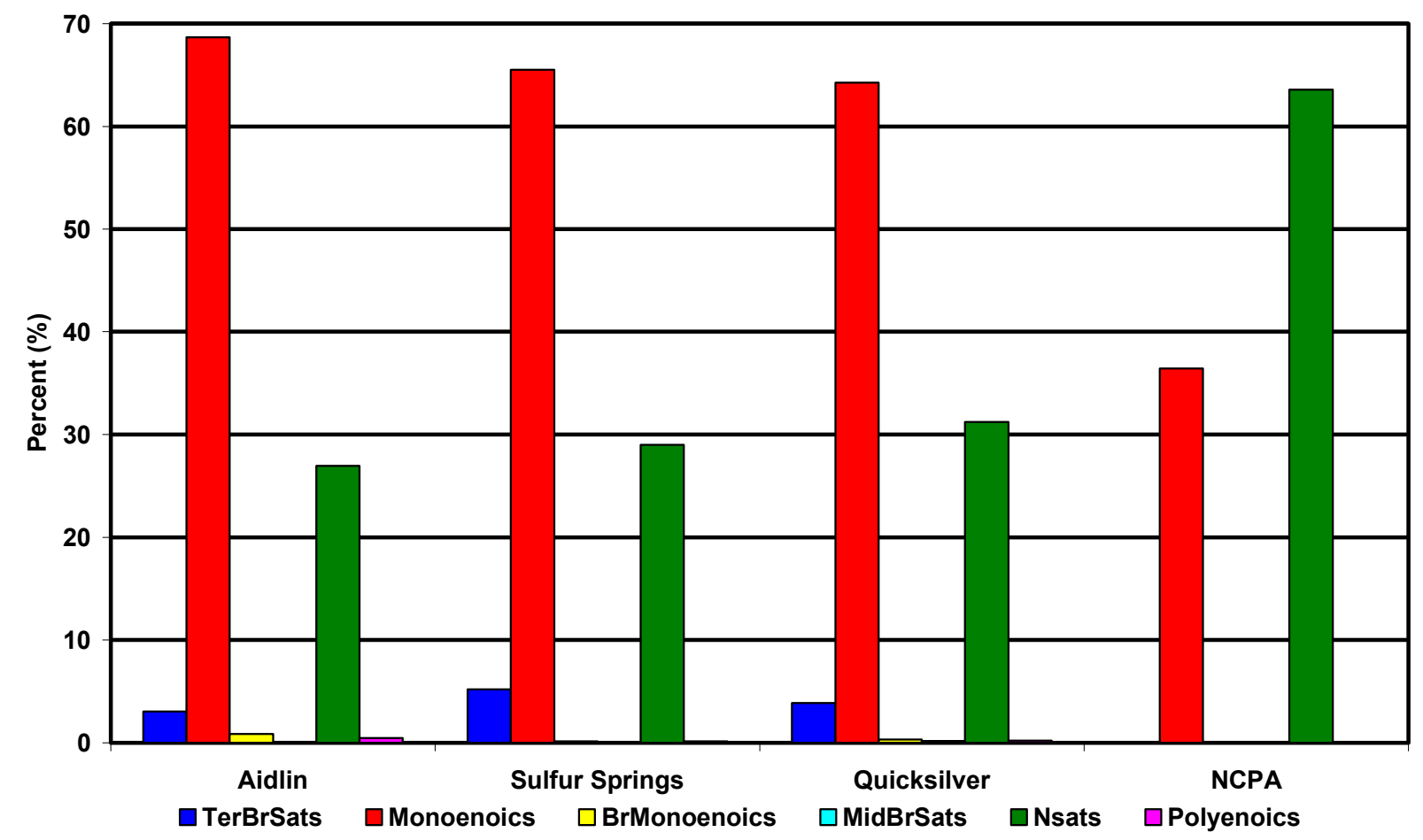

Figure 38. Primary PLFA types identified at various Geysers plants during September 1999 sampling.

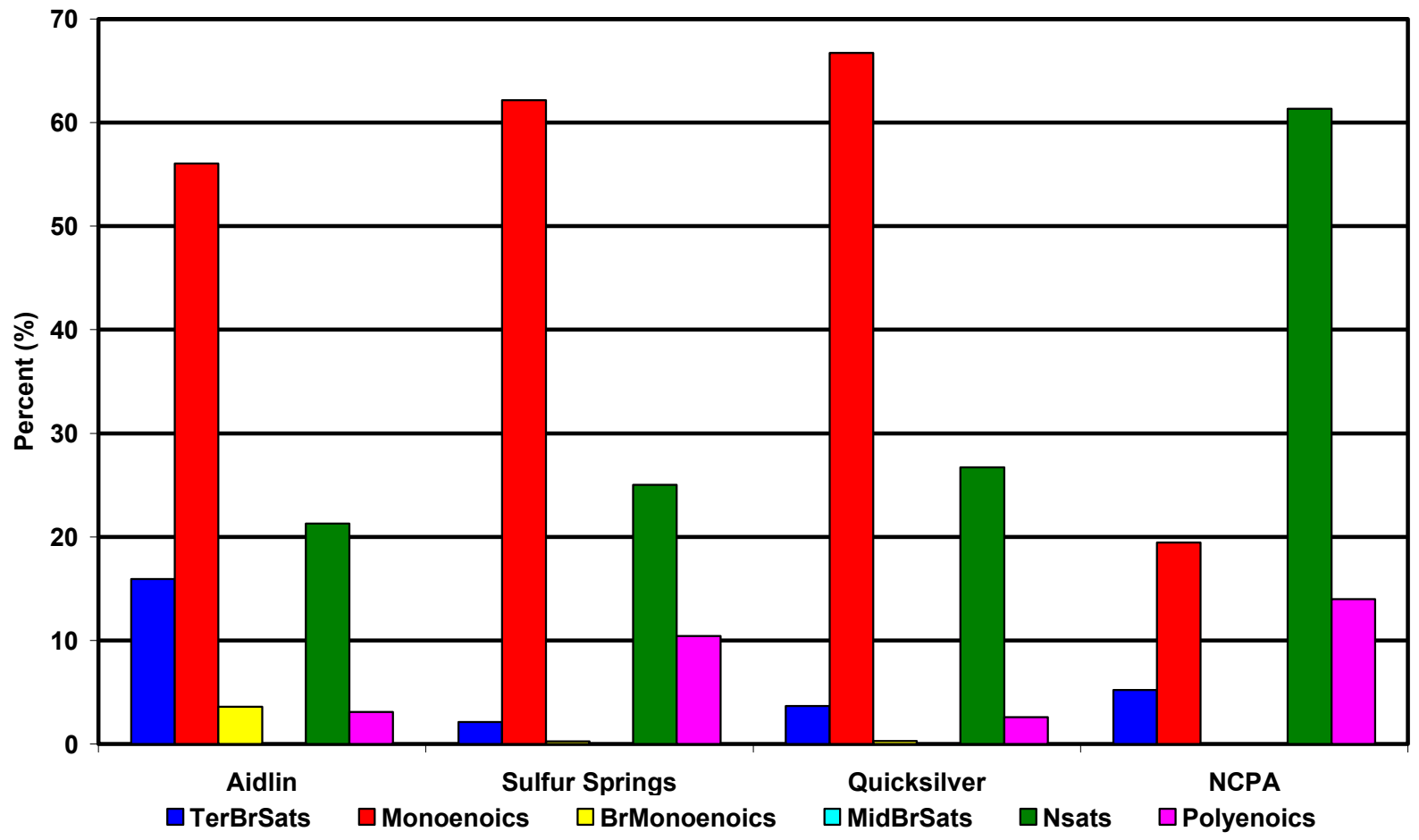

Figure 39. Primary PLFA types identified at various Geysers plants during February 2000 sampling. 


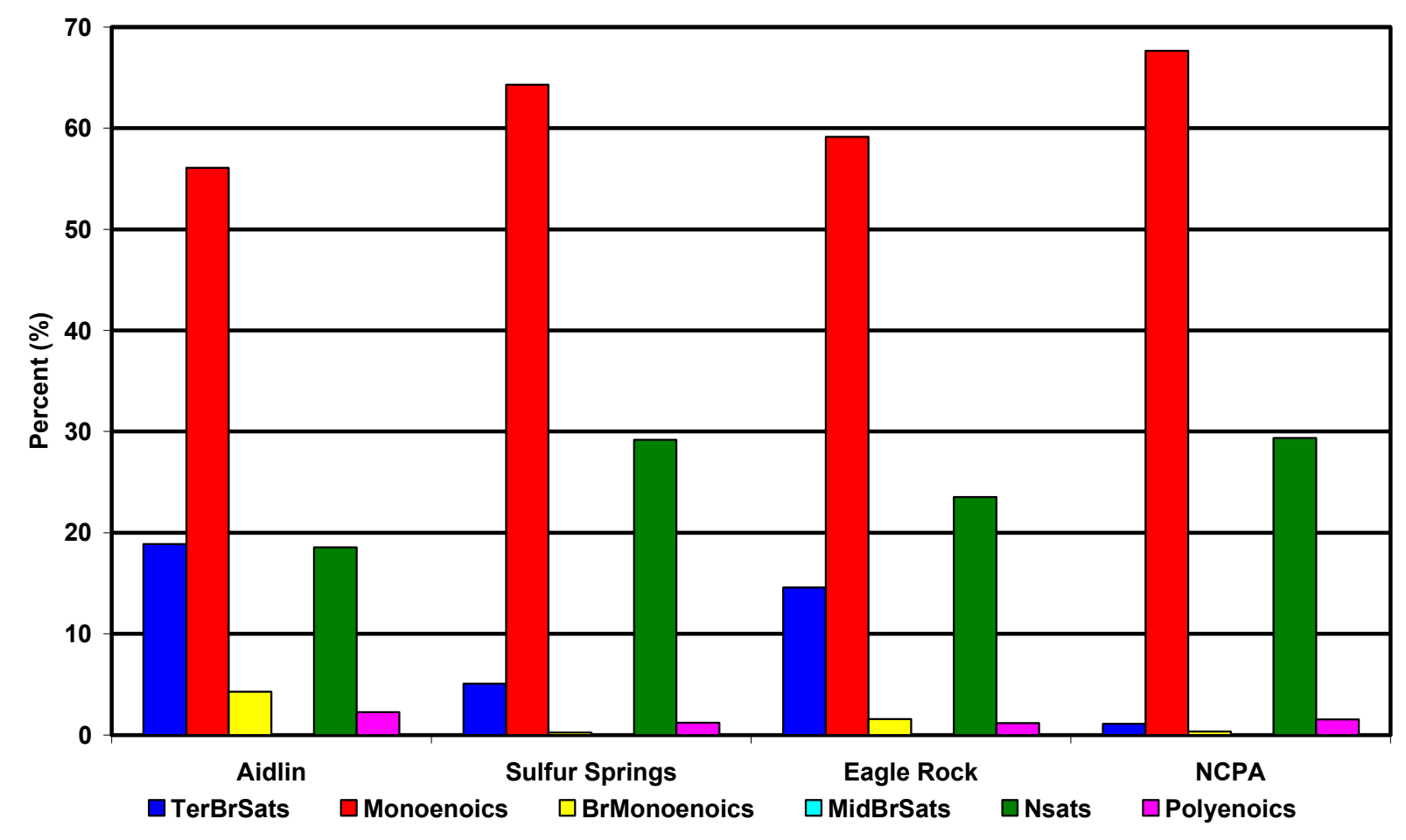

Figure 40. Primary PLFA types identified at various Geysers plants during June 2000 sampling.

The PLFA profiles indicated moderately diverse microbial communities at all of the plants sampled with the exception of NCPA, which was composed primarily of normal saturated (NSat) PLFA. High levels of NSats are typically associated with less diverse populations. The Aidlin, Quicksilver and Sulfur Springs communities were dominated by gram-negative bacteria, indicated by the high percentage of monoenoic PLFA found in these samples. Terminally-branched saturated PLFA (TerBrSats) were also detected in all of these samples. Terminally-branched PLFA are representative of gram positive bacteria, but may also be found in the cell membranes of many anaerobic gram-negative species, such as sulfate reducing bacteria. Generally, gram-positive bacteria are slower growing than gram-negative bacteria, more resilient and are capable of degrading more complex compounds. Anaerobic metal or iron reducing bacteria (BrMonos and MidBrSats) were also detected with the highest proportion observable in the samples from Aidlin.

In addition to PLFA, MPN analyses were also conducted using the seasonal samples from the plants. A plot in which biomass measured via the PLFA technique is compared to biomass measured via the MPN method is presented in Figure 41. For the comparison, the quantity of PLFA measured in the various samples is converted to cell numbers. The cell equivalent value has been derived from standard experiments with typical bacteria isolated from soil and water. This value is based on $2.0 \times 10^{12}$ cells per gram dry weight of cells and $10^{8}$ picomoles of phospholipid/gram dry weight of cells. This number is approximate and may vary with the environmental conditions from which microorganisms were recovered by a factor of up to 5. (This relates to the fact that organisms under nutritionally stressed conditions may be smaller in volume; and therefore, represent less biomass and contain less PLFA.)

Referring to the plot, the PLFA and MPN numbers are seen to track with the high numbers recorded at the Aidlin, Quicksilver, and Sulfur Springs plants and the considerably lower numbers recorded at NCPA during the September 1999 and February 2000 sampling periods. The number values do exhibit a 1 to $1 \frac{1}{2}$ order of magnitude difference between the two techniques. This variance can be explained by 
differences in the handling and processing of data used by the techniques. As noted above, the conversion of PLFA to number density is approximate, due to uncertainties in the bio-volumes used for the conversion. In addition, the MPN method relies on the culturing of organisms which is highly time dependent process. (The vendor-recommended culture time of 28 days for the MPN samples may have resulted in the higher numbers noted for this technique relative to the PLFA analyses.)

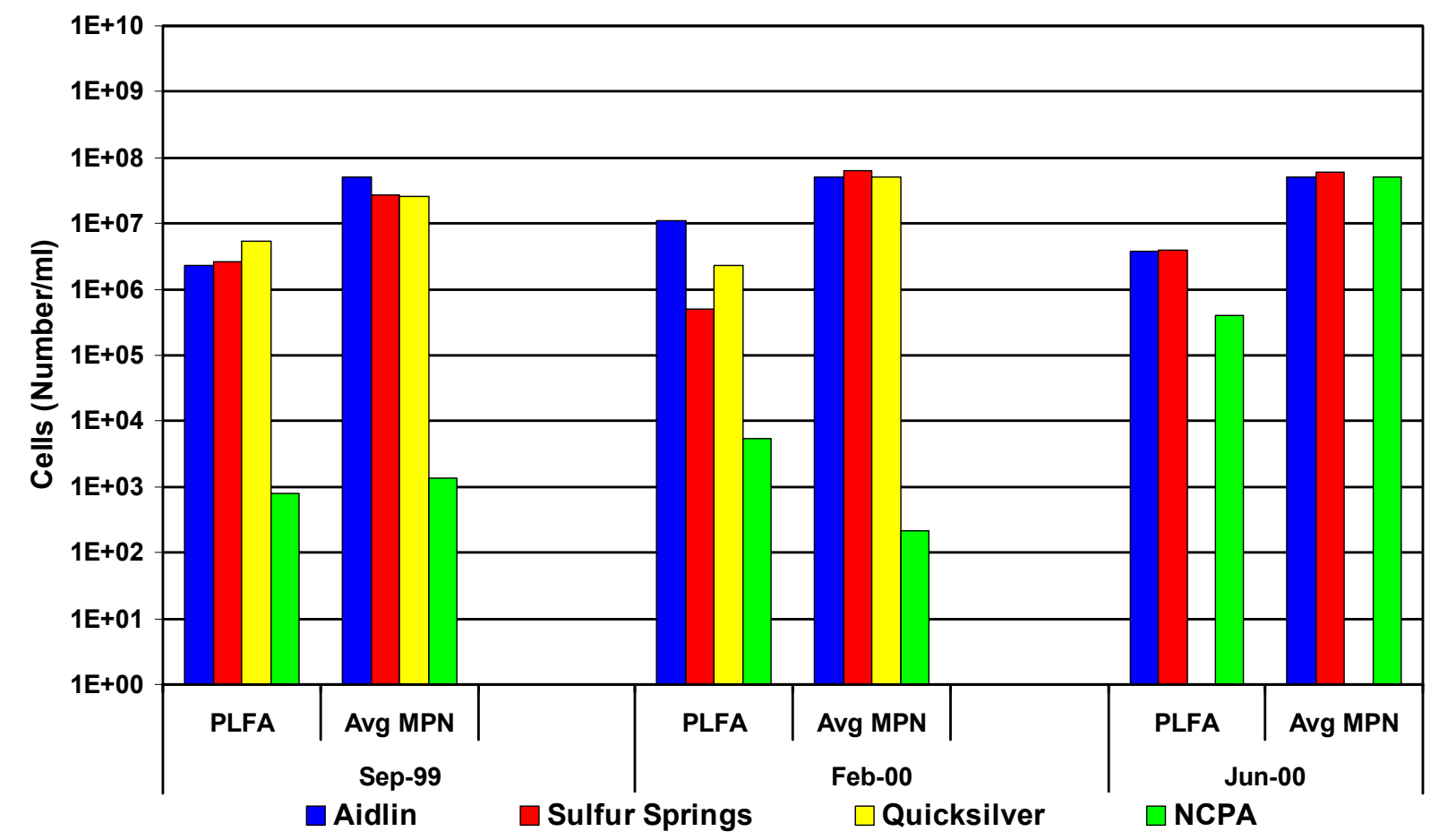

Figure 41. Comparison of cell numbers derived from PLFA analyses to averaged MPN values.

The results of the DGGE analyses are presented in Table 2, which displays the dominant species based on DNA profiling, found at the various plants during the sampling periods. These results complement the PLFA analyses, indicating more diverse populations at the Aidlin, Quicksilver, and Sulfur Springs plants. These species can be generally characterized as moderately thermophilic, sulfate and iron metabolizers as might be expected of bacteria found in the plant environments.

This study concluded that microbial growth trends at geothermal facilities can be observed by the both the selective culturing and PLFA analyses. However, the PLFA and DGGE techniques can provide much more information about microbial activity at the plants including the dominant species forming the microbiological community at the plant and their growth status. This information, while more expensive to obtain ( $\sim \$ 1000$ per sample versus $\$ 100$ per sample), may be very valuable to in achieving the longterm goals of determining what conditions trigger increased growth at the plants and in developing monitoring and treatment programs targeted at these activities. In particular, knowledge of the species present in the environment as a function of plant conditions could lead to the development of improved control agents, targeting key species and/or nutrient conditions. And while these types of analyses are presently not affordable for a typical plant operation, current efforts directed toward automating these techniques could eventually reduce costs, making them competitive with other methods. ${ }^{32}$ 
Table 2. Dominant species distribution identified from DGGE analyses.

\begin{tabular}{|c|c|c|c|}
\hline AIDLIN & SULFUR SPRINGS & QUICKSILVER & NCPA \\
\hline \multicolumn{4}{|l|}{ September 1999} \\
\hline Thiobacillus caldus & Flexibacter filiformis & Flexibacter filiformis & Moraxella osloensis \\
\hline $\begin{array}{l}\text { Thiobacillus } \\
\text { neapolitanus }\end{array}$ & Moraxella osloensis & Moraxella osloensis & \\
\hline \multirow[t]{3}{*}{ Thiobacillus sp. } & $\begin{array}{l}\text { Thiobacillus } \\
\text { neapolitanus }\end{array}$ & Piscrickettsia salmonis & \\
\hline & & Wobachia persica & \\
\hline & & $\begin{array}{l}\text { Thiobacillus } \\
\text { neapolitanus }\end{array}$ & \\
\hline \multicolumn{4}{|l|}{ February 2000} \\
\hline $\begin{array}{c}\text { Thermicanus } \\
\text { aegypticus }\end{array}$ & $\begin{array}{l}\text { Thiobacillus } \\
\text { neapolitanus }\end{array}$ & Thiobacillus caldus & \\
\hline Thiobacillus caldus & Methylococcus sp. & Methylococcus sp. & \\
\hline Ralstonia sp. & & Ralstonia sp. & \\
\hline \multicolumn{4}{|l|}{ Thiobacillus sp. } \\
\hline June 2000 & & EAGLE ROCK & \\
\hline $\begin{array}{l}\text { Thiobacillus } \\
\text { neapolitanus }\end{array}$ & Moraxella osloensis & $\begin{array}{l}\text { Methylococcus } \\
\text { capsulatus }\end{array}$ & Moraxella osloensis \\
\hline Bacillus sp. & $\begin{array}{l}\text { Methylococcus } \\
\text { capsulatus }\end{array}$ & $\begin{array}{l}\text { Thiomonas } \\
\text { thermosulfata }\end{array}$ & $\begin{array}{l}\text { Methylococcus } \\
\text { capsulatus }\end{array}$ \\
\hline Rhizobium sp. & & Thiobacillus sp. & Chromobacterium sp. \\
\hline Thiobacillus sp. & & & \\
\hline
\end{tabular}

The use of denaturing liquid chromatography for the separation and quantification of DNA is an example of one of these semi-automated technologies. The analysis takes advantage of the fact that DNA is composed of two individual strands arranged in an anti-parallel manner. Each of the strands is composed of a series of nucleotides containing a nitrogenous base covalently linked to a sugar (ribose) and a string of nucleotides that are covalently linked by a negatively charged phosphate backbone to form the chain. DNA contains four nitrogenous bases: adenine (A), thymine (T), cytosine (C) and guanine (G). Adenine and thymine and cytosine and guanine are complementary to one another, forming A-T and C-G 
base pairs. C-C base pairs share three hydrogen bonds, while the A-T base only shares two, making them inherently less stable. The double helical DNA structure forms as a result of the base stacking interactions that occur when two complementary single strands are of DNA are aligned. The base pair hydrogen bonds hold the two DNA strands together and van der Waals interactions between the complementary sets of bases help by contributing to the helical structure. In contrast, the nucleotides within a single strand are covalently bonded only along the sugar phosphate backbone. At high temperatures the hydrogen bonds between the base pairs break, but not the covalent bonds, along a single strand. The subsequent uncoiling of the helix, combined with the breakage of the hydrogen bonds, results into two single strands. This process is known as denaturation. Since A-T base pairs have fewer hydrogen bonds, regions of DNA containing them tend to denature, or melt out, faster than regions containing $\mathrm{G}-\mathrm{C}$ pairs.

Instruments, such as the Transgenomic WAVETM DNA Fragment Analysis System, utilizing this separation process and reverse-phase, ion-pair, high performance liquid chromatography principles, are commercially-available. The DNA fragments bind with different affinities to polymeric beads in the specially designed measurement column based upon size, under non-denaturing conditions, and/or sequence, under denaturing conditions. The instrument provides the capability of automated sampling and rapid fragment analyses. DNA fragments have been detected in biofilm samples collected from Bonnett Geothermal and condensate samples from The Geysers using this instrumentation.

\subsection{Molecular Probes}

New probing techniques are becoming available that have the specificity to not only identify types of bacteria but also monitor their activities. These probes are based the sequence-specific recognition that occurs when two molecules bind together. A known DNA sequence is targeted in the process. The gene may be organism specific or may encode for the production an enzyme unique to a metabolic pathway (such as sulfate reduction or oxidation). Once the target gene is identified, a complimentary strand of nucleic acid, or gene probe, is constructed and tagged with a fluorescent compound. After the formation of the gene probe, the sample DNA and the probes are then denatured, splitting the double strands into single strands. The two are then allowed to intermingle and hybridize. If hybridization does occur, that is an indication the targeted gene is present. The degree of hybridization can be correlated with the biomass of organisms containing the targeted gene by visualizing the fluorescent material through a microscopic imaging system. ${ }^{33-34}$ A schematic of the process is presented in Figure 42.

The application of fluorescently-tagged, in-situ hybridization (FISH) tags for use in tracking specific organisms or their activities in geothermal plants has been investigated. In particular, experiments were performed using a 16S rRNA oligonucleotide probe \#385 (CGGCGTCGCTGCGTCAGG) target for general sulfate reducers. The work was performed using samples prepared from cultures of two known sulfate reducers (DSM644-Desulfovobrio vulgaris and DSM642-Desulfovibrio desulfuricans), samples collected from the Sixfors bioreactor studies that were initially inoculated with DSM644, and a culture of Escherichia coli which served as a negative control. A general bacterial stain, DAPI, was also used to identify all cells present. The tests were able to identify the general population of cells stained with DAPI, as well as the known sulfate-reducing bacteria DSM642 \& DSM644. (The E. coli preparation could only be seen with DAPI filter sets.) Preparations from the Sixfors bioreactor studies indicated that a few sulfate reducing bacterial cells were present; however, some cells did exhibit fluorescence indicative of sulfate reduction. This test indicates that it is possible to use these procedures with geothermal samples without chemical interference. Figure 43 illustrates the ability of the probe to distinguish the sulfur reducing bacteria from the general population. 


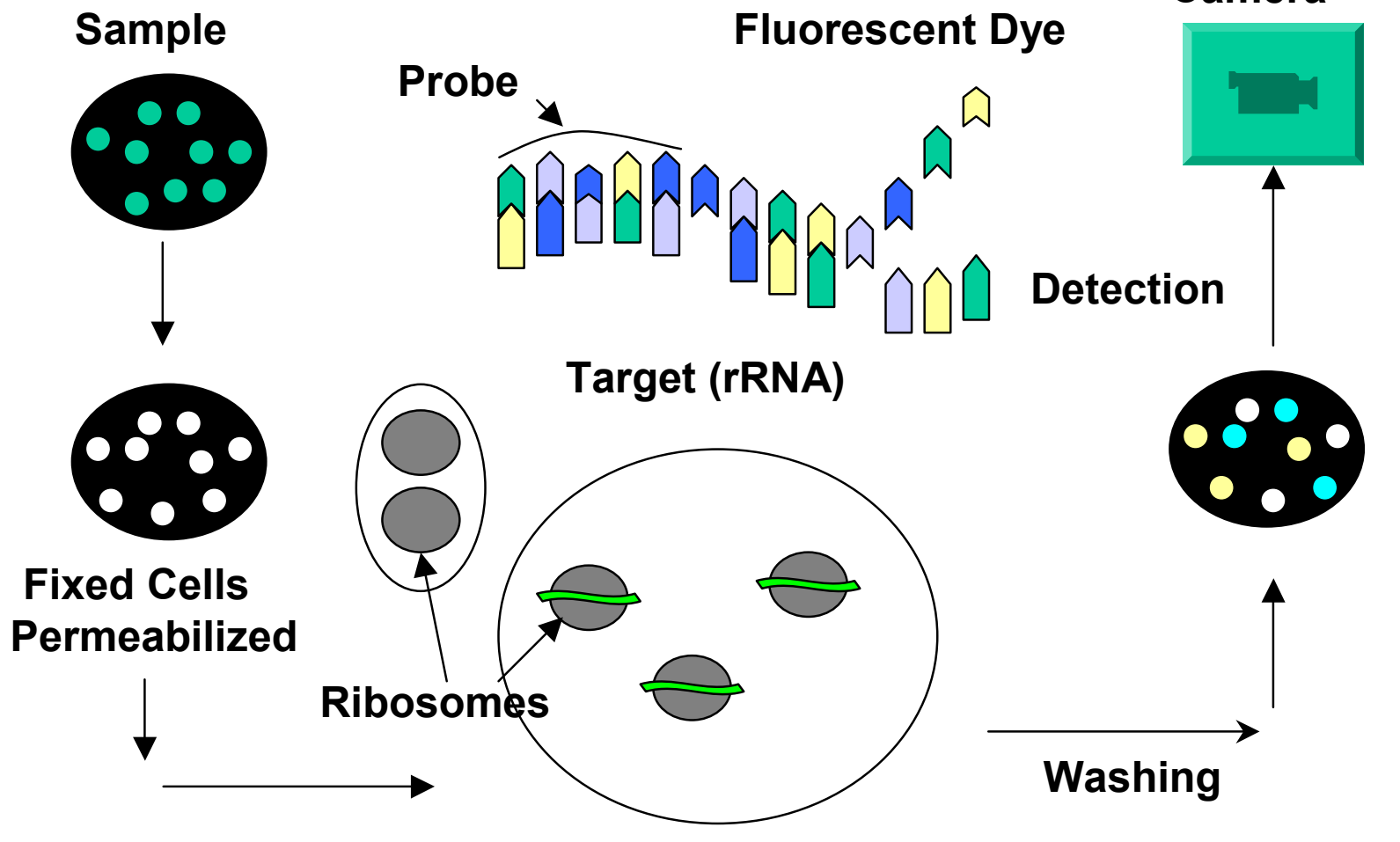

Figure 42. Molecular probe preparation.
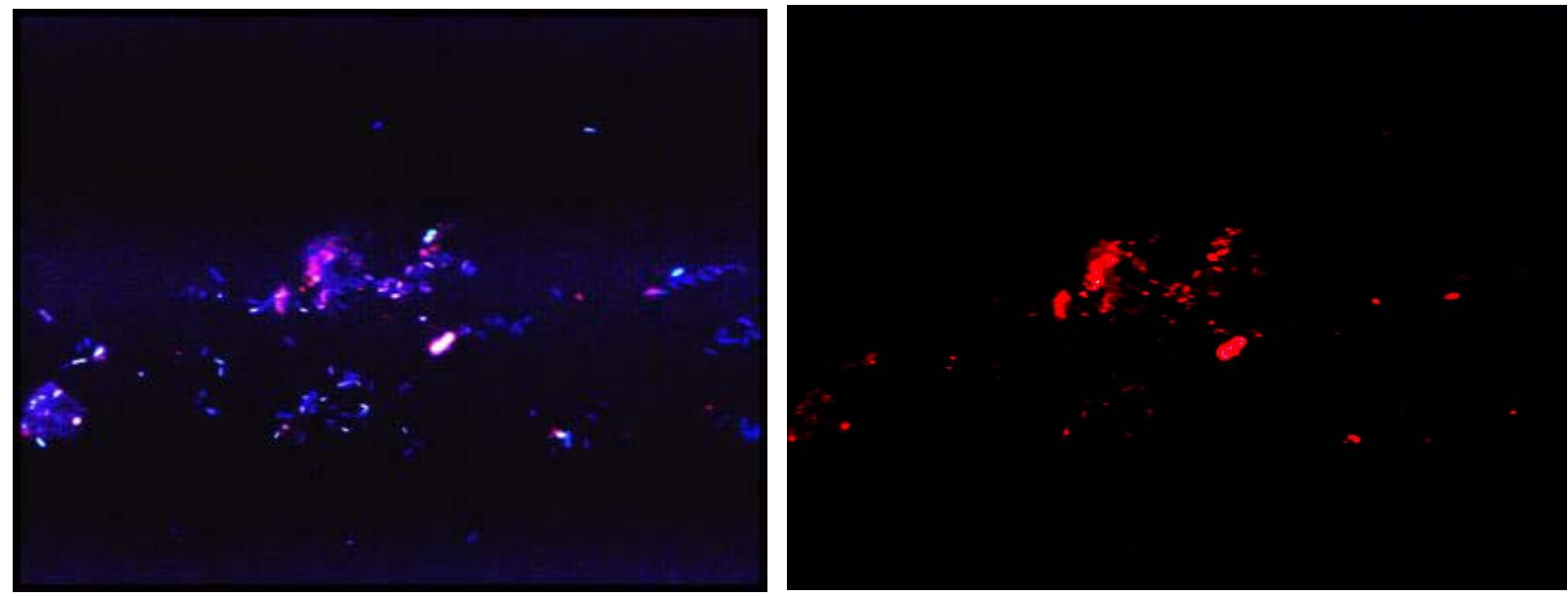

Figure 43. Molecular probe interaction with geothermal water sample. General population stain is presented at the left and the FISH probe for sulfate reducers is shown at the right. 
Additional probes are currently under development for tracking sulfur oxidation. These probes are being designed around the species Thiobacillus neapolitanus and Acidithiobacillus caldus identified in the sampling and characterization studies performed at The Geysers. These species are of interest since they are associated with sulfur metabolism; and in particular, have the capability of altering the $\mathrm{pH}$ of their environments. Probes based upon Methylococcus capsulatus are also being investigated. This species is also capable of reducing metals, increasing their motility in solution. In addition to providing a diagnostic for determining the potential for microbially-influenced corrosion in the plants, these probes could be also be valuable in the control of natural sulfide abatement processes under investigation at The Geysers. 


\section{CONCLUSIONS}

A number of techniques have been investigated that could be used for monitoring biological growth in geothermal power production facilities. Table 3 presents a summary of those highlighted in this paper including their mode of operation and estimated cost to obtain and use. The estimate assumes two samples, including the required calibration standards and replicates, are collected and processed per week for one year. Facility labor is estimated at $\$ 50 /$ hour.

Table 3. Cost comparison of biological measurement methods.

\begin{tabular}{|c|c|c|c|c|c|}
\hline Method & $\begin{array}{c}\text { Operational } \\
\text { Mode }\end{array}$ & $\begin{array}{c}\text { Equipment } \\
\text { Costs }\end{array}$ & $\begin{array}{c}\text { Materials } \\
\text { Costs }\end{array}$ & $\begin{array}{c}\text { Analysis } \\
\text { Costs }\end{array}$ & $\begin{array}{c}\text { Total } \\
\text { Costs }\end{array}$ \\
\hline Coupons & Sample & & $\$ 2400$ & $\$ 2600$ & $\$ 5000$ \\
\hline Electrochemical & Continuous & $\$ 8000$ & & $\$ 1300$ & $\$ 9300$ \\
\hline ATP & Sample & $\$ 2000$ & $\$ 6800$ & $\$ 5200$ & $\$ 14000$ \\
\hline MPN & Sample & & $\$ 6700$ & $\$ 7800$ & $\$ 14500$ \\
\hline TOC & Sample & $\$ 24000$ & $\$ 350$ & $\$ 6500$ & $\$ 30850$ \\
\hline DGGE/PLFA & Sample & & $\$ 1000$ & $\$ 55,000$ & $\$ 56000$ \\
\hline
\end{tabular}

( ${ }^{1}$ These analyses are performed via a subcontract to a commercial laboratory specializing in these measurements.)

In examining these data, it can be noted that the mostly frequently used technique, simple coupon analysis in which the coupon is weighed and then visually examined, is indeed the least expensive method. However, as previously discussed, the data obtained by this method is limited by the fact that a biofilm has already formed; and therefore, some plant efficiency has already been lost. MPN analyses are also relatively inexpensive; however, there is a significant delay between collecting the sample and assessing growth problems based upon its value. These studies indicate that other techniques, such as ATP or TOC analyses, may provide data in a more timely fashion for mitigating biological growth problems in geothermal facilities. In particular, the electrochemical monitor, the BIoGEORGE ${ }^{\mathrm{TM}}$ Biofilm Activity Monitor, was determined to be a cost-effective means of providing real-time data on biofilm development in geothermal cooling water systems.

While the DGGE and PLFA analyses are considerably more expensive than the other techniques, the detailed information about microbial activity, including the dominant species forming the microbiological community at the plant and their growth status, could be very valuable in designing and applying new treatment processes. In most applications, it would not be necessary to perform these analyses on a weekly basis but rather use them to establish an operational baseline and then retest as a function of an upset condition, such as an increase in fouling or change in plant chemistry. For processes, such as microbial sulfide abatement, the ability to measure and track populations of sulfur oxidizing and reducing bacteria as a function of nutrient additions could be extremely useful in controlling and optimizing this activity. 


\section{REFERENCES}

1. P. A. Pryfogle and J. L Renner, "An Investigation of Biofilm Development in Geothermal Facilities," Geothermal Resources Council Transactions, vol. 22, 1998, pp. 445-449.

2. M. C. M. Bruijis et. al.,"Biocide Optimization Using an On-Line Biofilm Monitor,” PowerPlant Chemistry, vol. 3, no. 7, 2001.

3. P. A. Pryfogle, "Evaluation of Biological Measurement Methods used at the Geysers," Geothermal Resources Council Transactions, vol. 24, 2000, pp. 311-315.

4. B. Little and P. Wagner, "Myths Related to Microbiologically Influenced Corrosion," Materials Performance, vol. 36, 1997, pp. 40-44.

5. A. Sonneville, B. Carlsen, and C. Flores, "Biological Abatement of Hydrogen Sulfide in a Geothermal Process," Geothermal Resources Council Transactions, vol. 25, 2001, pp. 37-40.

6. P. I. Wagner and R. I. Ray, "Surface Analytical Techniques for Microbiologically Influenced Corrosion-A Review," in Microbiologically Influenced Corrosion Testing ASTM STP 1232, Jeffery R. Kearns and Brenda J. Little, Eds., American Society for Testing and Materials, Philadelphia, 1994, pp. 153-169.

7. P. J. B. Scott and M. Davies, "Survey of Field Kits for Sulfate-Reducing Bacteria (SRB)," Material Performance, vol. 31, 1992, pp. 64-68.

8. T. D. Brock and M. T. Madigan, Biology of Microorganisms, $6^{\text {th }}$ Edition, Prentice Hall Inc., Engwood Cliffs, NJ, 1991.

9. C. Volk, et. al., "Monitoring Dissolved Carbon in Surface and Drinking Waters," Journal of Environmental Monitoring, Vol. 4, 2002, pp. 43-47.

10. N. Dubilier, C. Mulders, T. Ferdelman, D. de Beer, A. Pernthaler, M. Klein, M. Wagner, C. Eresus, F. Thiermann, J. Krieger, O. Glere, and R. Amann, 2001, "Endosymbiotic Sulfphate-Reducing and Sulphide-Oxidizing Bacteria in an Oligochaete Worm," Nature, vol. 411, 2001, pp. 298-302.

11. David J. Richardson, "Bacterial Respiration: A Flexible Process for a Changing Environment," Microbiology, vol. 146, 2000, pp. 551-571.

12. J. Zopfi, T.G. Ferdelman, B.B. Jorgensen, A. Teske, and B. Thamdrup,"Influence of Water Column Dynamics on Sulfide Oxidation and Other Major Biogeochemical Processes the Chemocline of Mariager Fjord (Denmark)," Marine Chemistry, vol. 74, 2001, pp. 29-51.

13. F. P.Ven den Ende, J. Meier, and H. van Gemerden,"Syntrophic Growth of Sulfate-Reducing Bacteria and Colorless Sulfur Bacteria during Oxygen Limitation," FEMS Microbiology Ecology, vol. 23, 1997, pp. 65-80.

14. S. Okabe, H. Satoh, T. Itoh, and Y. Watanabe, "Microbial Ecology of Sulfate-Reducing Bacteria in Wastewater Biofilms Analyzed by Microelectrodes and FISH (Fluorescent In-situ Hybridization) Technique," Water Science and Technology, vol. 39, 1999, pp. 41-47. 
15. A.L. Neal., S. Techkarnjanaruk, A. Dohnalkova, D. McCready, B. M. Peyton, and G.G. Geesey, "Iron Sulfides and Sulfur Species Produced at Hematite Surfaces in the Presence of SulfateReducing Bacteria," Geochimica et Cosmochimica Acta, vol. 65, 2001, pp. 223-235.

16. P. R. Norris, J.C. Murrell, and D. Hinson,"The Potential for Diazotrophy in Iron- and SulfurReducing Acidophilic Bacteria," Archives of Microbiology, 1999, vol. 164, pp. 294-300.

17. C. M. Santegoeds, G. Muyzer, and D. De Beer, "Biofilm Dynamics Studied with Microsensors and Molecular Techniques," Water Science and Technology, vol. 37, 1998, page 125-129.

18. E.T. Yoong, P. A. Lant, and P. F. Greenfield, "In-Situ Respirometry in and SBR Treating Wastewater with High Phenol Concentrations," Water Research, vol. 34, 2000, pp. 239-245.

19. R. G. Riefler, D. P. Ahlfeld, and B. F. Smets, "Respirometric Assay for Biofilm Kinetics Estimation: Parameter Identifiability and Retrievability," Biotechnology and Bioengineering, vol. 57, 1998, pp. 35-45.

20. F. Mansfield and B. Little, "A Technical Review of Electrochemical Techniques Applied to Microbiologically Influenced Corrosion," Corrosion Science, vol. 32, 1991, pp. 247-272.

21. S. M. Gerchakov, B. J. Little, and P. Wagner, "Probing Microbiologically Induced Corrosion," Corrosion, vol. 42, 1986, pp. 689-692.

22. G. J. Licina, "Monitoring Biofilms on Metallic Surfaces in Real Time," CORROSION 2001, Paper No. 1442, NACE, Houston, TX, 2001.

23. G. J. Licina and G. Nekoksa, "An Electrochemical Method for On-Line Monitoring of Biofilm Activity," CORROSION/93, Paper No. 403, NACE, Houston, TX, 1993.

24. G. Nekoksa and B. Gutherman, Cathodic Protection Criteria for Controlling Microbially Influenced Corrosion in Power Plants," EPRI NP-7312, Electric Power Research Institute, Palo Alto, CA, 1991.

25. P. A. Pryfogle, G. L. Mines, T. L. Sperry, and R. G. Allred, "Investigation of an Electrochemical Monitor for Tracking Biofilm Development at the Bonnett Geothermal Plant, Cove Fort, Utah, Transactions of the Geothermal Resources Council, vol. 26, 2002, pp. 745-748.

26. C. Tsai, K. Killham, and M. S. Cresser, "Dynamic Response of Microbial Biomass, Respiration Rate and ATP to Gluocose Additions," Soil Biology Biochemistry, vol. 29, 1997, pp. 1249-1256.

27. P. Gikas and A. G. Livingston, "Use of ATP to Characterize Biomass Viability in Freely Suspended and Immobilized Cell Bioreactors," Biotechnology and Bioengineering, vol. 42, 2004, pp. 1331- 1351.

28. A. Tunlid and D. C. White, "Biochemical Analysis of Biomass, Community Structure, Nutritional Status, and Metabolic Activity of Microbial Communities in Soil," Soil Biochemistry, vol. 7, 1991, pp. 229-262. 
29. D. C. White, "Is There Anything Else You Need to Understand about the Microbiota that Cannot be Derived from Analysis of Nucleic Acids?" Microbial Ecology, vol. 28, 1994, pp. 163-166.

30. G. Muyzer et. al., "Profiling of Complex Microbial Populations by Denaturing Gradient Gel Electrophoresis Analyses of Polymerase Chain Reaction-Amplified Genes Coding for 16S rRNA," Applied and Environmental Microbiology, vol. 59, 1993, pp. 695-700.

31. S. Rolleke et. al., "Analyses of Bacterial Communities on Historical Glass by Denaturing Gradient Gel Electrophoresis of PCR-Amplified Gene Fragments Coding for 16S rRNA," Journal of Microbial Methods, vol. 36, 1999, pp. 107-114.

32. C. G. Huber, P. J. Oefner, and G. K. Bonn, "Rapid and Accurate Sizing of DNA Fragments by Ion Pair Chromatograpy on Alkylated Non-Porous Poly(styrene-divinylbenzene) Particules," Analytical Chemistry, vol. 67, 1995, pp. 578-585.

33. G. S. Sayer et. al., "Molecular Probes and Biosensors in Remediation and Site Assessment," Bioremediation Principles and Practice, Technomic Publishing Company, Inc., 1996.

34. C. M. Santegoeds, T. G. Ferdelman, G. Muyzer, and D. De Beer, "Structural and Function Dynamics of Sulfate-Reducing Populations in Bacterial Films," Applied and Environmental Microbiology, vol. 64, 1998, pp. 3731-3739. 